Article

\title{
Synthesis of Novel Nitrogen-Containing Heterocycle Bromophenols and Their Interaction with Keap1 Protein by Molecular Docking
}

\author{
Xiu E. Feng ${ }^{1,+}$, Qin Jin Wang ${ }^{1,+}$, Jie Gao ${ }^{1}$, Shu Rong Ban ${ }^{1}$ and Qing Shan $\mathrm{Li}^{1,2, *}$ \\ 1 School of Pharmaceutical Science, Shanxi Medical University, 56 Xinjian South Road, Taiyuan 030001, China; \\ xiuefeng@163.com (X.E.F.); qinjinwang90@163.com (Q.J.W.); jiegao1989@163.com (J.G.); \\ shurongban@163.com (S.R.B.) \\ 2 Shanxi Key laboratory of Chronic Inflammatory Targeted Drugs, School of Chinese Materia Medica, \\ Shanxi University of Traditional Chinese Medicine, 121 University Street, Jinzhong 030619, China \\ * Correspondence: sxyxlqs@163.com; Tel./Fax: +86-351-469-0322 \\ + These authors contributed equally to this work.
}

Received: 15 November 2017; Accepted: 2 December 2017; Published: 4 December 2017

\begin{abstract}
We previously reported 5,2'-dibromo-2,4',5'-trihydroxydiphenylmethanoe (LM49), a bromophenol analogue that shows strong protection from oxidative stress injury owing to its superior anti-inflammatory, antioxidant, and anti-apoptotic properties. A series of novel nitrogen-containing heterocycle bromophenols were herein synthesized by introducing substituted piperidine, piperazine, and imidazole to modify 2-position of the lead compound LM49. By further evaluating their cytoprotective activity against $\mathrm{H}_{2} \mathrm{O}_{2}$ induced injury in EA.hy926 cells, 14 target bromophenols showed moderate-to-potent activity with $\mathrm{EC}_{50}$ values in the range of 0.9-6.3 $\mu \mathrm{M}$, which were stronger than that of quercetin $\left(\mathrm{EC}_{50}: 18.0 \mu \mathrm{M}\right)$, a positive reference compound. Of these, the most potent compound $\mathbf{2 2 b}$ is a piperazine bromophenol with an $\mathrm{EC}_{50}$ value of $0.9 \mu \mathrm{M}$ equivalent to the LM49. Molecular docking studies were subsequently performed to deduce the affinity and binding mode of derived halophenols toward the Keap1 Kelch domain, the docking results exhibited that the small molecule $\mathbf{2 2} \mathbf{b}$ is well accommodated by the bound region of Keap1-Kelch and Nrf2 through stable hydrogen bonds and hydrophobic interaction, which contributed to the enhancement of affinity and stability between the ligand and receptor. The above facts suggest that $\mathbf{2 2} \mathbf{b}$ is a promising pharmacological candidate for further cardiovascular drug development. Moreover, the targeting Keap1-Nrf2 protein-protein interaction may be an emerging strategy for halophenols to selectively and effectively activate Nrf2 triggering downstream protective genes defending against injury.
\end{abstract}

Keywords: heterocycle; bromophenol; synthesis; molecular docking; kelch-like ECH-associated protein 1 protein

\section{Introduction}

The vascular endothelium is the major barrier for a cardiovascular system fighting against oxidative stress injury and inflammation [1]. In recent years, various novel skeleton halophenols derived from natural marine algaes and their derivatives obtained by structural optimization have been discovered showing the excellent vascular endothelial protective properties [2-12]. In support of these growing interests, we expanded upon the continuing structural optimization and mechanistic investigation on halophenols for finding a candidate compound. As a fact, we have reported the plentiful synthesis of a series of diphenylketone, diphenylmethane and phenyl furan-2-yl ketone halophenols, and their protective activity against $\mathrm{H}_{2} \mathrm{O}_{2}$ induced injury in human 
umbilical vein endothelial cells (HUVECs) [11,13]. Moreover, we indeed found a "hit" compound, 5,2'-dibromo-2,4',5'-trihydroxydiphenylmethanoe (LM49) (Figure 1) possessing an $\mathrm{EC}_{50}$ value of $0.4 \mu \mathrm{M}$ with the strong vascular endothelium protective ability [11], as evidenced being attributed to its anti-apoptotic, antioxidant, and anti-inflammatory abilities by further mechanical study $[1,14]$. To our knowledge, nitrogen-containing heterocycle derivatives have been reported to exist in many natural products and applied in many fields such as medicines and chemical products [15]. The existence of a heterocyclic unit in numerous natural products often plays an essential role in their biological activities [16-22]. Moreover, it helps the dosage form design of drugs such as those being prepared for injection. Based on these considerations, we focused on introducing substituted piperidine, piperazine and imidazole to modify the 2-position of lead compound LM49 to synthesize a series of analogues aiming to find the promising pharmacological candidates for further cardiovascular drug development.

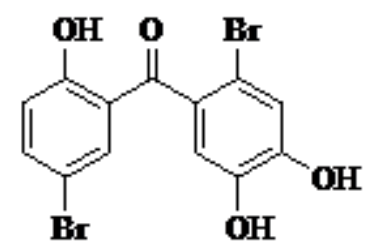

Figure 1. Chemical structure of the lead compound LM49.

In addition, sustained oxidative stress and elevated redox state are the major causes of the development of chronic inflammation related cardiovascular diseases such as atherosclerosis and diabetes. The Keap1 (Kelch-like ECH-associated protein 1)-Nrf2 (nuclear factor erythroid 2-related factor 2)-ARE pathway plays a key role in the endogenous antioxidant system. Under basal conditions, the antioxidant transcription factor Nrf2 is bound to Keap1 protein and targets proteasomal degradation in the cytoplasm. In response to cellular injury, Nrf2 dissociates from Keap1 and activates the transcription of protective genes, defending against injury [1,23]. In our recent study, we reported that diphenylketone halophenols can protect vascular endothelial cells against the oxidative stress injury and inflammation by the activation of Nrf2 up-regulating heme oxygenase-1 (HO-1) protein expression [1], which prompted us to investigate the influence of halophenols on the Keap1-Nrf2 protein-protein interaction (PPI). Inspired by the above, we herein investigated the action mode and mechanism of halophenols interacting with the Keap1 by molecular docking.

\section{Results and Discussion}

\subsection{Chemistry}

In this paper, 36 new target bromophenols were prepared by Friedel-Crafts acylation, aromatic bromination, radical substitution, nitrogen-containing heterocyclic nucleophilic substitution, and demethylation reaction according to the preparation route described in Scheme 1. All structures of target compounds were confirmed by ESI-MS, ${ }^{1} \mathrm{H}-\mathrm{NMR}$, and ${ }^{13} \mathrm{C}-\mathrm{NMR}$ spectrum. The obtained active bromophrnols were further characterized by IR and HR-MS spectra.

The intermediate 1 was prepared from 5-bromo-2-methyl benzoic acid with anhydrous $\mathrm{SOCl}_{2}$ dropped little $N, N$-dimethyl formamide (DMF) via acylating chlorination, then reacted with 1,2-dimethoxybenzene catalyzed by $\mathrm{AlCl}_{3}$ to yield intermediate 2 . Aluminum chloride is an effective and cheap Lewis acid catalyst and is widely used in Friedel-Crafts acylation. Bromination reaction of intermediate 2 was quickly conducted with bromine to obtain the important compound 3 in acetic acid solvent at room temperature by electrophilic substitution in benzene ring, and was subsequently reacted with $\mathrm{N}$-bromosuccinimide (NBS) to gain the key intermediate 4 in anhydrous $\mathrm{CH}_{2} \mathrm{Cl}_{2}$ using benzoyl peroxide (BPO) as the catalyst by free radical substitution. In this process, sunlight was beneficial to accelerate reaction velocity and shorten reaction time [24]. Compound 4 was treated with substituted piperidine, piperazine or imidazole in the presence of anhydrous $\mathrm{Na}_{2} \mathrm{CO}_{3}$ to prepare 
important intermediates 5a-40a. Then, 5a-40a were demethylated with $\mathrm{BBr}_{3}$ as the demethylation reagent in anhydrous $\mathrm{CH}_{2} \mathrm{Cl}_{2}$ at $-78{ }^{\circ} \mathrm{C}$ to obtain target bromophenols $5 \mathbf{b}-\mathbf{4 0 b}$ in moderate to high yields.

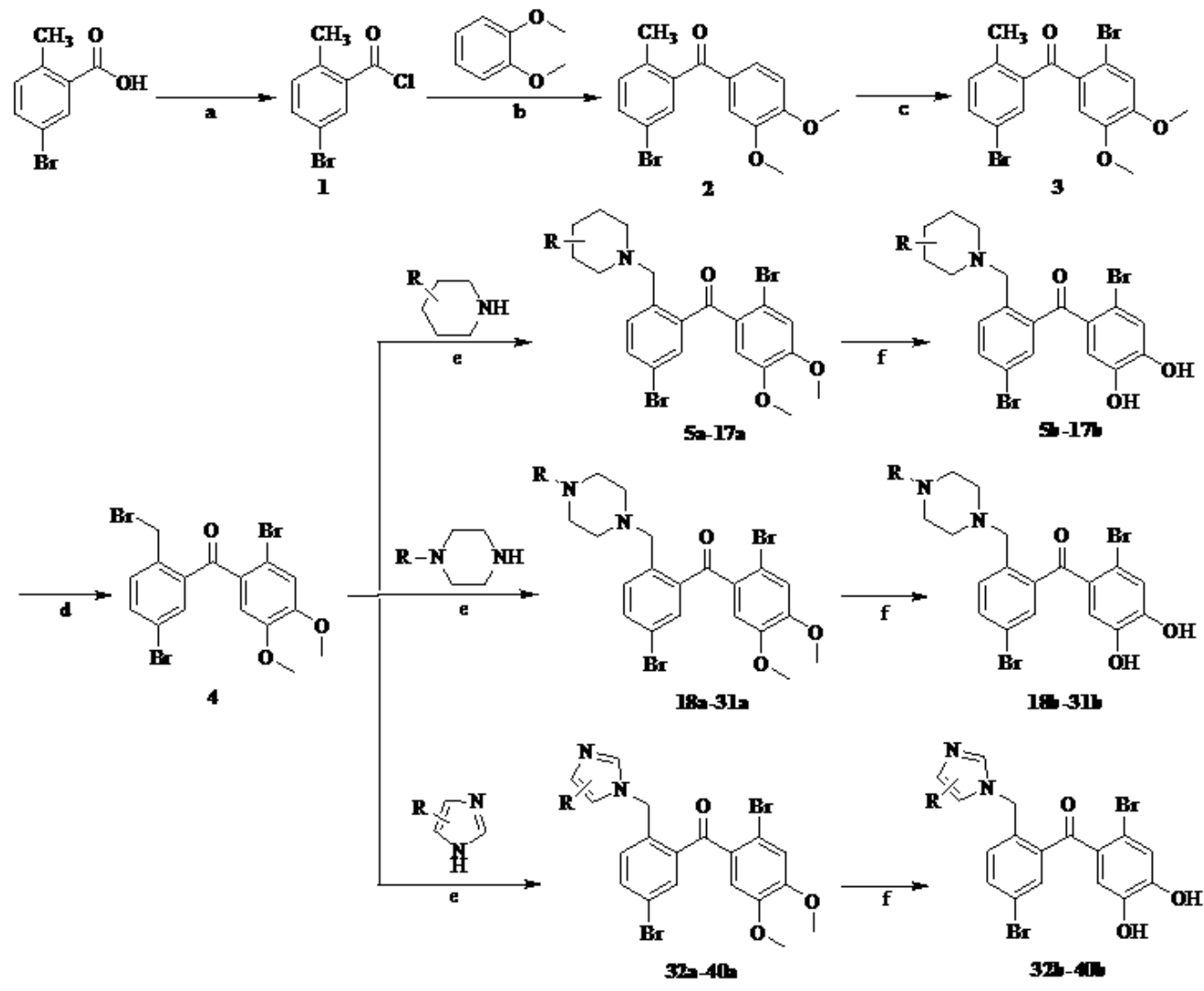

Scheme 1. Synthetic route of target compounds. Reagents and conditions: (a) $\mathrm{SOCl}_{2}(16.1 \mathrm{eq})$, $\mathrm{N}$,N-dimethyl formamide, reflux, $7 \mathrm{~h}, 70 \%$; (b) $\mathrm{CH}_{2} \mathrm{Cl}_{2}, \mathrm{AlCl}_{3}$, r.t., $3 \mathrm{~h}, 90 \%$; (c) $\mathrm{CH}_{3} \mathrm{COOH}, \mathrm{CH}_{2} \mathrm{Cl}_{2}$, $\mathrm{Br}_{2}$ (7.1 eq), r.t., 0.5 h, $77 \%$; (d) $\mathrm{N}$-bromosuccinimide (1.05 eq), benzoyl peroxide (0.1 eq), $\mathrm{CH}_{2} \mathrm{Cl}_{2}$, sun light, r.t., $5 \mathrm{~h}, 60 \%$; (e) $\mathrm{CH}_{2} \mathrm{Cl}_{2}$, anhydrous $\mathrm{Na}_{2} \mathrm{CO}_{3}$ (1.0 eq), r.t., $12 \mathrm{~h}, 70-93 \%$; (f) $\mathrm{CH}_{2} \mathrm{Cl}_{2}, \mathrm{BBr}_{3}$ (3.1 eq), $-78{ }^{\circ} \mathrm{C}$ to r.t, $1.5-2.5 \mathrm{~h}, 38-85 \%$.

\subsection{Biological Evaluation}

To assess the cytoprotective activity of all synthesized target compounds $\mathbf{5 b}-\mathbf{4 0 b}$ compared to important intermediates 5a-40a against $\mathrm{H}_{2} \mathrm{O}_{2}$ induced injury in endothelial-derived EA.hy926 cells by MTT assay, we first conducted the preliminary screening to test their cytoprotective rates at a concentration of $10 \mu \mathrm{M}$. If the protective rates of tested compounds were higher than $45 \%$ then their $\mathrm{EC}_{50}(50 \%$ effective concentration) values were determined by examining cell viability at different concentrations of $0.3125,0.625,1.25,2.5,5,10 \mu \mathrm{M}$, as presented in Tables $1-3$, the values are the average of at least three independent experiments. Quercetin was used as a positive reference standard. The activity data showed that 14 target bromophenols 11b-14b, 16b, 21b, 22b, 24b-26b, 35b-38b and 15 key intermediates 5a, 10a, 14a, 15a, 17a, 21a, 24a, 27a-32a, 39a, 40a exhibited moderate-to-potent activity with $\mathrm{EC}_{50}$ values in the range of $0.9-7.4 \mu \mathrm{M}$, which were stronger than that of quercetin $\left(\mathrm{EC}_{50}\right.$ : $18.0 \mu \mathrm{M})$. The most promising bromophenol derivative $\mathbf{2 2} \mathbf{b}$ showed the highest activity with an $\mathrm{EC}_{50}$ value of $0.9 \mu \mathrm{M}$, which was almost identical to that of the lead compound $\mathbf{L M} 49\left(\mathrm{EC}_{50}: 0.7 \mu \mathrm{M}\right)$. Due to the presence of a piperazine ring, compound $\mathbf{2 2 b}$ suggests the preferably potential druggability in comparison with LM49. 
Table 1. Structures of piperidine compounds $\mathbf{5 a - 1 7 a , 5 b - 1 7 b}$ and their cytoprotective activity against $\mathrm{H}_{2} \mathrm{O}_{2}$ induced injury in EA.hy926 cells.

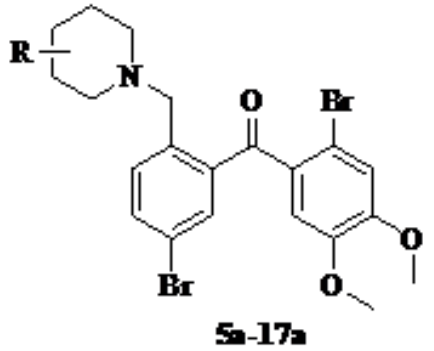<smiles>[R]CCN(C[AsH2])Cc1ccc(Br)cc1C(=O)c1cc(O)c(O)cc1Br</smiles>

\begin{tabular}{ccccc}
\hline $\mathbf{R}$ & Compd. & $\mathbf{E C}_{\mathbf{5 0}}{ }^{\mathbf{a}}(\boldsymbol{\mu M})$ & Compd. & EC $_{\mathbf{5 0}}{ }^{\mathbf{a}}(\boldsymbol{\mu \mathbf { M } )}$ \\
\hline $\mathrm{H}$ & $\mathbf{5 a}$ & 2.5 & $\mathbf{5 b}$ & $>30$ \\
$2-\mathrm{CH}_{3}$ & $\mathbf{6 a}$ & $>30$ & $\mathbf{6 b}$ & $>30$ \\
$3-\mathrm{CH}_{3}$ & $\mathbf{7 a}$ & $>30$ & $\mathbf{7 b}$ & $>30$ \\
$4-\mathrm{CH}_{3}$ & $\mathbf{8 a}$ & $>30$ & $\mathbf{8 b}$ & $>30$ \\
$3-\mathrm{CH}_{3}, 5-\mathrm{CH}_{3}$ & $\mathbf{9 a}$ & $>30$ & $\mathbf{9 b}$ & $>30$ \\
$4-\mathrm{COOH}$ & $\mathbf{1 0 a}$ & 1.9 & $\mathbf{1 0 b}$ & $>30$ \\
$3-\mathrm{COOCH}_{2} \mathrm{CH}_{3}$ & $\mathbf{1 1 a}$ & $>30$ & $\mathbf{1 1 b}$ & 1.4 \\
$4-\mathrm{OH}$ & $\mathbf{1 2 a}$ & $>30$ & $\mathbf{1 2 b}$ & 4.3 \\
$2-\mathrm{CH}_{3}, 6-\mathrm{CH}_{3}$ & $\mathbf{1 3 a}$ & $>30$ & $\mathbf{1 3 b}$ & 5.4 \\
$2,2,6,6-\mathrm{CH}_{3}$ & $\mathbf{1 4 a}$ & 1.9 & $\mathbf{1 4 b}$ & 6.1 \\
$2-\mathrm{CH}_{2} \mathrm{OH}$ & $\mathbf{1 5 a}$ & 1.7 & $\mathbf{1 5 b}$ & $>30$ \\
$4-\mathrm{CH}_{2} \mathrm{CH}_{2} \mathrm{OH}$ & $\mathbf{1 6 a}$ & $>30$ & $\mathbf{1 6 b}$ & 3.6 \\
$4-\mathrm{CH}_{2} \mathrm{OH}$ & $\mathbf{1 7 a}$ & 5.2 & $\mathbf{1 7 b}$ & $>30$ \\
& $\mathbf{L M 4 9}$ & 0.7 & Quercetin & \\
& & &
\end{tabular}

${ }^{a} \mathrm{EC}_{50}$ values were an average of three separate determinations. ${ }^{\mathrm{b}}$ Used as a lead compound. ${ }^{\mathrm{c}}$ Used as a positive control.

Table 2. Structures of piperazine compounds $\mathbf{1 8 a}-\mathbf{3 1 a}, \mathbf{1 8 b}-\mathbf{3 1 b}$ and their cytoprotective activity against $\mathrm{H}_{2} \mathrm{O}_{2}$ induced injury in EA.hy926 cells.

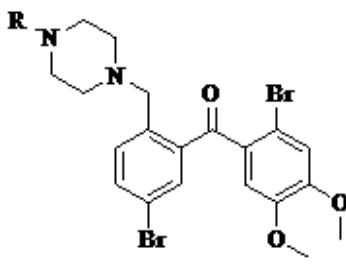

18-310

Compd

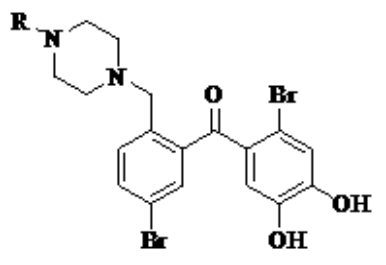

182-31

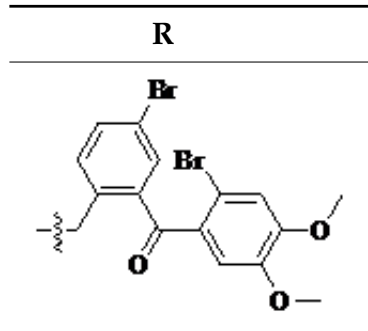

$18 \mathbf{a}$

$$
>30
$$

$18 b$

$>30$

$-\mathrm{CH}_{2} \mathbf{C H}_{3}$

19a

$>30$

19b

$>30$<smiles>CC(C)(C)C1=CC=CC=C=C1</smiles>

20a

$>30$

$20 b$

$>30$

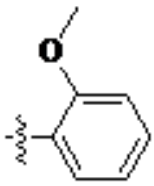

$21 a$

21b 
Table 2. Cont

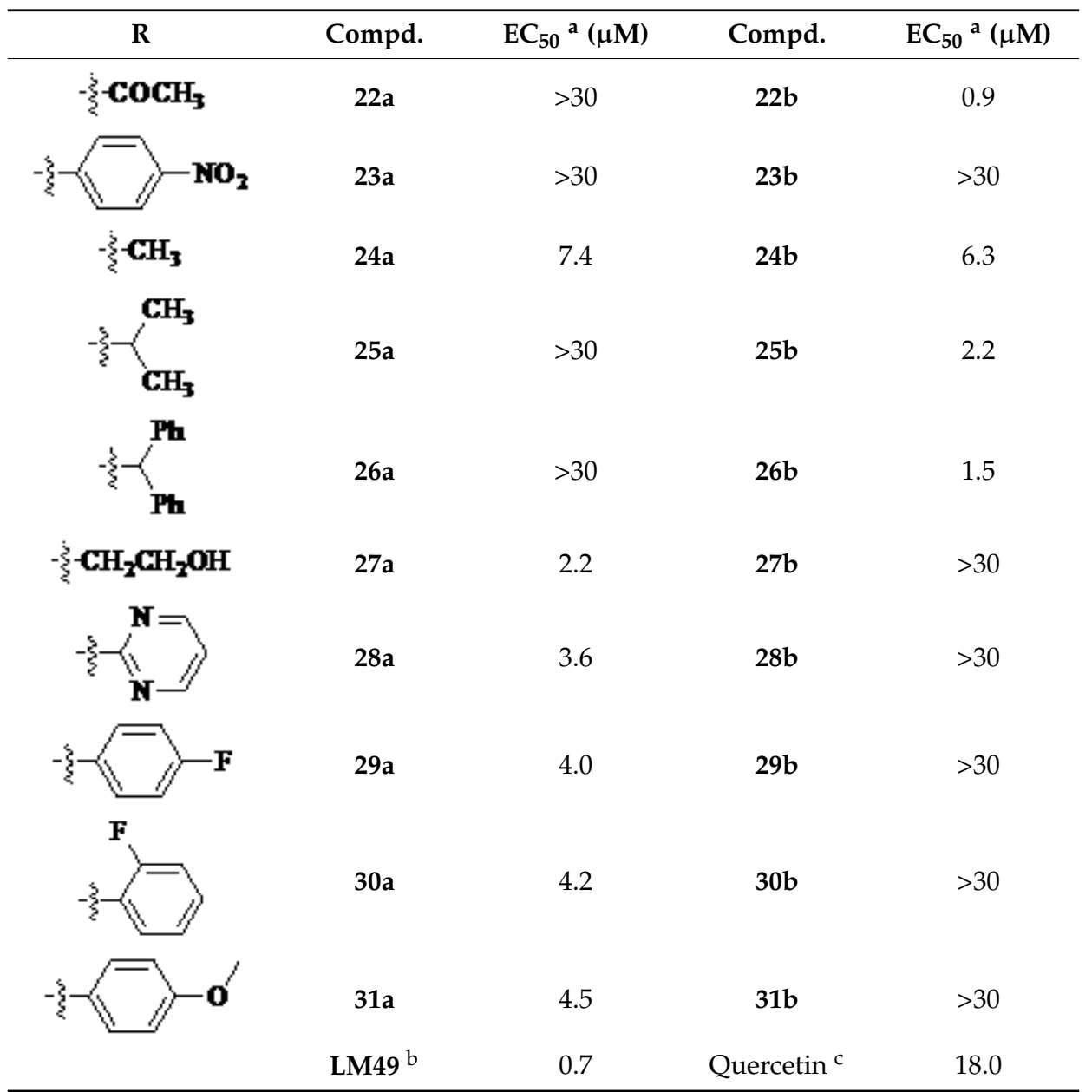

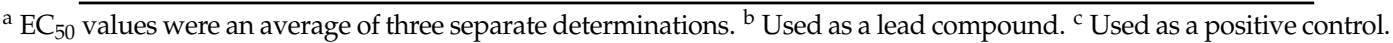

Table 3. Structures of imidazole compounds $\mathbf{3 2 a}-\mathbf{4 0 a}, \mathbf{3 2 b}-\mathbf{4 0 b}$ and their cytoprotective activity against $\mathrm{H}_{2} \mathrm{O}_{2}$ induced injury in EA.hy926 cells.

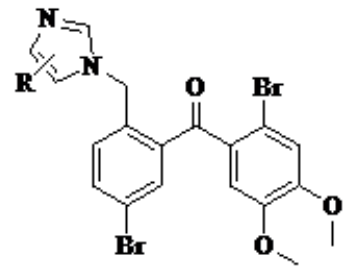

32-40

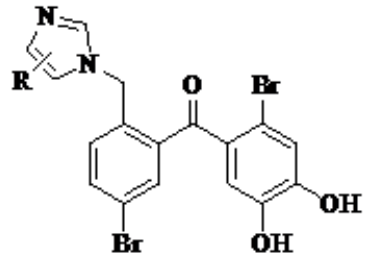

32-4

\begin{tabular}{|c|c|c|c|c|}
\hline $\mathbf{R}$ & Compd. & $\mathrm{EC}_{50}{ }^{\mathrm{a}}(\mu \mathrm{M})$ & Compd. & $\mathrm{EC}_{50}{ }^{\mathrm{a}}(\mu \mathrm{M})$ \\
\hline $\mathrm{H}$ & $32 a$ & 1.9 & $32 b$ & $>30$ \\
\hline $2-\mathrm{CH}_{3}$ & $33 a$ & $>30$ & $33 b$ & $>30$ \\
\hline $4-\mathrm{CH}_{3}$ & $34 a$ & $>30$ & $34 \mathrm{~b}$ & $>30$ \\
\hline $2-\mathrm{CH}_{2} \mathrm{CH}_{3}$ & $35 a$ & $>30$ & $35 b$ & 1.6 \\
\hline $2-\mathrm{CH}\left(\mathrm{CH}_{3}\right)_{2}$ & $36 a$ & $>30$ & $36 b$ & 1.3 \\
\hline $2-\mathrm{CH}_{2} \mathrm{CH}_{3}, 4-\mathrm{CH}_{3}$ & $37 a$ & $>30$ & $37 b$ & 1.6 \\
\hline $2-\mathrm{Ph}$ & $38 a$ & $>30$ & $38 b$ & 1.6 \\
\hline $2,4-\mathrm{CH}_{3}$ & $39 a$ & 4.0 & $39 b$ & $>30$ \\
\hline \multirow[t]{2}{*}[4,5-d]{$\mathrm{Ph}$} & $40 a$ & 3.2 & $40 \mathrm{~b}$ & $>30$ \\
\hline & LM49 ${ }^{b}$ & 0.7 & Quercetin $^{c}$ & 18.0 \\
\hline
\end{tabular}

${ }^{\mathrm{a}} \mathrm{EC}_{50}$ values were an average of three separate determinations. ${ }^{\mathrm{b}}$ Used as a lead compound. ${ }^{\mathrm{c}}$ Used as a positive control. 


\subsection{Structure-Activity Relationships}

Based on the data of cytoprotective activity listed in the Tables 1-3, the preliminary structure-activity relationships (SARs) of novel bromophenols analogues could be summarized. Target compound 11b-13b, 16b , 21b, 22b, 24b-26b, 35b-38b with two hydroxyl groups displayed better activity than their corresponding intermediates 11a-13a, 16a, 21a, 22a, 24a-26a, 35a-38a. These findings revealed that the presence of hetercycles and hydroxyl groups contributes to the increase of their anti-oxidative stress abilities, which is consistent with our previously presented results [11].

In 26 piperidine analogues (Table 1), five bromophenol derivatves $\mathbf{1 1} \mathbf{b}-\mathbf{1 4} \mathbf{b}, \mathbf{1 6} \mathbf{b}$ with $\mathrm{EC}_{50}$ values of 1.4-6.1 $\mu \mathrm{M}$ and five intermediates $5 \mathbf{a}, 10 \mathbf{a}, \mathbf{1 4 a}, \mathbf{1 5 a}, \mathbf{1 7} \mathbf{a}$ with $\mathrm{EC}_{50}$ values of $1.7-5.2 \mu \mathrm{M}$ exhibited moderate-excellent activity. Bromophenol derivatives $\mathbf{5 b - 8 b}$ with no substituted groups or only a single methyl group that existed in the ortho-, meta- or para-position of piperidine, showed no activity. Two isomers $\mathbf{1 3 b}$ and $\mathbf{9 b}$ with two methyl groups in the ortho- or meta-position of nitrogen atom, respectively, displayed significantly different activity, bromophenol $\mathbf{1 3 b}$ demonstrated higher activity with an $\mathrm{EC}_{50}$ value $5.4 \mu \mathrm{M}$ than compound $\mathbf{9 b}$. Compound $\mathbf{1 4 b}$ with an $\mathrm{EC}_{50}$ value $6.1 \mu \mathrm{M}$, all hydrogen atoms in the ortho-position of nitrogen atom replaced by methyl group, exhibited nearly the same activity to compound $\mathbf{1 3 b}$, moreover, corresponding intermediate $\mathbf{1 4 a}$ possessed more potent activity with an $\mathrm{EC}_{50}$ value $1.9 \mu \mathrm{M}$ than bromophenol derivative $\mathbf{1 4 b}$, which indicated that the presence of methyl groups in two ortho-positions of nitrogen atom favored for the activity. In addition, compounds $\mathbf{1 5 b}$ and $\mathbf{1 7 b}$ are isomers with a hydroxymethyl group in the ortho- or para-position of nitrogen atom, no activity was observed. However, their corresponding intermediates 15a and 17a showed better activity with an $\mathrm{EC}_{50}$ value of $1.7 \mu \mathrm{M}$ and $5.2 \mu \mathrm{M}$, respectively. Bromophenol derivative $\mathbf{1 1 b}$, the meta-position of nitrogen atom replaced by withdrawing group ethoxycarbonyl, demonstrated excellent activity with an $\mathrm{EC}_{50}$ value $1.4 \mu \mathrm{M}$ compared with compound $7 \mathbf{b}$ and $\mathbf{9 b}$ substituted by donating group methyl.

Among 28 piperazine analogues (Table 2), five bromophenol derivatives $\mathbf{2 1} \mathbf{b}, \mathbf{2 2} \mathbf{b}, \mathbf{2 4} \mathbf{b}-\mathbf{2} \mathbf{6} \mathbf{b}$ showed moderate-potent activity with $\mathrm{EC}_{50}$ values in the range of $0.9-6.3 \mu \mathrm{M}$, seven key intermediates 21a, 24a, 27a-31a exhibited middle activity with $\mathrm{EC}_{50}$ values of 2.2-7.4 $\mu \mathrm{M}$. Target compound 22b showed the most potent protective activity with an $\mathrm{EC}_{50}$ value $0.9 \mu \mathrm{M}$, which was comparable to the lead compound LM49 $\left(\mathrm{EC}_{50}=0.7 \mu \mathrm{M}\right)$. Replacement of 4-position of piperazine by methyl, isopropyl or diphenylmethyl group, bromophenol derivatives $\mathbf{2 4 b - 2 6 b}$ displayed moderate-superior activity with $\mathrm{EC}_{50}$ values of $6.3,2.2$ and $1.5 \mu \mathrm{M}$, respectively. To bromophenol derivatives $\mathbf{1 8 b}, \mathbf{2 0 b}, \mathbf{2 3 b}$, and 29b-30b, 4-position hydrogen of piperazine was replaced by acyl-, nitro- or fluro-substituted phenyl group, their activity was disappeared. Conversely, compound $\mathbf{2 1 b}$, with a methoxyl group on the 2-position of piperazine, showed better activity. Evidently, the electron withdrawing effect on the benzene ring exerted a negative effect on the activity. The above results suggest that the electronic effect and steric hindrance effect at the 4-position of piperazine play a pivotal role to the cytoprotective activity of bromophenols.

In 18 prepared imidazole analogues (Table 3), three intermediates 32a, 39a and 40a showed moderate activity with $\mathrm{EC}_{50}$ values of $1.9 \mu \mathrm{M}, 4.0 \mu \mathrm{M}$, and $3.2 \mu \mathrm{M}$, respectively. Target bromophenol derivatives $\mathbf{3 5 b} \mathbf{3} \mathbf{3} \mathbf{3 b}$, replaced by ethyl, isopropyl or phenyl group on the 2-position of imidazole, showed excellent activity with $\mathrm{EC}_{50}$ values of $1.3-1.6 \mu \mathrm{M}$. For bromophenol derivatives $\mathbf{3 2} \mathbf{b}, \mathbf{3 3} \mathbf{b}, \mathbf{3 4 \mathbf { b }}$ and $39 \mathbf{b}$, with no substituent or one to two methyl groups on the imidazole, no activity was observed. From these, we can conclude that the substitution groups such as ethyl, isopropyl and phenyl existed in the 2-position of imidazole and contributed to the activity improvement. Clearly, the protective activity of imidazole bromophenols is ascribed to the electron donating effect of alkyl groups.

\subsection{Molecular Docking Study}

Nrf2 contains multiple basic residues and possesses a tight four-residue $\beta$-hairpin conformation comprising of the residues Asp-77, Glu-78, Glu-79, Thr-80, Gly-81. In particular, Glu-79 is one of the critical functional residues in the interaction of Keap1 protein and Nrf2, the side chain of which 
is wedged between Arg-415 and Arg-508. The unique feature of Arg-415, adopting an unusual left-handed helical conformation $\left(58^{\circ}, 49^{\circ}\right)$, may cause the potential interaction of Arg-415 with Glu-79. When the ligand occupies the region closed to Arg-415, this may result in the change of the rotational isomer of Arg-415 and may also affect the electrostatic interaction. When the ligand enters the bound region of Keap1-Kelch and Nrf2, it may influence the nature of the residue Arg-415 in the active site, causing a series of changes in the electrostatic force and the acting force to weaken the interaction with Glu-79, and then bringing the dissociation of Nrf2 into the nucleus, completing the task of protein expression [23-27].

In the current study, the most potent compound $22 \mathrm{~b}$ was employed to investigate the binding modes of derived halophenols to the kelch domain of keap1 protein by molecular docking experiment. As can be seen from the left side of Figure 2, the closer to the brown it was, the higher lipotropy or hydrophobicity it showed. Conversely, the nearer to the blue it was, the stronger hydrophily it exhibited. The cavity of the receptor presented with a brown color, which suggested strong hydrophobicity. The benzene ring, a hydrophobic group, approached the inside of the cavity. In parallel, the hydrophile groups hydroxyls and carbonyls closed to the hydrophile area of the receptor. The docking results (Figure 2) showed that a small molecule $\mathbf{2 2 b}$ was well accommodated in the active pocket of the receptor and entered the bound region of Keap1-Kelch and Nrf2, and also exhibited excellent interaction via hydrogen bonds and hydrophobic interaction. Figure 3 showed that the amino acids in the distance of 5A from small molecule included Ser-602, Arg-415 and Gln-530. The hydroxyl group of $\mathbf{2 2 b}$ was $1.82 \mathrm{~A}$ distant from the Ser-602 residue. The carbonyl group linked to the two benzene rings was 1.87A and 2.09A away from Arg-415, respectively. The distance between the carbonyl group on the piperazine ring and the Gln-530 was 1.98A. The presence of multiple hydrogen bonds together with hydrophobic interaction contributed to the enhancement of affinity and stability between the ligand and receptor.

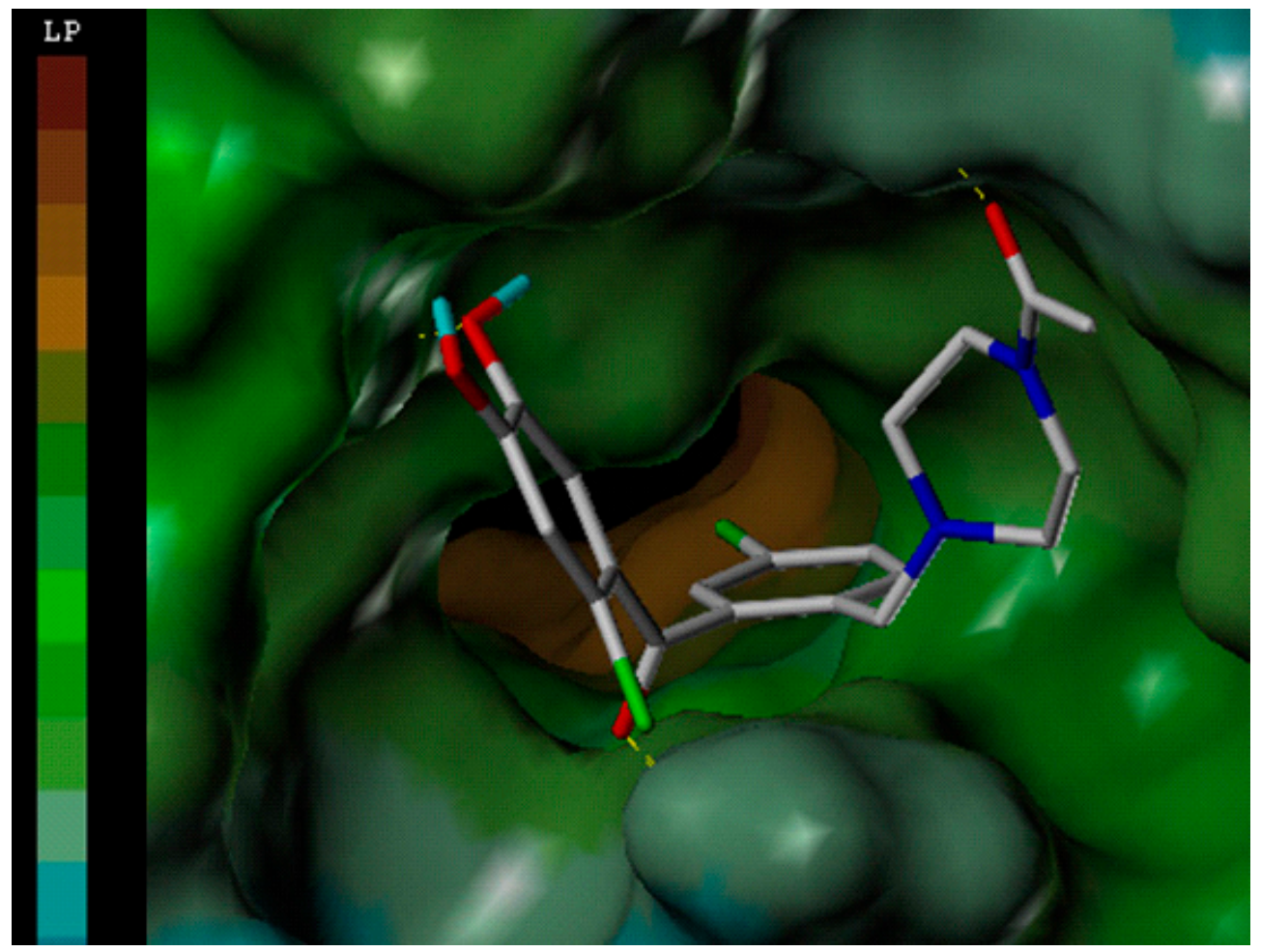

Figure 2. The potential energy diagram of compound 22b binding with the Keap1 Kelch domain. (The small molecule $\mathbf{2 2} \mathbf{b}$ was presented by a stick model.) 


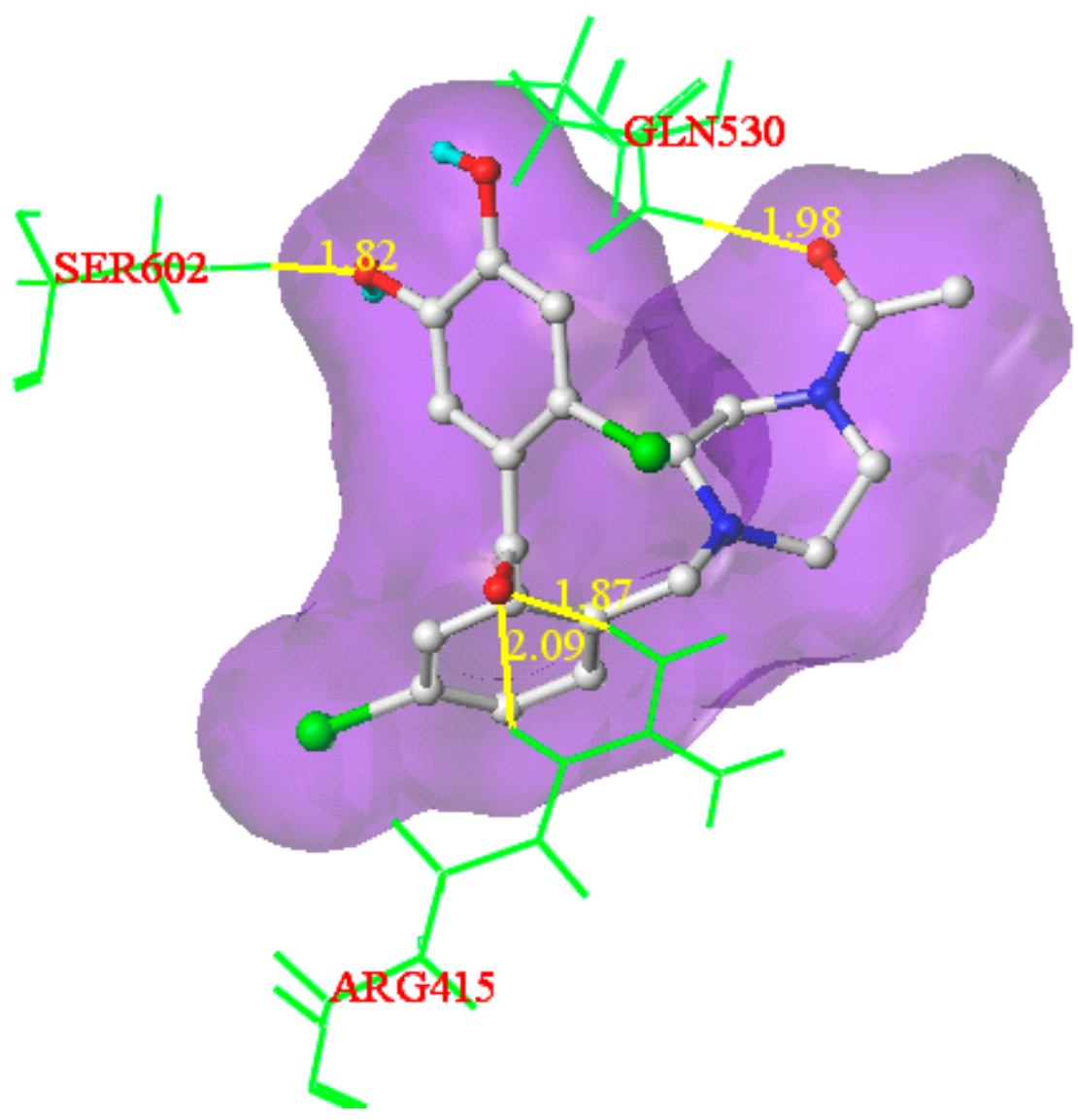

Figure 3. The binding modes of compound 22b with Keap1 Kelch domain showing interacting amino acids and H-bonds. (Green shows the interacting amino acid residues, yellow dotted lines show the formed hydrogen bonds.)

\section{Experimental Section}

\subsection{Chemistry}

The main reagents including 5-bromo-2-methyl benzoic acid, dimethoxybenzene, substituted piperdine, piperazine and imidazole were purchased from $J \mathcal{E} K$ Chemical Technology. Other chemical reagents and solvents were commercially available unless otherwise indicated. Dichloromethane was distilled from calcium hydride.

Melting points were taken on a micromelting point apparatus, which were uncorrected. The IR spectra of the compounds were recorded using a Thermo Scientific Nicolet iS 50 Fourier transform IR (FTIR) spectrometer. The ${ }^{1} \mathrm{H}$ - and ${ }^{13} \mathrm{C}-\mathrm{NMR}$ spectra were recorded with a Bruker-AV 600 spectrometer in $\mathrm{CDCl}_{3}$ or DMSO- $d_{6}$ with TMS as reference. Chemical shifts ( $\delta$ values) and coupling constants ( $J$ values) were given in ppm and $\mathrm{Hz}$, respectively. ESI mass spectra were obtained on an API QTRAP 3200 MS spectrometer, and HR-MS were recorded on a Bruker Daltonics Apex IV 70e FTICR-MS (Varian 7.0T).

\subsubsection{Preparation of Key Intermediate Compound 4}

5-Bromo-2-methyl benzoic acid $(4.5 \mathrm{~g}, 7.0 \mathrm{mmol})$ was dissolved in $24 \mathrm{~mL}$ dried $\mathrm{SOCl}_{2}$ with a few drops DMF, the mixture was refluxed for $7 \mathrm{~h}$. The solvent was evaporated under reduced pressure to give compound 1 as a transparent liquid. Dimethoxybenzene $4.5 \mathrm{~mL}$ ( $35.4 \mathrm{mmol})$ was added to $30 \mathrm{~mL}$ dried $\mathrm{CH}_{2} \mathrm{Cl}_{2}$ and stirred at $0{ }^{\circ} \mathrm{C}$. Next, anhydrous $\mathrm{AlCl}_{3}(3.0 \mathrm{~g}, 22.7 \mathrm{mmol})$ was added portion-wise. The obtained compound $\mathbf{1}$ was then added to the solution, which was allowed to warm 
to room temperature and stirred for $3 \mathrm{~h}$ and quenched with $30 \mathrm{~mL}$ distilled water. The organic phase was separated, washed with $30 \mathrm{~mL}$ water and dried over anhydrous $\mathrm{Na}_{2} \mathrm{SO}_{4}$, and then concentrated via rotary evaporation. The crude product was purified by silica gel chromatography with ethyl acetate-petroleum ether $(v / v, 1 / 8)$ as the eluent to afford compound 2 . The product was recrystallized from methanol to give a white powder in $63 \%$ total yield. m.p. $102.0-104.0{ }^{\circ} \mathrm{C}$; ${ }^{1} \mathrm{H}-\mathrm{NMR}(600 \mathrm{MHz}$, DMSO-d 6 ) $\delta: 2.53\left(\mathrm{~s}, 3 \mathrm{H}, \mathrm{Ar}-2-\mathrm{CH}_{3}\right), 3.86\left(\mathrm{~s}, 3 \mathrm{H}, \mathrm{Ar}-5^{\prime}-\mathrm{OCH}_{3}\right), 3.94$ (s, 3H, Ar-4'-OCH $\left.{ }^{\prime}\right), 6.99$ (s, $1 \mathrm{H}$, Ar-6'-H), 7.05 (s, 1H, Ar-6-H), 7.20 (t, J = 10.4 Hz,1H, Ar-3'-H), 7.31(d, J = 11.4 Hz, 1H, Ar-3-H), 7.34 (d, $J=11.4 \mathrm{~Hz}, 1 \mathrm{H}, \mathrm{Ar}-4-\mathrm{H}), 7.41\left(\mathrm{t}, J=10.4 \mathrm{~Hz}, 1 \mathrm{H}, \mathrm{Ar}-2^{\prime}-\mathrm{H}\right)$; ESI-MS m/z (\%): 334.88, $336.93\left([\mathrm{M}+\mathrm{H}]^{+}\right.$, $100,98)$.

Compound $22.3 \mathrm{~g}(5.5 \mathrm{mmol})$ was dissolved in the mixed solvent of $30 \mathrm{~mL}$ acetic acid and $8 \mathrm{~mL}$ dichloromethane. Next the bromine $2 \mathrm{~mL}$ was added to the mixture. The reaction process was monitored by thin layer chromatography (TLC). After being stirred for $0.5 \mathrm{~h}$ at room temperature, the mixture was slowly poured into $50 \mathrm{~mL}$ strong ammonia water and then cooled to room temperature. The mixture was extracted twice with $\mathrm{CH}_{2} \mathrm{Cl}_{2}(2 \times 30 \mathrm{~mL})$. The combined organics were washed to neutral with water, dried over anhydrous $\mathrm{Na}_{2} \mathrm{SO}_{4}$, and then concentrated via rotary evaporation. The crude product was purified by silica gel chromatography with ethyl acetate-petroleum ether $(v / v$, $1 / 16)$ as the eluent to gain $2.19 \mathrm{~g}$ white power compound 3 in $77 \%$ yield. m.p. $105.0-107.0{ }^{\circ} \mathrm{C} ;{ }^{1} \mathrm{H}-\mathrm{NMR}$ $\left(600 \mathrm{MHz}, \mathrm{DMSO}-d_{6}\right) \delta: 2.64\left(\mathrm{~s}, 3 \mathrm{H}, \mathrm{Ar}-2-\mathrm{CH}_{3}\right), 3.87$ (s, 3H, Ar-5'-OCH$\left.)_{3}\right), 3.92$ (s, 3H, Ar-4' $\left.-\mathrm{OCH}_{3}\right)$, 6.93 (s, 1H, Ar-6'-H), 7.20 (t, J = 11.4 Hz, 1H, Ar-3-H), 7.32 (s, 1H, Ar-3'-H), 7.34 (s, 1H, Ar-6-H), 7.44 (t, $J=11.4 \mathrm{~Hz}, 1 \mathrm{H}, \mathrm{Ar}-4-\mathrm{H})$. ESI-MS $m / z(\%): 412.85,414.91,416.81\left([\mathrm{M}+\mathrm{H}]^{+}, 51,100,49\right)$.

Compound $31.0 \mathrm{~g}(2.4 \mathrm{mmol})$, NBS $0.45 \mathrm{~g}(2.5 \mathrm{mmol})$ and BPO $58 \mathrm{mg}(0.24 \mathrm{mmol})$ was added to $5 \mathrm{~mL}$ dried $\mathrm{CH}_{2} \mathrm{Cl}_{2}$, the mixture was stirred for $5 \mathrm{~h}$ in sunlight. The solvent was evaporated via rotary evaporation. The crude product was purified by silica gel chromatography with ethyl acetate-petroleum ether $(v / v, 1 / 16)$ as the eluent to obtain $0.71 \mathrm{~g}$ pale yellow solid compound 4 in 60\% yield. m.p. 103.3-105.0 ${ }^{\circ} \mathrm{C} ;{ }^{1} \mathrm{H}-\mathrm{NMR}\left(600 \mathrm{MHz}, \mathrm{DMSO}-d_{6}\right) \delta: 3.87\left(\mathrm{~s}, 3 \mathrm{H}, \mathrm{Ar}-5^{\prime}-\mathrm{OCH}_{3}\right), 3.96(\mathrm{~s}, 3 \mathrm{H}$, Ar-4' $\left.-\mathrm{OCH}_{3}\right), 4.76$ (s, 2H, Ar-2- $\left.\mathrm{CH}_{2}-\right), 7.04$ (s, 1H, Ar-3'-H), 7.08 (s, 1H, Ar-6'-H), 7.44 (d, J = 12.0 Hz, 1H, Ar-3-H), 7.46 (d, J = 3.0 Hz, 1H, Ar-6-H), 7.64 (dd, $J=12.0 \mathrm{~Hz}, 3.0 \mathrm{~Hz}, 1 \mathrm{H}, \mathrm{Ar}-4-\mathrm{H})$; ESI-MS m/z (\%): 490.81, 492.81, $494.72\left([\mathrm{M}+\mathrm{H}]^{+}, 34,98,100\right)$.

\subsubsection{General Procedure for the Synthesis of Intermediate Compounds $\mathbf{5 a}-\mathbf{4 0 a}$}

Compound $40.2 \mathrm{~g}(0.41 \mathrm{mmol})$ and $25 \mu \mathrm{L}$ piperdine $(0.82 \mathrm{mmol})$ was added to the $1.0 \mathrm{~mL}$ dried $\mathrm{CH}_{2} \mathrm{Cl}_{2}$. Anhydrous $\mathrm{Na}_{2} \mathrm{CO}_{3} 20 \mathrm{mg}$ was then added to the mixture, which was stirred for $12 \mathrm{~h}$. The mixture was washed with the distilled water, the organic phase was separated and dried over anhydrous $\mathrm{Na}_{2} \mathrm{SO}_{4}$, and then concentrated viarotary evaporation. The crude product was purified by silica gel chromatography with petroleum ether-acetone-strong ammonia water $(v / v / v, 8 / 1 / 0.1)$ as the eluent to gain 0.18 g yellow solid compound 5 a in $90 \%$ yield.

Compounds $6 \mathbf{a}-40$ a were also obtained from intermediate 4 in a similar manner as for the preparation of $5 \mathbf{a}$ in $70-93 \%$ yield. Note that the preparation of compound 13a and 14a was requested for the circumstance of heating and refluxing.

Compound 5a: Yellow solid, yield 90\%, m.p. 103.3-105.0 ${ }^{\circ} \mathrm{C} ;{ }^{1} \mathrm{H}-\mathrm{NMR}\left(600 \mathrm{MHz}, \mathrm{CDCl}_{3}\right) \delta: 1.34-1.41$

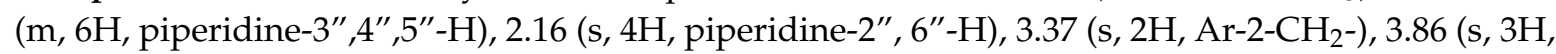
Ar-4'- $\mathrm{OCH}_{3}$ ), 3.95 (s, 3H, Ar-5'-OCH 3 ), 7.05 (s, 1H, Ar-3'-H), 7.15 (s, 1H, Ar-6'-H), 7.29 (s, 1H, Ar-6-H), 7.47 (d, $J=3.0 \mathrm{~Hz}, 1 \mathrm{H}, \mathrm{Ar}-3-\mathrm{H}), 7.51$ (dd, $J=3.0,12.0 \mathrm{~Hz}, 1 \mathrm{H}, \mathrm{Ar}-4-\mathrm{H})$; ESI-MS m/z (\%) 496.02, 498.08, $499.86\left([\mathrm{M}+\mathrm{H}]^{+}, 78,100,98\right)$.

Compound 6a: Yellow solid, yield 85\%, m.p. 116.0-117.3 ${ }^{\circ} \mathrm{C} ;{ }^{1} \mathrm{H}-\mathrm{NMR}\left(600 \mathrm{MHz}, \mathrm{CDCl}_{3}\right) \delta: 0.89$ $\left(\mathrm{d}, J=9.6 \mathrm{~Hz}, 3 \mathrm{H}\right.$, piperidine-2" $\left.-\mathrm{CH}_{3}\right), 1.36-1.95(\mathrm{~m}, 6 \mathrm{H}$, piperidine-3", 4", 5"- $\mathrm{H}), 2.30-2.56(\mathrm{~m}, 2 \mathrm{H}$, piperidine-6"'-H), $3.26(\mathrm{~d}, J=9.6 \mathrm{~Hz}, 1 \mathrm{H}$, piperidine-2" $-\mathrm{H}), 3.83\left(\mathrm{~s}, 3 \mathrm{H}, \mathrm{Ar}-4^{\prime}-\mathrm{OCH}_{3}\right), 3.91$ (s, $1 \mathrm{H}$, 
Ar-2- $\left.\mathrm{CH}_{2}-\right), 3.95$ (s, 3H, Ar-5'-OCH 3 ), 7.08 (s, 1H, Ar-3'-H), 7.11 (s, 1H, Ar-6'-H), 7.40 (d, J = $3.0 \mathrm{~Hz}, 1 \mathrm{H}$, Ar-3-H), 7.43 (s, 1H, Ar-6-H), 7.52 (dd, $J=3.0,12.6$ Hz, 1H, Ar-4-H); ESI-MS $m / z$ (\%) 510.03, 512.07, $513.85\left([\mathrm{M}+\mathrm{H}]^{+}, 70,100,90\right)$.

Compound 7a: Yellow solid, yield 87\%, m.p. 102.2-103.5 ${ }^{\circ} \mathrm{C} ;{ }^{1} \mathrm{H}-\mathrm{NMR}\left(600 \mathrm{MHz}, \mathrm{CDCl}_{3}\right) \delta: 0.74(\mathrm{~d}$, $J=9.0 \mathrm{~Hz}, 3 \mathrm{H}$, piperidine-3"'- $\left.\mathrm{CH}_{3}\right), 0.90(\mathrm{~m}, 1 \mathrm{H}$, piperidine- $\mathrm{H}), 1.35-1.78(\mathrm{~m}, 6 \mathrm{H}$, piperidine- $\mathrm{H}), 2.45$ (m, 2H, piperidine-6"-H), 3.38 (s, 2H, Ar-2- $\left.\mathrm{CH}_{2}-\right), 3.85\left(\mathrm{~s}, 3 \mathrm{H}, \mathrm{Ar}-4^{\prime}-\mathrm{OCH}_{3}\right), 3.95\left(\mathrm{~s}, 3 \mathrm{H}, \mathrm{Ar}-5^{\prime}-\mathrm{OCH}_{3}\right)$, 7.05 (s, 1H, Ar-3'-H), 7.14 (s, 1H, Ar-6'-H), 7.28 (s, 1H, Ar-6-H), 7.47 (d, J = 3.0 Hz, 1H, Ar-6-H), 7.53 $(\mathrm{dd}, J=3.0,12.6 \mathrm{~Hz}, 1 \mathrm{H}, \mathrm{Ar}-4-\mathrm{H})$; ESI-MS $m / z(\%)$ 510.06, 512.09, $513.86\left([\mathrm{M}+\mathrm{H}]^{+}, 77,87,100\right)$.

Compound 8a: Yellow solid, yield 87\%, m.p. $76.2-78.0{ }^{\circ} \mathrm{C} ;{ }^{1} \mathrm{H}-\mathrm{NMR}\left(600 \mathrm{MHz}, \mathrm{CDCl}_{3}\right) \delta: 0.83$ $\left(\mathrm{d}, J=9.6 \mathrm{~Hz}, 3 \mathrm{H}\right.$, piperidine-4"'- $\left.\mathrm{CH}_{3}\right), 0.88(\mathrm{~d}, J=9.6 \mathrm{~Hz}, 1 \mathrm{H}$, piperidine-4"- $\mathrm{H}), 1.04-2.52(\mathrm{~m}, 8 \mathrm{H}$, piperidine- $\mathrm{H}$ ), $3.38\left(\mathrm{~s}, 2 \mathrm{H}, \mathrm{Ar}-2-\mathrm{CH}_{2}-\right), 3.85\left(\mathrm{~s}, 3 \mathrm{H}, \mathrm{Ar}-4^{\prime}-\mathrm{OCH}_{3}\right), 3.94\left(\mathrm{~s}, 3 \mathrm{H}, \mathrm{Ar}-5^{\prime}-\mathrm{OCH}_{3}\right), 7.05(\mathrm{~s}, 1 \mathrm{H}$, Ar-3'-H), 7.15 (s, 1H, Ar-6'-H), 7.29 (s, 1H, Ar-6-H), 7.47 (d, J = 3.0 Hz, 1H, Ar-6-H), 7.53 (dd, J = 3.0, $12.6 \mathrm{~Hz}, 1 \mathrm{H}, \mathrm{Ar}-4-\mathrm{H})$; ESI-MS $m / z$ (\%) 510.03, 512.04, $513.90\left([\mathrm{M}+\mathrm{H}]^{+}, 55,100,65\right)$.

Compound 9a: Yellow solid, yield 86\%, m.p. 82.2-84.0 ${ }^{\circ} \mathrm{C} ;{ }^{1} \mathrm{H}-\mathrm{NMR}\left(600 \mathrm{MHz}, \mathrm{CDCl}_{3}\right) \delta: 0.72(\mathrm{~s}$, $3 \mathrm{H}$, piperidine-3" $\left.-\mathrm{CH}_{3}\right), 0.74\left(\mathrm{~s}, 3 \mathrm{H}\right.$, piperidine- $\left.5^{\prime \prime}-\mathrm{CH}_{3}\right), 0.86-2.46(\mathrm{~m}, 8 \mathrm{H}$, piperidine- $\mathrm{H}), 3.38(\mathrm{~s}, 2 \mathrm{H}$, Ar-2- $\left.\mathrm{CH}_{2}-\right)$, 3.84 (s, 3H, Ar-4'- $\left.\mathrm{OCH}_{3}\right), 3.94$ (s, 3H, Ar-5'-OCH $), 7.05$ (s, 1H, Ar-3'-H), 7.13 (s, 1H, Ar-6'-H), 7.26 (s, 1H, Ar-6-H), $7.47(\mathrm{~d}, J=3.0 \mathrm{~Hz}, 1 \mathrm{H}, \mathrm{Ar}-6-\mathrm{H}), 7.53(\mathrm{dd}, J=3.0,12.0 \mathrm{~Hz}, 1 \mathrm{H}, \mathrm{Ar}-4-\mathrm{H})$; ESI-MS $m / z(\%) 524.08,526.14,527.86\left([\mathrm{M}+\mathrm{H}]^{+}, 75,95,100\right)$.

Compound 10a: Yellow solid, yield 75\%, m.p. $48.3-49.5{ }^{\circ} \mathrm{C} ;{ }^{1} \mathrm{H}-\mathrm{NMR}\left(600 \mathrm{MHz}, \mathrm{CDCl}_{3}\right) \delta: 1.59-2.33$ (m, 9H, piperidine- $\mathrm{H}), 3.44\left(\mathrm{~s}, 2 \mathrm{H}, \mathrm{Ar}-2-\mathrm{CH}_{2}-\right), 3.87\left(\mathrm{~s}, 3 \mathrm{H}, \mathrm{Ar}-4^{\prime}-\mathrm{OCH}_{3}\right), 3.95\left(\mathrm{~s}, 3 \mathrm{H}, \mathrm{Ar}-5^{\prime}-\mathrm{OCH}_{3}\right), 7.05$ (s, 1H, Ar-3'-H), 7.16 (s, 1H, Ar-6'-H), 7.30 (s, 1H, Ar-6-H), 7.48 (d, J = 3.0 Hz, 1H, Ar-3-H), 7.55 (dd, $J=3.0,12.0 \mathrm{~Hz}, 1 \mathrm{H}, \mathrm{Ar}-4-\mathrm{H}), 10.2$ (s, $1 \mathrm{H}$, piperidine-4-COOH); ESI-MS $m / z$ (\%) 568.13, 570.15, 571.93 $\left([\mathrm{M}+\mathrm{H}]^{+}, 70,100,92\right)$.

Compound 11a: Yellow solid, yield 70\%, m.p. $44.8-46.2{ }^{\circ} \mathrm{C} ;{ }^{1} \mathrm{H}-\mathrm{NMR}\left(600 \mathrm{MHz}, \mathrm{CDCl}_{3}\right) \delta: 1.20(\mathrm{t}$, $J=7.2 \mathrm{~Hz}, 3 \mathrm{H}$, piperidine-3"'-COOCH$\left.{ }_{2}-\mathrm{CH}_{3}\right), 1.58-2.70(\mathrm{~m}, 9 \mathrm{H}$, piperidine- $\mathrm{H}), 3.49(\mathrm{q}, J=16.8 \mathrm{~Hz}, 2 \mathrm{H}$, piperidine-3"- $\left.\mathrm{COOCH}_{2}-\right), 3.85\left(\mathrm{~s}, 3 \mathrm{H}, \mathrm{Ar}-4^{\prime}-\mathrm{OCH}_{3}\right), 3.94\left(\mathrm{~s}, 3 \mathrm{H}, \mathrm{Ar}-5^{\prime}-\mathrm{OCH}_{3}\right), 4.07\left(\mathrm{~s}, 2 \mathrm{H}, \mathrm{Ar}-2-\mathrm{CH}_{2}-\right)$, 7.06 (s, 1H, Ar-3'-H), 7.11 (s, 1H, Ar-6'-H), 7.31 (d, J = 7.8 Hz, 1H, Ar-3-H), 7.46 (s, 1H, Ar-6-H), 7.53 (d, $J=8.4 \mathrm{~Hz}, 1 \mathrm{H}, \mathrm{Ar}-4-\mathrm{H})$; ESI-MS $m / z(\%) 568.22,570.14,572.29\left([\mathrm{M}+\mathrm{H}]^{+}, 100,65,97\right)$.

Compound 12a: Yellow solid, yield 75\%, m.p. 62.1-63.0 ${ }^{\circ} \mathrm{C} ;{ }^{1} \mathrm{H}-\mathrm{NMR}\left(600 \mathrm{MHz}, \mathrm{CDCl}_{3}\right) \delta: 1.40-2.51$ $(\mathrm{m}, 9 \mathrm{H}$, piperidine- $\mathrm{H}), 3.44\left(\mathrm{~s}, 2 \mathrm{H}, \mathrm{Ar}-2-\mathrm{CH}_{2}-\right), 3.62(\mathrm{brs}, 1 \mathrm{H}$, piperidine- $\mathrm{OH}), 3.85\left(\mathrm{~s}, 3 \mathrm{H}, \mathrm{Ar}-4^{\prime}-\mathrm{OCH}_{3}\right)$, $3.94\left(\mathrm{~s}, 3 \mathrm{H}, \mathrm{Ar}-5^{\prime}-\mathrm{OCH}_{3}\right), 7.06$ (s, 1H, Ar-3'-H), $7.15\left(\mathrm{~s}, 1 \mathrm{H}, \mathrm{Ar}-6^{\prime}-\mathrm{H}\right), 7.28(\mathrm{~d}, J=7.8 \mathrm{~Hz}, 1 \mathrm{H}, \mathrm{Ar}-3-\mathrm{H})$, $7.47(\mathrm{~d}, J=1.2 \mathrm{~Hz}, 1 \mathrm{H}, \mathrm{Ar}-6-\mathrm{H}), 7.53$ (dd, $J=1.2,8.4 \mathrm{~Hz}, 1 \mathrm{H}, \mathrm{Ar}-4-\mathrm{H})$; ESI-MS $m / z(\%)$ 512.20, 513.56, $516.26\left([\mathrm{M}+\mathrm{H}]^{+}, 100,65,97\right)$.

Compound 13a: Yellow solid, yield 75\%, m.p. $148.8-150.2{ }^{\circ} \mathrm{C} ;{ }^{1} \mathrm{H}-\mathrm{NMR}\left(600 \mathrm{MHz}, \mathrm{CDCl}_{3}\right) \delta: 0.92$ (d, $J=6.0 \mathrm{~Hz}, 6 \mathrm{H}$, piperidine-2",6"- $\left.\mathrm{CH}_{3}\right), 1.29-1.58\left(\mathrm{~m}, 6 \mathrm{H}\right.$, piperidine-3", $\left.4^{\prime \prime}, 5^{\prime \prime}-\mathrm{H}\right), 2.48(\mathrm{~m}, 2 \mathrm{H}$, piperidine-2", 6"-H), $3.86\left(\mathrm{~s}, 3 \mathrm{H}, \mathrm{Ar}-4^{\prime}-\mathrm{OCH}_{3}\right), 3.89\left(\mathrm{~s}, 2 \mathrm{H}, \mathrm{Ar}-2-\mathrm{CH}_{2}-\right), 3.95\left(\mathrm{~s}, 3 \mathrm{H}, \mathrm{Ar}-5^{\prime}-\mathrm{OCH}_{3}\right), 7.00$ $\left(\mathrm{s}, 1 \mathrm{H}, \mathrm{Ar}-3^{\prime}-\mathrm{H}\right), 7.06$ (s, $\left.1 \mathrm{H}, \mathrm{Ar}-6^{\prime}-\mathrm{H}\right), 7.36(\mathrm{~d}, J=1.8 \mathrm{~Hz}, 1 \mathrm{H}, \mathrm{Ar}-6-\mathrm{H}), 7.58(\mathrm{dd}, J=1.8,8.4 \mathrm{~Hz}, 1 \mathrm{H}$, Ar-3-H), 8.08 (d, J = 8.4 Hz, 1H, Ar-4-H); ESI-MS $m / z$ (\%) 524.16, 526.19, 528.03 ([M + H] $\left.]^{+}, 70,100,80\right)$.

Compound 14a: Yellow solid, yield 90\%, m.p. 140.0-142.0 ${ }^{\circ} \mathrm{C} ;{ }^{1} \mathrm{H}-\mathrm{NMR}\left(600 \mathrm{MHz}, \mathrm{CDCl}_{3}\right) \delta: 0.85-1.02$ (m, 12H, piperidine-2", 6"- $\left.\mathrm{CH}_{3}\right), 1.53\left(\mathrm{~m}, 6 \mathrm{H}\right.$, piperidine-3" , 4", 5"-H), $3.86\left(\mathrm{~s}, 3 \mathrm{H}, \mathrm{Ar}-4^{\prime}-\mathrm{OCH}_{3}\right), 3.95(\mathrm{~s}$, $\left.3 \mathrm{H}, \mathrm{Ar}-5^{\prime}-\mathrm{OCH}_{3}\right), 3.96$ (s, 2H, Ar-2- $\left.\mathrm{CH}_{2}-\right), 7.00\left(\mathrm{~s}, 1 \mathrm{H}, \mathrm{Ar}-3^{\prime}-\mathrm{H}\right), 7.07$ (s, $\left.1 \mathrm{H}, \mathrm{Ar}-6^{\prime}-\mathrm{H}\right), 7.36(\mathrm{~d}, J=1.8 \mathrm{~Hz}$, $1 \mathrm{H}, \mathrm{Ar}-6-\mathrm{H}), 7.57$ (dd, J = 1.8, $8.4 \mathrm{~Hz}, 1 \mathrm{H}, \mathrm{Ar}-3-\mathrm{H}), 8.10$ (d, $J=8.4 \mathrm{~Hz}, 1 \mathrm{H}, \mathrm{Ar}-4-\mathrm{H})$; ESI-MS $m / z(\%)$ $552.21,554.23,556.03\left([\mathrm{M}+\mathrm{H}]^{+}, 55,100,65\right)$.

Compound 15a: Yellow solid, yield 70\%, m.p. $138.9-140.5{ }^{\circ} \mathrm{C} ;{ }^{1} \mathrm{H}-\mathrm{NMR}\left(600 \mathrm{MHz}, \mathrm{CDCl}_{3}\right) \delta$ : 1.47-1.61 (m, 6H, piperidine-3", 4" ,5"-H), $2.03(\mathrm{t}, J=9.0 \mathrm{~Hz}, 2 \mathrm{H}$, piperidine-6"- $\mathrm{H}), 2.29-2.32(\mathrm{~m}, 1 \mathrm{H}$, piperidine-2"-H), $2.75(\mathrm{brs}, 1 \mathrm{H},-\mathrm{OH}), 3.31\left(\mathrm{~d}, J=7.8 \mathrm{~Hz}, 2 \mathrm{H}\right.$, piperidine- $\left.\mathrm{CH}_{2}-\right), 3.81\left(\mathrm{~s}, 2 \mathrm{H}, \mathrm{Ar}-2-\mathrm{CH}_{2}-\right)$, 
$3.83\left(\mathrm{~s}, 3 \mathrm{H}, \mathrm{Ar}-4^{\prime}-\mathrm{OCH}_{3}\right), 3.96$ (s, 3H, Ar-5'- $\left.\mathrm{OCH}_{3}\right), 7.06$ (s, 1H, Ar-3'-H), 7.10 (s, 1H, Ar-6'-H), 7.37 (d, $J=8.4 \mathrm{~Hz}, 1 \mathrm{H}, \mathrm{Ar}-3-\mathrm{H}), 7.40(\mathrm{~d}, J=1.8 \mathrm{~Hz}, 1 \mathrm{H}, \mathrm{Ar}-6-\mathrm{H}), 7.55$ (dd, $J=1.8,8.4 \mathrm{~Hz}, 1 \mathrm{H}, \mathrm{Ar}-4-\mathrm{H})$; ESI-MS $m / z(\%) 526.16,528.23,530.03\left([\mathrm{M}+\mathrm{H}]^{+}, 62,100,80\right)$.

Compound 16a: Yellow solid, yield 72\%, m.p. 50.5-51.9 ${ }^{\circ} \mathrm{C} ;{ }^{1} \mathrm{H}-\mathrm{NMR}\left(600 \mathrm{MHz}, \mathrm{CDCl}_{3}\right) \delta: 0.88-1.54$ (m, 7H, piperidine-3", 4", $5^{\prime \prime}-\mathrm{H}$, piperidine- $\left.4-\mathrm{CH}_{2}-\right), 1.85(\mathrm{t}, J=10.8 \mathrm{~Hz}, 2 \mathrm{H}$, piperidine-2"- $\mathrm{H}), 2.01$ (brs, $1 \mathrm{H},-\mathrm{OH}), 2.53(\mathrm{t}, J=10.8 \mathrm{~Hz}, 2 \mathrm{H}$, piperidine-6"- $\mathrm{H}), 3.40\left(\mathrm{~s}, 2 \mathrm{H}, \mathrm{Ar}-2-\mathrm{CH}_{2}-\right), 3.64(\mathrm{t}, J=9.6 \mathrm{~Hz}$, $\left.2 \mathrm{H}, \mathrm{HO}-\mathrm{CH}_{2}-\right), 3.84\left(\mathrm{~s}, 3 \mathrm{H}, \mathrm{Ar}-4^{\prime}-\mathrm{OCH}_{3}\right), 3.94\left(\mathrm{~s}, 3 \mathrm{H}, \mathrm{Ar}-5^{\prime}-\mathrm{OCH}_{3}\right), 7.06\left(\mathrm{~s}, 1 \mathrm{H}, \mathrm{Ar}-3^{\prime}-\mathrm{H}\right), 7.13(\mathrm{~s}, 1 \mathrm{H}$, Ar-6'-H), $7.29(\mathrm{~d}, J=12.0 \mathrm{~Hz}, 1 \mathrm{H}, \mathrm{Ar}-3-\mathrm{H}), 7.47(\mathrm{~d}, J=1.8 \mathrm{~Hz}, 1 \mathrm{H}, \mathrm{Ar}-6-\mathrm{H}), 7.52(\mathrm{dd}, J=2.4,12.0 \mathrm{~Hz}, 1 \mathrm{H}$, Ar-4-H); ESI-MS $m / z$ (\%) 540.24, 542.26, $544.13\left([\mathrm{M}+\mathrm{H}]^{+}, 65,100,75\right)$.

Compound 17a: White solid, yield 65\%, m.p. $44.2-45.8^{\circ} \mathrm{C} ;{ }^{1} \mathrm{H}-\mathrm{NMR}\left(600 \mathrm{MHz}, \mathrm{CDCl}_{3}\right) \delta: 1.09-1.58$ (m, 5H, piperidine-3", 4", 5"- $\mathrm{H}), 1.87(\mathrm{t}, J=14.4 \mathrm{~Hz}, 2 \mathrm{H}$, piperidine-2"- $\mathrm{H}), 2.05$ (brs, 1H, $-\mathrm{OH}), 2.57(\mathrm{t}$, $J=16.8 \mathrm{~Hz}, 2 \mathrm{H}$, piperidine-6"-H), $3.42\left(\mathrm{~d}, J=6.0 \mathrm{~Hz}, 2 \mathrm{H}, \mathrm{HO}-\mathrm{CH}_{2}-\right), 3.43\left(\mathrm{~s}, 2 \mathrm{H}, \mathrm{Ar}-2-\mathrm{CH}_{2}-\right), 3.84(\mathrm{~s}, 3 \mathrm{H}$, $\left.\mathrm{Ar}-4^{\prime}-\mathrm{OCH}_{3}\right), 3.94\left(\mathrm{~s}, 3 \mathrm{H}, \mathrm{Ar}-5^{\prime}-\mathrm{OCH}_{3}\right), 7.06\left(\mathrm{~s}, 1 \mathrm{H}, \mathrm{Ar}-3^{\prime}-\mathrm{H}\right), 7.13\left(\mathrm{~s}, 1 \mathrm{H}, \mathrm{Ar}-6^{\prime}-\mathrm{H}\right), 7.28$ (d, J = $12.0 \mathrm{~Hz}$, 1H, Ar-3-H), $7.47(\mathrm{~d}, J=3.0 \mathrm{~Hz}, 1 \mathrm{H}, \mathrm{Ar}-6-\mathrm{H}), 7.52(\mathrm{dd}, J=3.0,12.0 \mathrm{~Hz}, 1 \mathrm{H}, \mathrm{Ar}-4-\mathrm{H})$; ESI-MS $m / z(\%)$ $526.24,528.32,530.16\left([\mathrm{M}+\mathrm{H}]^{+}, 70,100,80\right)$.

Compound 18a: White solid, yield 60\%, m.p. 200.0-201.0 ${ }^{\circ} \mathrm{C} ;{ }^{1} \mathrm{H}-\mathrm{NMR}\left(600 \mathrm{MHz}, \mathrm{CDCl}_{3}\right) \delta: 2.13-2.24$ $\left(\mathrm{m}, 8 \mathrm{H}\right.$, piperazine-H), $3.37\left(\mathrm{~s}, 4 \mathrm{H}, \mathrm{Ar}-2-\mathrm{CH}_{2}-\right), 3.84\left(\mathrm{~s}, 6 \mathrm{H}, \mathrm{Ar}-4^{\prime}-\mathrm{OCH}_{3}\right), 3.94\left(\mathrm{~s}, 6 \mathrm{H}, \mathrm{Ar}-5^{\prime}-\mathrm{OCH}_{3}\right), 7.04$ (s, 2H, Ar-3'-H), 7.11 (s, 2H, Ar-6'-H), $7.24(\mathrm{~d}, J=12.0 \mathrm{~Hz}, 2 \mathrm{H}, \mathrm{Ar}-3-\mathrm{H}), 7.45$ (d, J = 3.0 Hz, 2H, Ar-6-H), 7.52 (dd, $J=3.0,12.0 \mathrm{~Hz}, 2 \mathrm{H}$, Ar-4-H); ESI-MS $m / z$ (\%) 909.12, 911.10, $912.95\left([\mathrm{M}+\mathrm{H}]^{+}, 65,100,75\right)$.

Compound 19a: White solid, yield 78\%, m.p. 74.3-76.0 ${ }^{\circ} \mathrm{C} ;{ }^{1} \mathrm{H}-\mathrm{NMR}\left(600 \mathrm{MHz}, \mathrm{CDCl}_{3}\right) \delta: 1.03(\mathrm{t}$, $J=10.8 \mathrm{~Hz}, 3 \mathrm{H}$, piperazine-4"- $\left.\mathrm{CH}_{3}\right), 1.70-2.36\left(\mathrm{~m}, 10 \mathrm{H}\right.$, piperazine-4" $-\mathrm{CH}_{2}$, piperazine- $\left.\mathrm{H}\right), 3.43(\mathrm{~s}$, 2H, Ar-2- $\left.\mathrm{CH}_{2}-\right), 3.86\left(\mathrm{~s}, 3 \mathrm{H}, \mathrm{Ar}-4^{\prime}-\mathrm{OCH}_{3}\right), 3.95$ (s, 3H, Ar-5'-OCH $\left.{ }_{3}\right), 7.05$ (s, 1H, Ar-3'-H), 7.15 (s, 1H, Ar-6'-H), 7.29 (s, J = 12.0 Hz, 1H, Ar-3-H), 7.48 (d, J = 3.0 Hz, 1H, Ar-6-H), 7.53 (dd, J = 3.0, $12.0 \mathrm{~Hz}, 1 \mathrm{H}$, Ar-4-H); ESI-MS $m / z$ (\%) 525.14, 527.20, $529.00\left([\mathrm{M}+\mathrm{H}]^{+}, 80,85,100\right)$.

Compound 20a: Yellow solid, yield 75\%, m.p. 65.8-66.9 ${ }^{\circ} \mathrm{C} ;{ }^{1} \mathrm{H}-\mathrm{NMR}\left(600 \mathrm{MHz}, \mathrm{CDCl}_{3}\right) \delta: 2.42(\mathrm{t}$, $J=7.2 \mathrm{~Hz}, 4 \mathrm{H}$, piperazine-2", $\left.6^{\prime \prime}-\mathrm{H}\right), 3.05\left(\mathrm{t}, J=7.2 \mathrm{~Hz}, 4 \mathrm{H}\right.$, piperazine-3", $\left.5^{\prime \prime}-\mathrm{H}\right), 3.52\left(\mathrm{~s}, 2 \mathrm{H}, \mathrm{Ar}-2-\mathrm{CH}_{2}-\right)$, $3.85\left(\mathrm{~s}, 3 \mathrm{H}, \mathrm{Ar}-4^{\prime}-\mathrm{OCH}_{3}\right), 3.94\left(\mathrm{~s}, 3 \mathrm{H}, \mathrm{Ar}-5^{\prime}-\mathrm{OCH}_{3}\right), 6.82-6.87\left(\mathrm{~m}, 3 \mathrm{H}, 3 \mathrm{H}\right.$, piperazine-Ar-3"', $\left.4^{\prime \prime \prime}, 5^{\prime \prime \prime}-\mathrm{H}\right)$, $7.05\left(\mathrm{~s}, 1 \mathrm{H}, \mathrm{Ar}-3^{\prime}-\mathrm{H}\right), 7.16\left(\mathrm{~s}, 1 \mathrm{H}, \mathrm{Ar}-6^{\prime}-\mathrm{H}\right), 7.24\left(\mathrm{~d}, J=11.4 \mathrm{~Hz}, 2 \mathrm{H}\right.$, piperazine-Ar-2"', $\left.6^{\prime \prime \prime}-\mathrm{H}\right), 7.33(\mathrm{~d}$, $J=12.0 \mathrm{~Hz}, 1 \mathrm{H}, \mathrm{Ar}-3-\mathrm{H}), 7.50$ (d, $J=3.0 \mathrm{~Hz}, 1 \mathrm{H}, \mathrm{Ar}-6-\mathrm{H}), 7.57$ (dd, $J=3.0,12.0 \mathrm{~Hz}, 1 \mathrm{H}, \mathrm{Ar}-4-\mathrm{H}) ;$ ESI-MS $m / z(\%) 573.10,575.09,576.95\left([\mathrm{M}+\mathrm{H}]^{+}, 48,100,58\right)$.

Compound 21a: Yellow solid, yield 75\%, m.p. $68.2-69.7^{\circ} \mathrm{C} ;{ }^{1} \mathrm{H}-\mathrm{NMR}\left(600 \mathrm{MHz}, \mathrm{CDCl}_{3}\right) \delta: 2.45(\mathrm{~s}, 4 \mathrm{H}$,

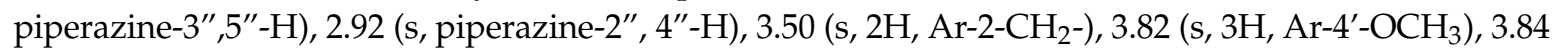
$\left(\mathrm{s}, 3 \mathrm{H}, \mathrm{Ar}-5^{\prime}-\mathrm{OCH}_{3}\right), 3.93(\mathrm{~s}, 3 \mathrm{H}$, piperazine-Ar-2"'--OCH 3$), 6.82(\mathrm{~d}, J=8.4 \mathrm{~Hz}, 1 \mathrm{H}$, piperazine-Ar-6"'--H), $6.85\left(\mathrm{~d}, J=7.8 \mathrm{~Hz}, 1 \mathrm{H}, \mathrm{Ar}-3^{\prime \prime \prime}-\mathrm{H}, \mathrm{Ar}-6^{\prime \prime \prime}-\mathrm{H}\right), 6.89$ (t, $\left.J=7.8 \mathrm{~Hz}, 1 \mathrm{H}, \mathrm{Ar}-4^{\prime \prime \prime}-\mathrm{H}\right), 6.97$ (t, $J=7.8 \mathrm{~Hz}, 1 \mathrm{H}$, Ar-5'”-H), 7.05 (s, 1H, Ar-3'-H), 7.18 (s, 1H, Ar-6'-H), 7.31 (s, J = 7.8 Hz, 1H, Ar-3-H), 7.51 (s, 1H, Ar-6-H), $7.55(\mathrm{dd}, J=1.2,7.8 \mathrm{~Hz}, 1 \mathrm{H}, \mathrm{Ar}-4-\mathrm{H})$; ESI-MS $m / z(\%) 603.26,604.57,607.42\left([\mathrm{M}+\mathrm{H}]^{+}, 100,70,90\right)$.

Compound 22a: Yellow solid, yield 68\%, m.p. $64.8-66.5^{\circ} \mathrm{C} ;{ }^{1} \mathrm{H}-\mathrm{NMR}\left(600 \mathrm{MHz}, \mathrm{CDCl}_{3}\right) \delta: 2.03(\mathrm{~s}, 3 \mathrm{H}$, piperazine-4"- $\left.\mathrm{COCH}_{3}\right), 2.24(\mathrm{t}, J=4.8 \mathrm{~Hz}, 2 \mathrm{H}$, piperazine-2"- $\mathrm{H}), 2.29(\mathrm{t}, J=5.4 \mathrm{~Hz}, 2 \mathrm{H}$, piperazine- 6 "'-H), $3.31\left(\mathrm{t}, J=4.8 \mathrm{~Hz}, 2 \mathrm{H}\right.$, piperazine-3"'-H), $3.48\left(\mathrm{t}, 2 \mathrm{H}, J=5.4 \mathrm{~Hz}\right.$, piperazine-5"'-H), $3.51\left(\mathrm{~s}, 2 \mathrm{H}, \mathrm{Ar}-2-\mathrm{CH}_{2}-\right)$, $3.85\left(\mathrm{~s}, 3 \mathrm{H}, \mathrm{Ar}-4^{\prime}-\mathrm{OCH}_{3}\right), 3.95$ (s, 3H, Ar-5'-OCH $\left.{ }_{3}\right), 7.07$ (s, 1H, Ar-3'-H), 7.13 (s, 1H, Ar-6'-H), 7.29 (d, $J=8.4 \mathrm{~Hz}, 1 \mathrm{H}, \mathrm{Ar}-3-\mathrm{H}), 7.48(\mathrm{~d}, J=1.8 \mathrm{~Hz}, 1 \mathrm{H}, \mathrm{Ar}-6-\mathrm{H}), 7.55$ (dd, $J=1.8,8.4 \mathrm{~Hz}, 1 \mathrm{H}, \mathrm{Ar}-4-\mathrm{H})$; ESI-MS $m / z(\%) 539.21,541.18,543.14\left([\mathrm{M}+\mathrm{H}]^{+}, 85,50,100\right)$.

Compound 23a: Yellow solid, yield 60\%, m.p. $64.5-66.3^{\circ} \mathrm{C} ;{ }^{1} \mathrm{H}-\mathrm{NMR}\left(600 \mathrm{MHz}, \mathrm{CDCl}_{3}\right) \delta: 2.44(\mathrm{t}$, $J=4.8 \mathrm{~Hz}, 4 \mathrm{H}$, piperazine-2", $\left.6^{\prime \prime}-\mathrm{H}\right), 3.30\left(\mathrm{t}, J=4.8 \mathrm{~Hz}\right.$, piperazine-3", $\left.5^{\prime \prime}-\mathrm{H}\right), 3.56\left(\mathrm{~s}, 2 \mathrm{H}, \mathrm{Ar}-2-\mathrm{CH}_{2}-\right)$, $3.85\left(\mathrm{~s}, 3 \mathrm{H}, \mathrm{Ar}-4^{\prime}-\mathrm{OCH}_{3}\right), 3.94\left(\mathrm{~s}, 3 \mathrm{H}, \mathrm{Ar}-5^{\prime}-\mathrm{OCH}_{3}\right), 6.75(\mathrm{~d}, J=9.6 \mathrm{~Hz}, 2 \mathrm{H}$, piperazine-Ar-2"', 6"' $-\mathrm{H})$, 7.07 (s, 1H, Ar-3'-H), 7.15 (s, 1H, Ar-6'-H), 7.34 (d, J = 7.8 Hz, 1H, Ar-3-H), 7.50 (d, J = 1.8 Hz, 1H, 
Ar-6-H), 7.57 (dd, J = 1.8, 7.8 Hz, 1H, Ar-4-H), 8.10 (d, $J=9.0 \mathrm{~Hz}, 2 \mathrm{H}$, piperazine-Ar-3"', 5"'-H); ESI-MS $m / z(\%) 618.23,620.12,622.02\left([\mathrm{M}+\mathrm{H}]^{+}, 48,100,58\right)$.

Compound 24a: Yellow solid, yield 77\%, m.p. 125.0-127.0 ${ }^{\circ} \mathrm{C} ;{ }^{1} \mathrm{H}-\mathrm{NMR}\left(600 \mathrm{MHz}, \mathrm{CDCl}_{3}\right) \delta: 2.02(\mathrm{t}$, $J=8.4 \mathrm{~Hz}, 8 \mathrm{H}$, piperazine-H), $2.21\left(\mathrm{~s}, 3 \mathrm{H}\right.$, piperazine- $\left.4^{\prime \prime}-\mathrm{CH}_{3}\right), 3.44\left(\mathrm{~s}, 2 \mathrm{H}, \mathrm{Ar}-2-\mathrm{CH}_{2}-\right), 3.86(\mathrm{~s}, 3 \mathrm{H}$, Ar-4'-OCH 3 ), 3.95 (s, 3H, Ar-5'-OCH 3 ), $7.06\left(\mathrm{~s}, 1 \mathrm{H}, \mathrm{Ar}-3^{\prime}-\mathrm{H}\right), 7.15\left(\mathrm{~s}, 1 \mathrm{H}, \mathrm{Ar}-6^{\prime}-\mathrm{H}\right), 7.28$ (d, J = $8.4 \mathrm{~Hz}$, 1H, Ar-3-H), 7.48 (s, 1H, Ar-6-H), 7.53 (d, J = 8.4 Hz, 1H, Ar-4-H); ESI-MS m/z (\%) 511.12, 513.13, 515.00 $\left([\mathrm{M}+\mathrm{H}]^{+}, 50,100,60\right)$.

Compound 25a: White solid, yield 71\%, m.p. 70.0-71.5 ${ }^{\circ} \mathrm{C} ;{ }^{1} \mathrm{H}-\mathrm{NMR}\left(600 \mathrm{MHz}, \mathrm{CDCl}_{3}\right) \delta: 0.97(\mathrm{~d}$, $J=6.6 \mathrm{~Hz}, 6 \mathrm{H}$, piperazine-4" $\left.-\mathrm{CH}_{3}\right), 2.28(\mathrm{~s}, 4 \mathrm{H}$, piperazine-3",5"-H), $2.37(\mathrm{~s}, 4 \mathrm{H}$, piperazine-2", 6"- $\mathrm{H})$, $2.57\left(\mathrm{~m}, 1 \mathrm{H}\right.$, piperazine-4"-CH-), $3.42\left(\mathrm{~s}, 2 \mathrm{H}, \mathrm{Ar}-2-\mathrm{CH}_{2}-\right), 3.85\left(\mathrm{~s}, 3 \mathrm{H}, \mathrm{Ar}-4^{\prime}-\mathrm{OCH}_{3}\right), 3.94(\mathrm{~s}, 3 \mathrm{H}$, Ar-5'-OCH 3 ), 7.06 (s, 1H, Ar-3'-H), 7.15 (s, 1H, Ar-6'-H), 7.28 (d, J = 8.4 Hz, 1H, Ar-3-H), 7.48 (d, $J=1.8 \mathrm{~Hz}, 1 \mathrm{H}, \mathrm{Ar}-6-\mathrm{H}), 7.52$ (dd, $J=1.8,8.4 \mathrm{~Hz}, 1 \mathrm{H}, \mathrm{Ar}-4-\mathrm{H})$; ESI-MS $m / z(\%)$ 539.02, 541.10, 543.26 $\left([\mathrm{M}+\mathrm{H}]^{+}, 50,100,50\right)$.

Compound 26a: Yellow solid, yield 67\%, m.p. 160.0-162.0 ${ }^{\circ} \mathrm{C} ;{ }^{1} \mathrm{H}-\mathrm{NMR}\left(600 \mathrm{MHz}, \mathrm{CDCl}_{3}\right) \delta: 2.26$ (s, 8H, piperazine-H), $3.43\left(\mathrm{~s}, 2 \mathrm{H}, \mathrm{Ar}-2-\mathrm{CH}_{2}-\right), 3.81\left(\mathrm{~s}, 3 \mathrm{H}, \mathrm{Ar}-4^{\prime}-\mathrm{OCH}_{3}\right), 3.93\left(\mathrm{~s}, 3 \mathrm{H}, \mathrm{Ar}-5^{\prime}-\mathrm{OCH}_{3}\right)$, $4.15\left(\mathrm{~s}, 1 \mathrm{H}\right.$, piperazine-4"'-CH-), $7.03\left(\mathrm{~s}, 1 \mathrm{H}, \mathrm{Ar}-3^{\prime}-\mathrm{H}\right), 7.11\left(\mathrm{~s}, 1 \mathrm{H}, \mathrm{Ar}-6^{\prime}-\mathrm{H}\right), 7.15(\mathrm{t}, J=7.8 \mathrm{~Hz}, 2 \mathrm{H}$, piperazine-CH-Ar-4"'-H), $7.23\left(\mathrm{t}, J=7.8 \mathrm{~Hz}, 4 \mathrm{H}\right.$, piperazine-CH-Ar-3"', $\left.5^{\prime \prime \prime}-\mathrm{H}\right), 7.27(\mathrm{~d}, J=7.8 \mathrm{~Hz}, 1 \mathrm{H}$, Ar-3-H), 7.34 (d, J = 7.2 Hz, 4H, piperazine-CH-Ar-2"', 6"''-H), 7.45 (d, J = 1.8 Hz, 1H, Ar-6-H), 7.50 (dd, $J=1.8,7.8 \mathrm{~Hz}, 1 \mathrm{H}$, Ar-4-H); ESI-MS $m / z(\%) 663.26,665.29,667.10\left([\mathrm{M}+\mathrm{H}]^{+}, 55,100,72\right)$.

Compound 27a: Yellow solid, yield 79\%, m.p. 56.0-58.0 ${ }^{\circ} \mathrm{C} ;{ }^{1} \mathrm{H}-\mathrm{NMR}\left(600 \mathrm{MHz}, \mathrm{CDCl}_{3}\right) \delta: 1.78(\mathrm{~s}$, $1 \mathrm{H}$, piperazine-4"'-OH), $2.02(\mathrm{~s}, 8 \mathrm{H}$, piperazine- $\mathrm{H}), 2.47\left(\mathrm{t}, J=5.4 \mathrm{~Hz}, 2 \mathrm{H}\right.$, piperazine- $\left.4^{\prime \prime}-\mathrm{CH}_{2}-\right), 3.45(\mathrm{~s}$, $\left.2 \mathrm{H}, \mathrm{Ar}-2-\mathrm{CH}_{2-}\right), 3.56\left(\mathrm{t}, J=5.4 \mathrm{~Hz}, 2 \mathrm{H}, \mathrm{HO}-\mathrm{CH}_{2}-\right), 3.85\left(\mathrm{~s}, 3 \mathrm{H}, \mathrm{Ar}-4^{\prime}-\mathrm{OCH}_{3}\right), 3.95\left(\mathrm{~s}, 3 \mathrm{H}, \mathrm{Ar}-5^{\prime}-\mathrm{OCH}_{3}\right)$, 5.52 (brs, 1H, -OH), 7.06 (s, 1H, Ar-3'-H), $7.14\left(\mathrm{~s}, 1 \mathrm{H}, \mathrm{Ar}-6^{\prime}-\mathrm{H}\right), 7.28$ (d, J = 7.8 Hz, 1H, Ar-3-H), 7.48 (d, $J=1.8 \mathrm{~Hz}, 1 \mathrm{H}, \mathrm{Ar}-6-\mathrm{H}), 7.53(\mathrm{dd}, J=1.8,7.8 \mathrm{~Hz}, 1 \mathrm{H}, \mathrm{Ar}-4-\mathrm{H})$; ESI-MS $m / z(\%)$ 541.15, 543.18, 545.03 $\left([\mathrm{M}+\mathrm{H}]^{+}, 60,100,70\right)$.

Compound 28a: Yellow solid, yield 71\%, m.p. $146.0-148.0{ }^{\circ} \mathrm{C} ;{ }^{1} \mathrm{H}-\mathrm{NMR}\left(600 \mathrm{MHz}, \mathrm{CDCl}_{3}\right) \delta: 2.34(\mathrm{t}$, $J=4.8 \mathrm{~Hz}, 4 \mathrm{H}$, piperazine-2" ,6"-H), $3.52\left(\mathrm{~s}, 2 \mathrm{H}, \mathrm{Ar}-2-\mathrm{CH}_{2}-\right), 3.68(\mathrm{t}, J=4.8 \mathrm{~Hz}, 4 \mathrm{H}$, piperazine-3", 5"- $\mathrm{H})$, $3.85\left(\mathrm{~s}, 3 \mathrm{H}, \mathrm{Ar}-4^{\prime}-\mathrm{OCH}_{3}\right), 3.94\left(\mathrm{~s}, 3 \mathrm{H}, \mathrm{Ar}-5^{\prime}-\mathrm{OCH}_{3}\right), 6.45(\mathrm{t}, J=4.8 \mathrm{~Hz}, 1 \mathrm{H}$, pyrimidine-5'”'-H), $7.07(\mathrm{~s}$, $\left.1 \mathrm{H}, \mathrm{Ar}-3^{\prime}-\mathrm{H}\right), 7.16\left(\mathrm{~s}, 1 \mathrm{H}, \mathrm{Ar}-6^{\prime}-\mathrm{H}\right), 7.34(\mathrm{~d}, 1 \mathrm{H}, J=8.4 \mathrm{~Hz}, \mathrm{Ar}-3-\mathrm{H}), 7.48(\mathrm{~d}, J=1.8 \mathrm{~Hz}, 1 \mathrm{H}, \mathrm{Ar}-6-\mathrm{H}), 7.55$ $(\mathrm{dd}, J=1.8,8.4 \mathrm{~Hz}, 1 \mathrm{H}, \mathrm{Ar}-4-\mathrm{H}), 8.26\left(\mathrm{~d}, J=4.8 \mathrm{~Hz}, 2 \mathrm{H}\right.$, pyrimidine-4"', $\left.6^{\prime \prime \prime}-\mathrm{H}\right)$; ESI-MS $m / z$ (\%) 575.14, 577.12, $579.02\left([\mathrm{M}+\mathrm{H}]^{+}, 48,100,58\right)$.

Compound 29a: Yellow solid, yield 65\%, m.p. $115.2-116.1^{\circ} \mathrm{C} ;{ }^{1} \mathrm{H}-\mathrm{NMR}\left(600 \mathrm{MHz}, \mathrm{CDCl}_{3}\right) \delta: 2.43(\mathrm{t}$, $J=4.8 \mathrm{~Hz}, 4 \mathrm{H}$, piperazine-2" ,6"-H), $2.97(\mathrm{t}, J=4.8 \mathrm{~Hz}, 4 \mathrm{H}$, piperazine-3", 5" $-\mathrm{H}), 3.52\left(\mathrm{~s}, 2 \mathrm{H}, \mathrm{Ar}-2-\mathrm{CH}_{2}-\right)$, $3.84\left(\mathrm{~s}, 3 \mathrm{H}, \mathrm{Ar}-4^{\prime}-\mathrm{OCH}_{3}\right), 3.94\left(\mathrm{~s}, 3 \mathrm{H}, \mathrm{Ar}-5^{\prime}-\mathrm{OCH}_{3}\right), 6.80\left(\mathrm{dd}, J=4.8,9.0 \mathrm{~Hz}, 2 \mathrm{H}, \mathrm{Ar}-2^{\prime \prime \prime}, 66^{\prime \prime \prime}-\mathrm{H}\right), 6.93(\mathrm{t}$, $\left.J=9.0 \mathrm{~Hz}, 2 \mathrm{H}, \mathrm{Ar}-3^{\prime \prime \prime}, 5^{\prime \prime \prime}-\mathrm{H}\right), 7.05$ (s, 1H, Ar-3'-H), 7.15 (s, 1H, Ar-6'-H), 7.33 (d, 1H, J = 8.4 Hz, Ar-3-H), $7.50(\mathrm{~d}, J=1.8 \mathrm{~Hz}, 1 \mathrm{H}, \mathrm{Ar}-6-\mathrm{H}), 7.55$ (dd, $J=1.8,8.4 \mathrm{~Hz}, 1 \mathrm{H}$, Ar-4-H); ESI-MS $m / z$ (\%) 591.16, 593.16, $595.03\left([\mathrm{M}+\mathrm{H}]^{+}, 48,100,58\right)$.

Compound 30a: Yellow solid, yield 70\%, m.p. 46.2-48.0 ${ }^{\circ} \mathrm{C} ;{ }^{1} \mathrm{H}-\mathrm{NMR}\left(600 \mathrm{MHz}, \mathrm{CDCl}_{3}\right) \delta: 2.44(\mathrm{t}$, $J=7.2 \mathrm{~Hz}, 4 \mathrm{H}$, piperazine-2", 6"-H), $2.95\left(\mathrm{t}, J=7.2 \mathrm{~Hz}, 4 \mathrm{H}\right.$, piperazine-3", 5"-H), $3.52\left(\mathrm{~s}, 2 \mathrm{H}, \mathrm{Ar}-2-\mathrm{CH}_{2}-\right.$ ), $3.84\left(\mathrm{~s}, 3 \mathrm{H}, \mathrm{Ar}-4^{\prime}-\mathrm{OCH}_{3}\right), 3.94\left(\mathrm{~s}, 3 \mathrm{H}, \mathrm{Ar}-5^{\prime}-\mathrm{OCH}_{3}\right), 6.84-7.03(\mathrm{~m}, 4 \mathrm{H}$, piperazine-Ar-H), $7.06(\mathrm{~s}, 1 \mathrm{H}$, Ar-3'-H), 7.16 (s, 1H, Ar-6'-H), 7.32 (d, 1H, J = 12.0 Hz, Ar-3-H), 7.50 (d, J = 3.0 Hz, 1H, Ar-6-H), 7.55 $(\mathrm{dd}, J=3.0,12.0 \mathrm{~Hz}, 1 \mathrm{H}, \mathrm{Ar}-4-\mathrm{H})$; ESI-MS $m / z(\%) 591.20,593.23,595.10\left([\mathrm{M}+\mathrm{H}]^{+}, 65,100,75\right)$.

Compound 31a: Yellow solid, yield 83\%, m.p. 129.1-130.8 ${ }^{\circ} \mathrm{C} ;{ }^{1} \mathrm{H}-\mathrm{NMR}\left(600 \mathrm{MHz}, \mathrm{CDCl}_{3}\right) \delta: 2.42(\mathrm{t}$, $J=7.2 \mathrm{~Hz}, 4 \mathrm{H}$, piperazine-2", 6"- $\mathrm{H}), 2.94(\mathrm{t}, J=7.2 \mathrm{~Hz}$, piperazine-3", 5"- $\mathrm{H}), 3.51\left(\mathrm{~s}, 2 \mathrm{H}, \mathrm{Ar}-2-\mathrm{CH}_{2}-\right)$, $3.75\left(\mathrm{~s}, 3 \mathrm{H}\right.$, piperazine- $\left.\mathrm{Ar}-\mathrm{OCH}_{3}\right), 3.84\left(\mathrm{~s}, 3 \mathrm{H}, \mathrm{Ar}-4^{\prime}-\mathrm{OCH}_{3}\right), 3.94\left(\mathrm{~s}, 3 \mathrm{H}, \mathrm{Ar}-5^{\prime}-\mathrm{OCH}_{3}\right), 6.79-684(\mathrm{~m}, 4 \mathrm{H}$, piperazine-Ar-H), 7.05 (s, 1H, Ar-3'-H), $7.16\left(\mathrm{~s}, 1 \mathrm{H}, \mathrm{Ar}-6^{\prime}-\mathrm{H}\right), 7.30(\mathrm{~d}, J=12.0 \mathrm{~Hz}, 1 \mathrm{H}, \mathrm{Ar}-3-\mathrm{H}), 7.50$ (d, 
$J=3.0 \mathrm{~Hz}, 1 \mathrm{H}, \mathrm{Ar}-6-\mathrm{H}), 7.55$ (dd, $J=3.0,12.0 \mathrm{~Hz}, 1 \mathrm{H}, \mathrm{Ar}-4-\mathrm{H})$; ESI-MS $m / z(\%) 603.19,605.19,607.08$ $\left([\mathrm{M}+\mathrm{H}]^{+}, 48,100,58\right)$.

Compound 32a: Yellow solid, yield 85\%, m.p. $150.3-152.0{ }^{\circ} \mathrm{C} ;{ }^{1} \mathrm{H}-\mathrm{NMR}\left(600 \mathrm{MHz}, \mathrm{CDCl}_{3}\right) \delta: 3.89$ $\left(\mathrm{s}, 3 \mathrm{H}, \mathrm{Ar}-4^{\prime}-\mathrm{OCH}_{3}\right), 3.96\left(\mathrm{~s}, 3 \mathrm{H}, \mathrm{Ar}-5^{\prime}-\mathrm{OCH}_{3}\right), 5.44\left(\mathrm{~s}, 2 \mathrm{H}, \mathrm{Ar}-2-\mathrm{CH}_{2}-\right), 6.90(\mathrm{~d}, J=12.6 \mathrm{~Hz}, 1 \mathrm{H}$, imidazole-5"-H), 6.93 (s, J = 12.6 Hz, H, imidazole-4"-H), $6.94(\mathrm{~d}, J=12.0 \mathrm{~Hz}, 1 \mathrm{H}, \mathrm{Ar}-3-\mathrm{H}), 7.06(\mathrm{~s}, 1 \mathrm{H}$, Ar-3'-H), $\left.7.10\left(\mathrm{~s}, 1 \mathrm{H}, \mathrm{Ar}-6^{\prime}-\mathrm{H}\right)\right), 7.47(\mathrm{~d}, J=3.0 \mathrm{~Hz}, 1 \mathrm{H}, \mathrm{Ar}-6-\mathrm{H}), 7.57$ (s, 1H, imidazole-2"-H), 7.60 (dd, $J=3.0,12.0 \mathrm{~Hz}, 1 \mathrm{H}, \mathrm{Ar}-4-\mathrm{H})$; ESI-MS $m / z(\%) 479.03,481.07,482.86\left([\mathrm{M}+\mathrm{H}]^{+}, 70,100,88\right)$.

Compound 33a: Yellow solid, yield 84\%, m.p. 57.2-59.0 ${ }^{\circ} \mathrm{C} ;{ }^{1} \mathrm{H}-\mathrm{NMR}\left(600 \mathrm{MHz}, \mathrm{CDCl}_{3}\right) \delta: 2.44(\mathrm{~s}, 3 \mathrm{H}$, imidazole-2"- $\left.\mathrm{CH}_{3}\right), 3.90\left(\mathrm{~s}, 3 \mathrm{H}, \mathrm{Ar}-4^{\prime}-\mathrm{OCH}_{3}\right), 3.96\left(\mathrm{~s}, 3 \mathrm{H}, \mathrm{Ar}-5^{\prime}-\mathrm{OCH}_{3}\right), 5.37\left(\mathrm{~s}, 2 \mathrm{H}, \mathrm{Ar}-2-\mathrm{CH}_{2}-\right), 6.59$ (d, $J=8.4 \mathrm{~Hz}, 1 \mathrm{H}$, imidazole-5"'-H), $6.86\left(\mathrm{~s}, 1 \mathrm{H}, \mathrm{Ar}-3^{\prime}-\mathrm{H}\right), 6.98(\mathrm{~d}, J=7.8 \mathrm{~Hz}, 1 \mathrm{H}, \mathrm{Ar}-3-\mathrm{H}), 7.00(\mathrm{~d}, J=7.8 \mathrm{~Hz}$, $1 \mathrm{H}$, imidazole-4"'-H), 7.07 (s, 1H, Ar-6'-H), 7.49 (d, J = 1.8 Hz, 1H, Ar-6-H), 7.57 (dd, J = 1.8, 8.4 Hz, 1H, Ar-4-H); ESI-MS $m / z$ (\%) 493.14, 495.17, 496.97 ([M + H] $\left.]^{+}, 75,100,95\right)$.

Compound 34a: Yellow solid, yield 81\%, m.p. $49.5-50.0{ }^{\circ} \mathrm{C} ;{ }^{1} \mathrm{H}-\mathrm{NMR}\left(600 \mathrm{MHz}, \mathrm{CDCl}_{3}\right) \delta: 2.22(\mathrm{~s}, 3 \mathrm{H}$, imidazole-4"'- $\left.\mathrm{CH}_{3}\right), 3.88\left(\mathrm{~s}, 3 \mathrm{H}, \mathrm{Ar}-4^{\prime}-\mathrm{OCH}_{3}\right), 3.96\left(\mathrm{~s}, 3 \mathrm{H}, \mathrm{Ar}-5^{\prime}-\mathrm{OCH}_{3}\right), 5.35\left(\mathrm{~s}, 2 \mathrm{H}, \mathrm{Ar}-2-\mathrm{CH}_{2}-\right), 6.63$ (s, 1H, imidazole-5"'-H), 6.89 (d, J = 12.0 Hz, 1H, Ar-3-H), $6.94\left(\mathrm{~s}, 1 \mathrm{H}, \mathrm{Ar}-3^{\prime}-\mathrm{H}\right), 7.06\left(\mathrm{~s}, 1 \mathrm{H}, \mathrm{Ar}-6^{\prime}-\mathrm{H}\right), 7.44$ (s, 1H, imidazole-2"-H), $7.47(\mathrm{~d}, J=10.8 \mathrm{~Hz}, 1 \mathrm{H}, \mathrm{Ar}-6-\mathrm{H}), 7.59$ (d, $J=12.0 \mathrm{~Hz}, 1 \mathrm{H}, \mathrm{Ar}-4-\mathrm{H})$; ESI-MS m/z (\%) 493.12, 495.17, $496.93\left([\mathrm{M}+\mathrm{H}]^{+}, 75,100,98\right)$.

Compound 35a: White solid, yield 85\%, m.p. 167.0-168.5 ${ }^{\circ} \mathrm{C} ;{ }^{1} \mathrm{H}-\mathrm{NMR}\left(600 \mathrm{MHz}, \mathrm{CDCl}_{3}\right) \delta: 1.27$ $(\mathrm{t}, J=10.8 \mathrm{~Hz}, 3 \mathrm{H}$, imidazole-2"-C-CH 3$), 2.59\left(\mathrm{q}, J=10.8 \mathrm{~Hz}, 2 \mathrm{H}\right.$, imidazole-2" $\left.-\mathrm{CH}_{2}-\right), 3.91(\mathrm{~s}, 3 \mathrm{H}$, $\left.\mathrm{Ar}-4^{\prime}-\mathrm{OCH}_{3}\right), 3.97\left(\mathrm{~s}, 3 \mathrm{H}, \mathrm{Ar}-5^{\prime}-\mathrm{OCH}_{3}\right), 5.38\left(\mathrm{~s}, 2 \mathrm{H}, \mathrm{Ar}-2-\mathrm{CH}_{2}-\right), 6.57$ (d, J = 12.0 Hz, 1H, Ar-3-H), 6.85 (d, $J=1.8 \mathrm{~Hz}, 1 \mathrm{H}$, imidazole-5"-H), $7.00(\mathrm{~s}, 1 \mathrm{H}$, Ar-3'-H), $7.04(\mathrm{~d}, J=1.8 \mathrm{~Hz}, 1 \mathrm{H}$, imidazole-4"'-H), 7.07 $\left(\mathrm{s}, 1 \mathrm{H}, \mathrm{Ar}-6^{\prime}-\mathrm{H}\right), 7.49$ (d, J = 3.0 Hz, 1H, Ar-6-H), 7.56 (dd, J = 3.0, $12.0 \mathrm{~Hz}, 1 \mathrm{H}$, Ar-4-H); ESI-MS m/z (\%) $507.07,509.05,510.97\left([\mathrm{M}+\mathrm{H}]^{+}, 50,100,62\right)$.

Compound 36a: Yellow solid, yield 77\%, m.p. 162.0-163.0 ${ }^{\circ} \mathrm{C} ;{ }^{1} \mathrm{H}-\mathrm{NMR}\left(600 \mathrm{MHz}, \mathrm{CDCl}_{3}\right) \delta: 1.25$ (d, $J=6.6 \mathrm{~Hz}, 6 \mathrm{H}$, imidazole-2" -C- $\left.\mathrm{CH}_{3}\right), 2.89$ (m, 1H, imidazole-2"-CH-), 3.91 (s, 3H, Ar-4'-OCH $\left.{ }_{3}\right), 3.97$ $\left(\mathrm{s}, 3 \mathrm{H}, \mathrm{Ar}-5^{\prime}-\mathrm{OCH}_{3}\right), 5.41\left(\mathrm{~s}, 2 \mathrm{H}, \mathrm{Ar}-2-\mathrm{CH}_{2}-\right), 6.57(\mathrm{~d}, J=8.4 \mathrm{~Hz}, 1 \mathrm{H}, \mathrm{Ar}-3-\mathrm{H}), 6.81(\mathrm{~d}, 1 \mathrm{H}, J=1.2 \mathrm{~Hz}$, imidazole-5"-H), 7.00 (s, 1H, Ar-3'-H), 7.06 (d, J = 1.2 Hz, 1H, imidazole-4"'-H), 7.07 (s, 1H, Ar-6'-H), $7.49(\mathrm{~d}, J=1.2 \mathrm{~Hz}, 1 \mathrm{H}, \mathrm{Ar}-6-\mathrm{H}), 7.56$ (dd, $J=1.8,8.4 \mathrm{~Hz}, 1 \mathrm{H}, \mathrm{Ar}-4-\mathrm{H})$; ESI-MS $m / z$ (\%) 521.17, 523.05, $525.04\left([\mathrm{M}+\mathrm{H}]^{+}, 85,98,100\right)$.

Compound 37a: Yellow solid, yield 72\%, m.p. $32.8-34.5^{\circ} \mathrm{C} ;{ }^{1} \mathrm{H}-\mathrm{NMR}\left(600 \mathrm{MHz}, \mathrm{CDCl}_{3}\right) \delta$ : 1.24 (s, $3 \mathrm{H}$, imidazole-2"--C- $\left.\mathrm{CH}_{3}\right), 2.23$ (s, 3H, imidazole-4"- $\left.\mathrm{CH}_{3}\right), 2.58$ (q, 2H, imidazole-2"- $\left.\mathrm{CH}_{2}-\right), 3.90(\mathrm{~s}, 3 \mathrm{H}$, $\left.\mathrm{Ar}-4^{\prime}-\mathrm{OCH}_{3}\right), 3.97$ (s, 3H, Ar-5'-OCH 3 ), 5.30 (s, 2H, Ar-2- $\left.\mathrm{CH}_{2}-\right), 6.54$ (s, 1H, imidazole-5"'-H), 6.63 (d, $J=8.4 \mathrm{~Hz}, 1 \mathrm{H}, \mathrm{Ar}-3-\mathrm{H}), 6.99$ (s, 1H, Ar-3'-H), 7.07 (s, 1H, Ar-6'-H), 7.48 (d, J = 1.8 Hz, 1H, Ar-6-H), 7.57 $\left(\mathrm{dd}, J=1.8,8.4 \mathrm{~Hz}, 1 \mathrm{H}\right.$, Ar-4-H); ESI-MS $m / z(\%) 521.18,523.22,525.06\left([\mathrm{M}+\mathrm{H}]^{+}, 80,100,95\right)$.

Compound 38a: White solid, yield 70\%, m.p. 183.0-185.0 ${ }^{\circ} \mathrm{C} ;{ }^{1} \mathrm{H}-\mathrm{NMR}\left(600 \mathrm{MHz}, \mathrm{CDCl}_{3}\right) \delta: 3.89(\mathrm{~s}, 3 \mathrm{H}$, $\left.\mathrm{Ar}-4^{\prime}-\mathrm{OCH}_{3}\right), 3.95\left(\mathrm{~s}, 3 \mathrm{H}, \mathrm{Ar}-5^{\prime}-\mathrm{OCH}_{3}\right), 5.54\left(\mathrm{~s}, 2 \mathrm{H}, \mathrm{Ar}-2-\mathrm{CH}_{2}-\right), 6.73(\mathrm{~d}, J=8.4 \mathrm{~Hz}, 1 \mathrm{H}, \mathrm{Ar}-3-\mathrm{H}), 6.96(\mathrm{~s}$, 1H, Ar-3'-H), 7.02 (s, 1H, Ar-6'-H), 7.03 (s, 1H, imidazole-4"-H), 7.24 (s, 1H, imidazole-5"-H), 7.35-7.36 (m, 3H, imidazole-2"-Ph-H), 7.48 (d, J = 1.8 Hz, 1H, Ar-6-H), 7.49-7.50 (m, 2H, imidazole-2"-Ph-H), 7.59 (dd, J = 1.8, 8.4 Hz, 1H, Ar-4-H); 555.14, 557.17, 558.99 ([M + H] $\left.]^{+}, 52,100,48\right)$.

Compound 39a: White solid, yield 79\%, m.p. 164.2-165.1 ${ }^{\circ} \mathrm{C} ;{ }^{1} \mathrm{H}-\mathrm{NMR}\left(600 \mathrm{MHz}, \mathrm{CDCl}_{3}\right) \delta: 2.20(\mathrm{~s}, 3 \mathrm{H}$, imidazole-4" $\left.-\mathrm{CH}_{3}\right), 2.26\left(\mathrm{~s}, 3 \mathrm{H}\right.$, imidazole-2" $\left.-\mathrm{CH}_{3}\right), 3.90\left(\mathrm{~s}, 3 \mathrm{H}, \mathrm{Ar}-4^{\prime}-\mathrm{OCH}_{3}\right), 3.97\left(\mathrm{~s}, 3 \mathrm{H}, \mathrm{Ar}-5^{\prime}-\mathrm{OCH}_{3}\right)$, $5.29\left(\mathrm{~s}, 2 \mathrm{H}, \mathrm{Ar}-2-\mathrm{CH}_{2}-\right), 6.55$ (s, imidazole-5"'-H), $6.64(\mathrm{~d}, J=12.6 \mathrm{~Hz}, 1 \mathrm{H}, \mathrm{Ar}-3-\mathrm{H}), 7.01\left(\mathrm{~s}, 1 \mathrm{H}, \mathrm{Ar}-3^{\prime}-\mathrm{H}\right)$, 7.07 (s, 1H, Ar-6'-H), 7.48 (d, J=3.0 Hz, 1H, Ar-6-H), 7.58 (dd, J = 3.0, $12.6 \mathrm{~Hz}, 1 \mathrm{H}$, Ar-4-H); ESI-MS $m / z(\%) 507.22,509.25,511.10\left([\mathrm{M}+\mathrm{H}]^{+}, 68,100,78\right)$.

Compound 40a: Yellow solid, yield 63\%, m.p. $130.0-132.0{ }^{\circ} \mathrm{C} ;{ }^{1} \mathrm{H}-\mathrm{NMR}\left(600 \mathrm{MHz}, \mathrm{CDCl}_{3}\right) \delta: 3.78$ (s, 3H, Ar-4'-OCH 3 ), 3.95 (s, 3H, Ar-5'-OCH 3 ), 5.68 (s, 2H, Ar-2- $\left.\mathrm{CH}_{2}-\right), 6.83$ (s, 1H, Ar-3'-H), 6.89 (d, 
$J=12.6 \mathrm{~Hz}, 1 \mathrm{H}, \mathrm{Ar}-3-\mathrm{H}), 7.05\left(\mathrm{~s}, 1 \mathrm{H}, \mathrm{Ar}-6^{\prime}-\mathrm{H}\right), 7.23-7.24(\mathrm{~m}, 2 \mathrm{H}$, imidazole-Ar-H), 7.29-7.30 (m, 1H, imidazole-Ar-H), 7.49 (d, $J=3.0 \mathrm{~Hz}, 1 \mathrm{H}, \mathrm{Ar}-6-\mathrm{H}), 7.55(\mathrm{dd}, J=3.0,12.0 \mathrm{~Hz}, 1 \mathrm{H}$, imidazole-Ar-H), $7.83(\mathrm{~d}, J=12.6 \mathrm{~Hz}, 1 \mathrm{H}, \mathrm{Ar}-4-\mathrm{H}$ ), 7.97 (s, 1H, imidazole-2"'-H); ESI-MS m/z (\%) 529.16, 531.20, 533.04 $\left([\mathrm{M}+\mathrm{H}]^{+}, 68,100,80\right)$.

\subsubsection{General Procedure for the Synthesis of Target Compounds $\mathbf{5 b - 4 0 b}$}

$\mathrm{BBr}_{3}$ solution $\left(\mathrm{BBr}_{3} / \mathrm{CH}_{2} \mathrm{Cl}_{2}, v / v, 1 / 9\right) 1.5 \mathrm{~mL}$ was dropwise added to a cooled $\left(-78{ }^{\circ} \mathrm{C}\right)$ solution of $0.259 \mathrm{~g}(0.52 \mathrm{mmol})$ compound $5 \mathrm{a}$ in $5 \mathrm{~mL}$ dried $\mathrm{CH}_{2} \mathrm{Cl}_{2}$. The mixture was allowed to warm to room temperature and stirred for $2 \mathrm{~h}$, and poured into $30 \mathrm{~mL}$ ice-water. The precipitate was filtered, washed with a little distilled water and dried $\mathrm{CH}_{2} \mathrm{Cl}_{2}$, respectively, and dried in a vacuum drying oven to obtain $0.183 \mathrm{~g}$ yellow solid compound $\mathbf{5 b}$ in $75 \%$ yield. The total yield of target compound $\mathbf{5 b}$ was $18.8 \%$.

Target compounds $\mathbf{6 b}-\mathbf{4 0} \mathbf{b}$ were obtained from $\mathbf{6 a}$ to $\mathbf{4 0} \mathbf{a}$ in a similar manner as for the preparation of $\mathbf{5 b}$ in $38-85 \%$ yield, the total yields of which were $7.7-23 \%$.

Compound 5b: Yellow solid, final yield $18.8 \%$, m.p. $148.0-150.0{ }^{\circ} \mathrm{C} ;{ }^{1} \mathrm{H}-\mathrm{NMR}\left(600 \mathrm{MHz}\right.$, DMSO- $\left.d_{6}\right) \delta$ : 1.73-1.82 (m, 6H, piperidine-3", 4", $\left.5^{\prime \prime}-\mathrm{H}\right), 3.08(\mathrm{t}, J=10.2 \mathrm{~Hz} 2 \mathrm{H}$, piperidine-2"- $\mathrm{H}), 3.43(\mathrm{t}, J=12 \mathrm{~Hz}$, $2 \mathrm{H}$, piperidine-6"-H), 4.37 (s, 2H, Ar-2- $\left.\mathrm{CH}_{2}-\right), 6.95\left(\mathrm{~s}, 1 \mathrm{H}, \mathrm{Ar}-6^{\prime}-\mathrm{H}\right), 7.08\left(\mathrm{~s}, 1 \mathrm{H}, \mathrm{Ar}-3^{\prime}-\mathrm{H}\right), 7.58(\mathrm{~s}, 1 \mathrm{H}$, Ar-6-H), 7.77 (d, J = 7.8 Hz, 1H, Ar-3-H), 7.98 (d, J = 8.4 Hz, 1H, Ar-4-H), 9.73 (brs, 1H, Ar-4'-OH), 10.41 (brs, $\left.1 \mathrm{H}, \mathrm{Ar}-5{ }^{\prime}-\mathrm{OH}\right) ;{ }^{13} \mathrm{C}-\mathrm{NMR}\left(150 \mathrm{MHz}\right.$, DMSO- $\left.d_{6}\right) \delta: 21.6 \times 2,22.7 \times 2,53.1 \times 2,56.9,110.7,119.7$, $120.9,123.1,129.0,129.7,133.8,135.4,135.6,141.4,145.3,151.0,194.9$; ESI-MS $m / z$ (\%): 468.11, 470.13, $471.96\left([\mathrm{M}+\mathrm{H}]^{+}, 78,100,98\right)$.

Compound 6b: Yellow solid, final yield 17.3\%, m.p. 172.5-174. ${ }^{\circ} \mathrm{C} ;{ }^{1} \mathrm{H}-\mathrm{NMR}\left(600 \mathrm{MHz}, \mathrm{DMSO}-\mathrm{d}_{6}\right)$ $\delta: 1.48\left(\mathrm{~d}, J=6.0 \mathrm{~Hz}, 3 \mathrm{H}\right.$, piperidine-2"- $\left.\mathrm{CH}_{3}\right), 1.69-1.92\left(\mathrm{~m}, 6 \mathrm{H}\right.$, piperidine-3", $\left.4^{\prime \prime}, 5^{\prime \prime}-\mathrm{H}\right), 2.90-2.96(\mathrm{~m}$, $1 \mathrm{H}$, piperidine-2"-H), $3.12(\mathrm{t}, J=4.8 \mathrm{~Hz}, 2 \mathrm{H}$, piperidine-6"- $\mathrm{H}), 4.83\left(\mathrm{~s}, 1 \mathrm{H}, \mathrm{Ar}-2-\mathrm{CH}_{2}-\right), 6.95(\mathrm{~s}, 1 \mathrm{H}$, Ar-6'-H), 7.08 (s, 1H, Ar-3'-H), 7.61 (d, J = 23.4 Hz, 1H, Ar-6-H), 7.79 (d, J = 8.4 Hz, 1H, Ar-3-H), 7.97 (d, $J=8.4 \mathrm{~Hz}, 1 \mathrm{H}, \mathrm{Ar}-4-\mathrm{H}), 9.72$ (brs, 1H, Ar-4'-OH), 10.40 (brs, 1H, Ar-5'-OH); ${ }^{13} \mathrm{C}-\mathrm{NMR}(150 \mathrm{MHz}$, DMSO- $d_{6}$ ) $\delta: 18.1,22.4,28.0,30.9,51.3,57.6,61.6,110.8,119.8,121.0,123.0,128.9,129.9,133.8,135.4$, 135.9, 141.5, 145.2, 151.0, 194.8; ESI-MS $m / z$ (\%): 482.16, 484.19, $486.05\left([\mathrm{M}+\mathrm{H}]^{+}, 82,80,100\right)$.

Compound 7b: Yellow solid, final yield 16.5\%, m.p. 174.0-175. ${ }^{\circ} \mathrm{C} ;{ }^{1} \mathrm{H}-\mathrm{NMR}\left(600 \mathrm{MHz}, \mathrm{DMSO}-d_{6}\right)$ $\delta: 0.88\left(\mathrm{~d}, J=6.6 \mathrm{~Hz}, 3 \mathrm{H}\right.$, piperidine-3"'- $\left.\mathrm{CH}_{3}\right), 1.06-1.13(\mathrm{~m}, 1 \mathrm{H}$, piperidine-3"- $\mathrm{H}), 1.71-1.84(\mathrm{~m}, 4 \mathrm{H}$, piperidine- $\left.4^{\prime \prime}, 5^{\prime \prime}-\mathrm{H}\right), 2.66-2.71(\mathrm{~m}, 2 \mathrm{H}$, piperidine-2" $-\mathrm{H}), 3.32-3.45(\mathrm{~m}, 2 \mathrm{H}$, piperidine-6"- $\mathrm{H}), 4.38(\mathrm{~s}$, 2H, Ar-2- $\left.\mathrm{CH}_{2}\right), 6.96$ (s, 1H, Ar-6'-H), 7.08 (s, 1H, Ar-3'-H), 7.58 (s, 1H, Ar-6-H), 7.80 (d, J = 8.4 Hz, 1H, Ar-3-H), 7.98 (d, J = 8.4 Hz, 1H, Ar-4-H), 9.71 (brs, 1H, Ar-4'-OH), 10.40 (brs, 1H, Ar-5'-OH); ${ }^{13}$ C-NMR $\left(150 \mathrm{MHz}\right.$, DMSO- $\left.d_{6}\right) \delta: 19.0,22.8,29.1,30.2,52.7,57.3,58.4,110.7,119.8,121.0,123.2,128.9,129.5,133.7$, 135.4, 135.7, 141.5, 145.3, 151.0, 194.8; ESI-MS $m / z$ (\%): 482.15, 484.16, $485.98\left([\mathrm{M}+\mathrm{H}]^{+}, 80,95,100\right)$.

Compound 8b: Yellow solid, final yield 15.9\%, m.p. 103.3-105.0 ${ }^{\circ} \mathrm{C} ;{ }^{1} \mathrm{H}-\mathrm{NMR}\left(600 \mathrm{MHz}\right.$, DMSO- $\left.d_{6}\right)$ $\delta: 0.92\left(\mathrm{~d}, J=9.6 \mathrm{~Hz}, 3 \mathrm{H}\right.$, piperidine-4"- $\left.\mathrm{CH}_{3}\right), 1.01-1.03(\mathrm{~m}, 1 \mathrm{H}$, piperidine-4"- $\mathrm{H}), 1.38-1.47(\mathrm{~m}, 2 \mathrm{H}$, piperidine-3"-H), 1.78-1.81 (m, 2H, piperidine-5"-H), $3.09(\mathrm{t}, J=18.6 \mathrm{~Hz}, 2 \mathrm{H}$, piperidine-2"'-H), $3.44(\mathrm{t}$, $J=16.2 \mathrm{~Hz}, 2 \mathrm{H}$, piperidine-6"'-H), $4.37\left(\mathrm{~s}, 2 \mathrm{H}, \mathrm{Ar}-2-\mathrm{CH}_{2}-\right), 6.95\left(\mathrm{~s}, 1 \mathrm{H}, \mathrm{Ar}-6^{\prime}-\mathrm{H}\right), 7.08\left(\mathrm{~s}, 1 \mathrm{H}, \mathrm{Ar}-3^{\prime}-\mathrm{H}\right)$, $7.58(\mathrm{~d}, J=3.0 \mathrm{~Hz}, 1 \mathrm{H}, \mathrm{Ar}-6-\mathrm{H}), 7.79(\mathrm{~d}, J=12.0 \mathrm{~Hz}, 1 \mathrm{H}, \mathrm{Ar}-3-\mathrm{H}), 7.97(\mathrm{dd}, J=12 \mathrm{~Hz}, 3.0 \mathrm{~Hz}, 1 \mathrm{H}$, Ar-4-H), 9.75 (brs, 1H, Ar-4'-OH), 10.42 (brs, 1H, Ar-5'-OH); ${ }^{13}$ C-NMR (150 MHz, DMSO-d 6 ) 21.5, 28.4, $31.2 \times 2,53.0 \times 2,57.2,110.8,113.8,119.7,120.9,123.1,129.8,133.8,135.6,141.5,145.3,151.0,156.3$, 195.7; ESI-MS $m / z$ (\%): 481.99, 484.02, $485.92\left([\mathrm{M}+\mathrm{H}]^{+}, 50,100,58\right)$.

Compound 9b: Yellow solid, final yield 15.3\%, m.p. $173.0-175.3{ }^{\circ} \mathrm{C} ;{ }^{1} \mathrm{H}-\mathrm{NMR}\left(600 \mathrm{MHz}\right.$, DMSO- $\left.d_{6}\right) \delta$ : $0.88\left(\mathrm{~d}, J=6.6 \mathrm{~Hz}, 6 \mathrm{H}\right.$, piperidine-3", $\left.5^{\prime \prime}-\mathrm{CH}_{3}\right), 1.74(\mathrm{t}, J=12.6 \mathrm{~Hz}, 2 \mathrm{H}$, piperidine-4"-H), 1.93-1.94 (m, $2 \mathrm{H}$, piperidine-3", 5"-H), 2.59-2.65 (m, 2H, piperidine-2"- $\mathrm{H}), 3.29-3.37(\mathrm{~m}, 2 \mathrm{H}$, piperidine-6"- $\mathrm{H}), 4.37$ (s, 2H, Ar-2- $\left.\mathrm{CH}_{2}-\right), 6.97\left(\mathrm{~s}, 1 \mathrm{H}, \mathrm{Ar}-3^{\prime}-\mathrm{H}\right), 7.08\left(\mathrm{~s}, 1 \mathrm{H}, \mathrm{Ar}-6^{\prime}-\mathrm{H}\right), 7.59$ (s, 1H, Ar-6-H), $7.81(\mathrm{~d}, J=8.4 \mathrm{~Hz}, 1 \mathrm{H}$, Ar-3-H), 7.98 (d, J = 8.4 Hz, 1H, Ar-4-H), 9.71 (brs, 1H, Ar-4'-OH), 10.41 (brs, 1H, Ar-5'-OH); ${ }^{13} \mathrm{C}-\mathrm{NMR}$ 
$\left(150 \mathrm{MHz}\right.$, DMSO- $\left.d_{6}\right) 18.3 \times 2,28.3,38.4 \times 2,56.7 \times 2,57.4,110.3,119.3,120.5,122.7,128.3,128.9,133.2$, 134.9, 135.4, 141.1, 144.7, 150.5, 194,3; ESI-MS $m / z$ (\%) 496.17, 498.42, $500.07\left([\mathrm{M}+\mathrm{H}]^{+}, 82,78,100\right)$.

Compound 10b: Yellow solid, final yield $12.3 \%$, m.p. $158.3-159.5{ }^{\circ} \mathrm{C} ;{ }^{1} \mathrm{H}-\mathrm{NMR}\left(600 \mathrm{MHz}, \mathrm{DMSO}-d_{6}\right)$ $\delta: 1.79-2.12\left(\mathrm{~m}, 5 \mathrm{H}\right.$, piperidine-3", $\left.4^{\prime \prime}, 5^{\prime \prime}-\mathrm{H},\right), 3.14(\mathrm{t}, J=12.6 \mathrm{~Hz}, 2 \mathrm{H}$, piperdine-2"- $\mathrm{H}), 3.50(\mathrm{t}, 2 \mathrm{H}$, $J=12.0 \mathrm{~Hz}, 2 \mathrm{H}$, piperidine-6"'-H), 4.38 (s, 2H, Ar-2- $\left.\mathrm{CH}_{2}-\right), 6.95$ (s, 1H, Ar-3'-H), 7.08 (s, 1H, Ar-6'-H), 7.58 (s, 1H, Ar-6-H), 7.78 (d, J = 8.4 Hz, 1H, Ar-3-H), 7.98 (d, J = 7.8 Hz, 1H, Ar-4-H), 9.72 (s, 1H, Ar-4'-OH), 10.40 (s, $\left.1 \mathrm{H}, \mathrm{Ar}-5^{\prime}-\mathrm{OH}\right), 12.57$ (s, $1 \mathrm{H}$, piperidine-4" $\left.-\mathrm{COOH}\right) ;{ }^{13} \mathrm{C}-\mathrm{NMR}$ (150 MHz, DMSO- $d_{6}$ ) 25.7, $38.1 \times 2,52.1 \times 2,57.1,110.7,120.0,120.9,123.2,129.0,129.6,133.8,135.4,135.6,141.3,145.3,151.0$, 175.0, 194.8; ESI-MS $m / z$ (\%) 512.08, 514.12, $515.93\left([\mathrm{M}+\mathrm{H}]^{+}, 65,100,75\right)$.

Compound 11b: Yellow solid, final yield 15.7\%, m.p. 180.0-181.3 ${ }^{\circ} \mathrm{C}$; FT-IR (ATR) $v\left(\mathrm{~cm}^{-1}\right)$ : 3191, 2979, 2878, 1716, 1652, 1586, 1401, 1287, 1188, 1012, 796, 639; ${ }^{1} \mathrm{H}-\mathrm{NMR}\left(600 \mathrm{MHz}, \mathrm{DMSO}-d_{6}\right) \delta: 1.20(\mathrm{t}$, $J=10.8 \mathrm{~Hz}, 3 \mathrm{H}$, piperidine-3"- $\left.\mathrm{COOCH}_{2}-\mathrm{CH}_{3}\right), 1.50-2.04(\mathrm{~m}, 4 \mathrm{H}$, piperidine-5",6"- $\mathrm{H}), 3.07-3.60(\mathrm{~m}$, $5 \mathrm{H}$, piperidine-2" , 3", $\left.4^{\prime \prime}-\mathrm{H}\right), 4.10\left(\mathrm{q}, 2 \mathrm{H}\right.$, piperidine-3"- $\left.\mathrm{COOCH}_{2}-\right), 4.45\left(\mathrm{~s}, 2 \mathrm{H}, \mathrm{Ar}-2-\mathrm{CH}_{2}-\right), 6.96(\mathrm{~s}, 1 \mathrm{H}$, Ar-3'-H), 7.08 (s, 1H, Ar-6'-H), 7.59 (d, J = 3.0 Hz, 1H, Ar-6-H), 7.81 (d, J = 12.0 Hz, 1H, Ar-3-H), 7.98 $(\mathrm{d}, J=12.0 \mathrm{~Hz}, 1 \mathrm{H}, \mathrm{Ar}-4-\mathrm{H}), 9.74$ (brs, $\left.1 \mathrm{H}, \mathrm{Ar}-4^{\prime}-\mathrm{OH}\right), 10.43$ (brs, $\left.1 \mathrm{H}, \mathrm{Ar}-5^{\prime}-\mathrm{OH}\right) ;{ }^{13} \mathrm{C}-\mathrm{NMR}(150 \mathrm{MHz}$, DMSO- $d_{6}$ ) 14.4, 22.2, 25.1, 52.6, 55.4, 57.7, 61.2, 61.5, 110.8, 113.8, 119.7, 120.9, 123.3, 129.0, 133.8, 135.7, 141.5, 145.3, 151.0, 156.3, 171.4, 194.8; ESI-MS $m / z$ (\%) 539.96, 541.95, $543.78\left([\mathrm{M}+\mathrm{H}]^{+}\right.$, 52, 100, 70); HR-MS (ESI) calcd for $\mathrm{C}_{22} \mathrm{H}_{23} \mathrm{Br}_{2} \mathrm{NO}_{5}[\mathrm{M}-\mathrm{H}]^{-}$: 539.9840; found: 539.9835 .

Compound 12b: Yellow solid, final yield 19.0\%, m.p. 184.0-186.0 ${ }^{\circ} \mathrm{C}$; FT-IR (ATR) $v\left(\mathrm{~cm}^{-1}\right.$ ): 3191, 2960, 2764, 1649, 1586, 1411, 1286, 1191, 1152, 1010, 796, 638; ${ }^{1} \mathrm{H}-\mathrm{NMR}\left(600 \mathrm{MHz}\right.$, DMSO- $\left.d_{6}\right) \delta: 1.75-1.99$ (m, 4H, piperidine-3", $\left.5^{\prime \prime}-\mathrm{H}\right), 3.12-3.45(\mathrm{~m}, 4 \mathrm{H}$, piperidine-2", 6 "'-H), $3.94(\mathrm{~s}, 1 \mathrm{H}$, piperidine-4"-OH), 3.67-3.72 (m, 1H, piperidine-4"'-H), 4.39 (s, 2H, Ar-2- $\left.\mathrm{CH}_{2}-\right), 6.96$ (s, 1H, Ar-3'-H), 7.09 (s, 1H, Ar-6'-H), $7.58(\mathrm{~d}, J=3.0 \mathrm{~Hz}, 1 \mathrm{H}, \mathrm{Ar}-6-\mathrm{H}), 7.84(\mathrm{~d}, J=12.0 \mathrm{~Hz}, 1 \mathrm{H}, \mathrm{Ar}-3-\mathrm{H}), 7.98(\mathrm{~d}, J=12.6 \mathrm{~Hz}, 1 \mathrm{H}, \mathrm{Ar}-4-\mathrm{H}), 9.78$ (s, 1H, Ar-4'-OH), 10.37 (s, 1H, Ar-5'-OH); ${ }^{13} \mathrm{C}-\mathrm{NMR}\left(150 \mathrm{MHz}\right.$, DMSO-d $\left.d_{6}\right) 29.8 \times 2,48.1 \times 2,59.9$, $64.2,110.6,119.6,120.9,123.2,129.1,129.7,133.9,135.5,135.8,141.4,145.3,150.9,195.0$; ESI-MS $\mathrm{m} / z$ (\%) 483.74, 485.71, $487.62\left([\mathrm{M}+\mathrm{H}]^{+}, 48,100,58\right)$; HR-MS (ESI) calcd for $\mathrm{C}_{19} \mathrm{H}_{19} \mathrm{Br}_{2} \mathrm{NO}_{4}[\mathrm{M}+\mathrm{H}]^{+}: 485.9730$; found: 485.9692 .

Compound 13b: Yellow solid, final yield 15.3\%, m.p. 98.0-99.5 ${ }^{\circ} \mathrm{C}$; FT-IR (ATR) $v\left(\mathrm{~cm}^{-1}\right)$ : 3191, 2975, 2941, 1655, 1586, 1409, 1279, 1191, 1118, 1009, 805, 637; ${ }^{1} \mathrm{H}-\mathrm{NMR}$ (600 MHz, DMSO-d $\left.{ }_{6}\right) \delta: 1.20$ $\left(\mathrm{d}, J=9.0 \mathrm{~Hz}, 6 \mathrm{H}\right.$, piperidine-2",6"- $\left.\mathrm{CH}_{3}\right), 3.40-3.50(\mathrm{~m}, 6 \mathrm{H}$, piperidine-3", 4", 5"-H), 4.63-4.67 (m, 2H, piperidine-2", 6"-H), 5.76 (s, 2H, Ar-2- $\left.\mathrm{CH}_{2}-\right), 6.98$ (s, 1H, Ar-3'-H), 7.10 (s, 1H, Ar-6'-H), 7.58 (d, $J=2.4 \mathrm{~Hz}, 1 \mathrm{H}, \mathrm{Ar}-3-\mathrm{H}), 7.79$ (d, $J=5.4 \mathrm{~Hz}, 1 \mathrm{H}, \mathrm{Ar}-6-\mathrm{H}), 7.98(\mathrm{~d}, J=3.0 \mathrm{~Hz}, 1 \mathrm{H}, \mathrm{Ar}-4-\mathrm{H}), 9.75$ (brs, $1 \mathrm{H}$, Ar-4'-OH), 10.48 (brs, 1H, Ar-5'-OH); ${ }^{13} \mathrm{C}-\mathrm{NMR}(150 \mathrm{MHz}$, DMSO-d 6 ) 18.4, $19.5 \times 2,30.1 \times 2,52.8 \times 2$, 55.4, 110.8, 119.8, 121.1, 122.2, 128.9, 132.7, 133.7, 134.3, 135.3, 139.4, 145.1, 151.0, 195.1; ESI-MS $\mathrm{m} / z$ (\%) 494.20, 496.18, $498.15\left([\mathrm{M}-\mathrm{H}]^{-}, 50,100,50\right)$; HR-MS (ESI) calcd for $\mathrm{C}_{21} \mathrm{H}_{23} \mathrm{Br}_{2} \mathrm{NO}_{3}[\mathrm{M}-\mathrm{H}]^{-}$: 495.9940, found: 495.9961 .

Compound 14b: Yellow solid, final yield 5.3\%, m.p. 176.0-177.3 ${ }^{\circ} \mathrm{C}$; FT-IR (ATR) $v\left(\mathrm{~cm}^{-1}\right)$ : 2951, 2921, 2850, 1654, 1606, 1442, 1394, 1283, 1048, 999, 864, 686; ${ }^{1} \mathrm{H}-\mathrm{NMR}\left(600 \mathrm{MHz}, \mathrm{DMSO}-d_{6}\right) \delta: 0.87$ (s, 12H, piperidine-2", 6"- $\left.\mathrm{CH}_{3}\right), 1.23-1.29\left(\mathrm{~m}, 6 \mathrm{H}\right.$, piperidine-3", 4" ,5"-H), $3.77\left(\mathrm{~s}, 2 \mathrm{H}, \mathrm{Ar}-2-\mathrm{CH}_{2}-\right), 6.67(\mathrm{~s}, 1 \mathrm{H}$, Ar-3'-H), 6.92 (s, 1H, Ar-6'-H), 7.34 (d, J = 3.0 Hz, 1H, Ar-6-H), 7.69 (d, J = 12.6 Hz, 1H, Ar-3-H), 7.95 (d, $J=12.6 \mathrm{~Hz}, 1 \mathrm{H}, \mathrm{Ar}-4-\mathrm{H}), 9.74$ (brs, $\left.1 \mathrm{H}, \mathrm{Ar}-4{ }^{\prime}-\mathrm{OH}\right), 10.38$ (brs, $\left.1 \mathrm{H}, \mathrm{Ar}-5^{\prime}-\mathrm{OH}\right) ;{ }^{13} \mathrm{C}-\mathrm{NMR}(150 \mathrm{MHz}$, DMSO- $d_{6}$ ) $17.8,41.2 \times 4,45.5 \times 2,54.8 \times 2,54.9,109.7,110.3,113.5,118.5,125.0,129.6,131.3,131.4$, 133.7, 139.2, 144.9, 155.8, 196.5; ESI-MS $m / z$ (\%) 523.98, 525.96, $527.82\left([\mathrm{M}+\mathrm{H}]^{+}, 48,100,58\right)$; HR-MS (ESI) calcd for $\mathrm{C}_{25} \mathrm{H}_{31} \mathrm{Br}_{2} \mathrm{NO}_{4}$-H: 524.026, found: 524.0268.

Compound 15b: Yellow solid, final yield $12.7 \%$, m.p. $122.5-124.0{ }^{\circ} \mathrm{C} ;{ }^{1} \mathrm{H}-\mathrm{NMR}\left(600 \mathrm{MHz}\right.$, DMSO- $\left.d_{6}\right)$ $\delta:$ 1.52-1.90 (m, 6H, piperidine-3", 4", 5"-H), 3.03-3.13 (m, 2H, piperidine-6"-H), $3.34(\mathrm{~s}, 1 \mathrm{H}$, piperidine-2"-H), 3.74-3.92 (m, 2H, piperidine-2"'- $\left.\mathrm{CH}_{2}-\right), 4.37\left(\mathrm{~s}, 2 \mathrm{H}, \mathrm{Ar}-2-\mathrm{CH}_{2}-\right), 6.96\left(\mathrm{~s}, 1 \mathrm{H}, \mathrm{Ar}-3^{\prime}-\mathrm{H}\right)$, 7.08 (s, 1H, Ar-6'-H), 7.56 (s, 1H, Ar-6-H), 7.78 (d, J = 12.6 Hz, 1H, Ar-3-H), 7.99 (d, J = 12 Hz, 1H, 
Ar-4-H), 9.78 (brs, 1H, Ar-4'-OH), 10.46 (brs, $\left.1 \mathrm{H}, \mathrm{Ar}-5^{\prime}-\mathrm{OH}\right){ }^{13} \mathrm{C}-\mathrm{NMR}\left(150 \mathrm{MHz}, \mathrm{DMSO}-d_{6}\right)$ 20.8, 21.7, 25.4, 50.7, 53.3, 55.4, 59.6, 111.0, 119.9, 121.0, 123.1, 128.8, 129.8, 133.8, 135.4, 135.9, 141.7, 145.2, 151.1, 195.2; ESI-MS $m / z(\%) 497.74,499.67,501.64\left([\mathrm{M}+\mathrm{H}]^{+}, 75,100,70\right)$.

Compound 16b: Yellow solid, final yield 16.2\%, m.p. 50.0-51.0 ${ }^{\circ} \mathrm{C}$; FT-IR (ATR) $v\left(\mathrm{~cm}^{-1}\right.$ ): 3360, 2920, $2851,1631,1588,1500,1362,1289,1237,1153,1012,878,798 ;{ }^{1} \mathrm{H}-\mathrm{NMR}\left(600 \mathrm{MHz}\right.$, DMSO- $\left.d_{6}\right) \delta: 1.04-1.46$ (m, 7H, piperidine- $3^{\prime \prime}, 4^{\prime \prime}, 5^{\prime \prime}-\mathrm{H}$, piperidine-4" $\left.-\mathrm{CH}_{2}\right), 3.03-3.45\left(\mathrm{~m}, 6 \mathrm{H}\right.$, piperidine-2", 6"- $\mathrm{H}, \mathrm{HO}-\mathrm{CH}_{2}-$ ), 4.37 (s, 2H, Ar-2-CH $\left.2_{2}^{-}\right), 6.96$ (s, 1H, Ar-3'-H), 7.08 (s, 1H, Ar-6'-H), 7.57 (d, J = 3.0 Hz, 1H, Ar-6-H), 7.81 (d, $J=12.6 \mathrm{~Hz}, 1 \mathrm{H}, \mathrm{Ar}-3-\mathrm{H}), 7.98$ (dd, $J=3.0,12.6 \mathrm{~Hz}, 1 \mathrm{H}, \mathrm{Ar}-4-\mathrm{H}), 9.74$ (brs, 1H, Ar-4'-OH), 10.41 (brs, $\left.1 \mathrm{H}, \mathrm{Ar}-5^{\prime}-\mathrm{OH}\right) ;{ }^{13} \mathrm{C}-\mathrm{NMR}\left(150 \mathrm{MHz}\right.$, DMSO- $\left.d_{6}\right) 29.3,30.2 \times 2,38.8 \times 2,53.1,57.1,58.4,110.7,119.7$, $120.9,123.1,129.0,129.7,133.7,135.4,135.6,141.5,145.3,150.9,194.8$; ESI-MS $m / z$ (\%) 511.96, 513.95, $515.79\left([\mathrm{M}+\mathrm{H}]^{+}, 55,100,70\right)$.

Compound 17b: White solid, fianl yield 13.5\%, m.p. 113.0-115.0 ${ }^{\circ} \mathrm{C} ;{ }^{1} \mathrm{H}-\mathrm{NMR}\left(600 \mathrm{MHz}\right.$, DMSO- $\left.d_{6}\right)$ $\delta: 1.42-1.85\left(\mathrm{~m}, 5 \mathrm{H}\right.$, piperidine- $\left.3^{\prime \prime}, 4^{\prime \prime}, 5^{\prime \prime}-\mathrm{H}\right), 3.04-3.13(\mathrm{~m}, 2 \mathrm{H}$, piperidine-2" $-\mathrm{H}), 3.28(\mathrm{~d}, J=8.4 \mathrm{~Hz}$, $\left.2 \mathrm{H}, \mathrm{HO}-\mathrm{CH}_{2}-\right), 3.42-3.57\left(\mathrm{~m}, 2 \mathrm{H}\right.$, piperidine-6"-H), 4.39 (s, 2H, Ar-2- $\left.\mathrm{CH}_{2}-\right), 5.76(\mathrm{~s}, 1 \mathrm{H},-\mathrm{OH}), 6.96$ $\left(\mathrm{d}, J=5.4 \mathrm{~Hz}, 1 \mathrm{H}, \mathrm{Ar}-3^{\prime}-\mathrm{H}\right), 7.08\left(\mathrm{~s}, 1 \mathrm{H}, \mathrm{Ar}-6^{\prime}-\mathrm{H}\right), 7.57(\mathrm{~s}, 1 \mathrm{H}, \mathrm{Ar}-6-\mathrm{H}), 7.78(\mathrm{dd}, J=3.6,12.6 \mathrm{~Hz}, 1 \mathrm{H}$, Ar-3-H), 7.98 (d, J = 12.6 Hz, 1H, Ar-4-H), 9.75 (brs, 1H, Ar-4'-OH), 10.42 (brs, 1H, Ar-5'-OH); ${ }^{13} \mathrm{C}-\mathrm{NMR}$ $\left(150 \mathrm{MHz}\right.$, DMSO- $\left.d_{6}\right) 26.2 \times 2,36.1,52.8 \times 2,57.2,65.2,110.8,119.7,120.9,123.1,129.0,129.7,133.8$, 135.4, 135.5, 141.5, 145.2, 151.0, 194.8; ESI-MS $m / z(\%) 497.91,499.94,501.79\left([\mathrm{M}+\mathrm{H}]^{+}, 60,100,75\right)$.

Compound 18b: White solid, final yield 10.0\%, m.p. $183.0-185.0{ }^{\circ} \mathrm{C} ;{ }^{1} \mathrm{H}-\mathrm{NMR}\left(400 \mathrm{MHz}, \mathrm{DMSO}-d_{6}\right)$ $\delta: 3.34\left(\mathrm{~s}, 8 \mathrm{H}\right.$, piperazine-2", $\left.3^{\prime \prime}, 5^{\prime \prime}, 6^{\prime \prime}-\mathrm{H}\right), 4.29$ (s, 4H, Ar-2- $\left.\mathrm{CH}_{2}-\right), 6.96$ (s, 2H, Ar-3'-H), 7.09 (s, 2H, Ar-6'-H), 7.57 (s, 2H, Ar-6-H), 7.76 (d, J = 9.6 Hz, 2H, Ar-3-H), 7.94 (d, J = 9.0 Hz, 2H, Ar-4-H), 9.90 (brs, 4H, Ar-4'-OH, Ar-5'-OH); ${ }^{13}$ C-NMR (150 MHz, DMSO-d 6$) 49.6 \times 4,57.1 \times 2,110.7 \times 2,119.7 \times 2$, $121.0 \times 2,122.9 \times 2,126.3 \times 2,128.7 \times 2,133.5 \times 2,135.1 \times 2,141.5 \times 2,145.2 \times 2,150.9 \times 2,156.2 \times$ 2, $194.7 \times 2$; ESI-MS $m / z(\%) 850.69,852.83,854.92\left([\mathrm{M}+\mathrm{H}]^{+}, 52,100,48\right)$.

Compound 19b: Yellow solid, final yield 18.4\%, m.p. 195.8-197.5 ${ }^{\circ} \mathrm{C} ;{ }^{1} \mathrm{H}-\mathrm{NMR}(600 \mathrm{MHz}$, DMSO- $\left.d_{6}\right) \delta: 1.20-1.28\left(\mathrm{~m}, 5 \mathrm{H}\right.$, piperazine- $\left.\mathrm{CH}_{2} \mathrm{CH}_{3}\right), 3.16\left(\mathrm{~m}, 4 \mathrm{H}\right.$, piperazine- $\left.3^{\prime \prime}, 5^{\prime \prime}-\mathrm{H}\right), 3.53(\mathrm{~m}, 4 \mathrm{H}$, piperazine-2",6"'-H), 3.88 (s, 2H, Ar-2- $\left.\mathrm{CH}_{2}-\right), 6.95$ (s, 1H, Ar-3'-H), 7.06 (s, 1H, Ar-6'-H), 7.09 (s, 1H, Ar-3-H), 7.14 (s, 1H, Ar-4-H), 7.23 (s, 1H, Ar-6-H), 9.02 (brs, 1H, Ar-4'-OH), 9.67 (brs, 1H, Ar-5'-OH); ${ }^{13}$ C-NMR $\left(150 \mathrm{MHz}\right.$, DMSO-d $\left.d_{6}\right)$ 9.3, 25.7, $31.7 \times 2,50.5 \times 2,52.3,110.7,116.9,119.8,121.2,128.5,132.9$, 134.8, 141.6, 145.1, 148.5, 150.8, 152.5, 194.5; ESI-MS $m / z$ (\%) 497.11, 499.11, 500.96 ([M + H] $\left.]^{+}, 48,100,55\right)$.

Compound 20b: Yellow solid, fianl yield $18.1 \%$, m.p. $219.5-220.8{ }^{\circ} \mathrm{C} ;{ }^{1} \mathrm{H}-\mathrm{NMR}\left(600 \mathrm{MHz}\right.$, DMSO- $\left.d_{6}\right) \delta$ : $3.15(\mathrm{~s}, 2 \mathrm{H}$, piperazine-2"-H), 3.35 (s, 2H, piperazine-6"-H), $3.54(\mathrm{~s}, 2 \mathrm{H}$, piperazine-3"- $-\mathrm{H}), 3.84(\mathrm{~s}, 2 \mathrm{H}$, piperazine-5"-H), $4.51\left(\mathrm{~s}, 2 \mathrm{H}, \mathrm{Ar}-2-\mathrm{CH}_{2}-\right), 6.87-7.01\left(\mathrm{~m}, 5 \mathrm{H}\right.$, piperazine- $\left.\mathrm{C}_{6} \mathrm{H}_{5}\right), 7.27\left(\mathrm{~s}, 2 \mathrm{H}, \mathrm{Ar}-3^{\prime}, 6^{\prime}-\mathrm{H}\right)$, 7.60 (s, 1H, Ar-3-H), 7.83 (s, 1H, Ar-4-H), 8.00 (s, 1H, Ar-6-H), 9.78 (brs, 1H, Ar-4'-OH), 10.38 (brs, 1H, Ar-5'-H); ${ }^{13}$ C-NMR $\left(150 \mathrm{MHz}\right.$, DMSO- $\left.d_{6}\right) 45.5 \times 2,51.5 \times 2,56.9,110.7,111.7,118.4 \times 2,119.7,120.9$, $123.3,129.0,129.6,132.2 \times 2,133.9,135.5,135.7,141.4,145.3,149.1,151.0,195.0$; ESI-MS $m / z$ (\%) 545.11, $547.15,548.96\left([\mathrm{M}+\mathrm{H}]^{+}, 60,100,80\right)$.

Compound 21b: White solid, fianl yield 15.9\%, m.p. 156.0-157. ${ }^{\circ} \mathrm{C}$; FT-IR (ATR) $v\left(\mathrm{~cm}^{-1}\right)$ : 3189, 2636, $2251,2261,1654,1588,1500,1411,1191,1014,752,637 ;{ }^{1} \mathrm{H}-\mathrm{NMR}\left(600 \mathrm{MHz}, \mathrm{DMSO}-d_{6}\right) \delta: 3.02-3.53$ $\left(\mathrm{m}, 8 \mathrm{H}\right.$, piperazine-2" , 3", 5", 6"-H), $3.80(\mathrm{~s}, 3 \mathrm{H}, \mathrm{Ar-OCH}), 4.50\left(\mathrm{~s}, 2 \mathrm{H}, \mathrm{Ar}-2-\mathrm{CH}_{2}-\right), 6.92-7.04(\mathrm{~m}, 5 \mathrm{H}$, piperazine- $\left.\mathrm{C}_{6} \mathrm{H}_{4}{ }^{-}, \mathrm{Ar}-3^{\prime}-\mathrm{H}\right), 7.09$ (s, 1H, Ar-6'-H), $7.60(\mathrm{~s}, 1 \mathrm{H}, \mathrm{Ar}-6-\mathrm{H}), 7.82(\mathrm{~d}, J=12 \mathrm{~Hz}, 1 \mathrm{H}, \mathrm{Ar}-6-\mathrm{H})$, 8.01 (d, J = $12.6 \mathrm{~Hz}, 1 \mathrm{H}, \mathrm{Ar}-4-\mathrm{H}), 9.29$ (brs, 2H, Ar-4'-OH, Ar-5'-OH); ${ }^{13} \mathrm{C}-\mathrm{NMR}$ (150 MHz, DMSO-d 6 ) $47.3,52.2 \times 2,52.3 \times 2,56.0,110.7,112.5,115.5,118.9,119.7,120.9,121.4,123.3,124.1,129.0,129.4,133.9$, $135.5,135.9,141.1,145.3,150.9,152.3,195.0$; ESI-MS $m / z(\%) 560.71,562.71,564.86\left([\mathrm{M}+\mathrm{H}]^{+}, 45,100\right.$, 55); HR-MS (ESI) calcd for $\mathrm{C}_{25} \mathrm{H}_{24} \mathrm{Br}_{2} \mathrm{~N}_{2} \mathrm{O}_{4}[\mathrm{M}-\mathrm{H}]^{-}:$575.0000, found: 575.0241.

Compound 22b: Yellow solid, fianl yield 14.2\%, m.p. 208.0-209.0 ${ }^{\circ}$ C; FT-IR (ATR) $v\left(\mathrm{~cm}^{-1}\right)$ : 3193, 2770, 2708, 2262, 1649, 1587, 1410, 1280, 1191, 1151, 1010, 796, 638; ${ }^{1} \mathrm{H}-\mathrm{NMR}\left(600 \mathrm{MHz}\right.$, DMSO- $\left.d_{6}\right) \delta: 2.05$ (s, 
$3 \mathrm{H}$, piperazine-CO- $\left.\mathrm{CH}_{3}\right), 3.08-3.50(\mathrm{~m}, 8 \mathrm{H}$, piperazine-2", 3", 5", 6"- $\mathrm{H}),, 4.48\left(\mathrm{~s}, 2 \mathrm{H}, \mathrm{Ar}-2-\mathrm{CH}_{2}-\right), 6.99(\mathrm{~s}$, $\left.1 \mathrm{H}, \mathrm{Ar}-3^{\prime}-\mathrm{H}\right), 7.10\left(\mathrm{~s}, 1 \mathrm{H}, \mathrm{Ar}-6^{\prime}-\mathrm{H}\right), 7.58(\mathrm{~d}, J=3.6 \mathrm{~Hz}, 1 \mathrm{H}, \mathrm{Ar}-6-\mathrm{H}), 7.86(\mathrm{~d}, J=12.6 \mathrm{~Hz}, 1 \mathrm{H}, \mathrm{Ar}-3-\mathrm{H})$, 8.00 (dd, $J=3.0,12.6 \mathrm{~Hz}, 1 \mathrm{H}, \mathrm{Ar}-4-\mathrm{H}), 9.08$ (brs, $\left.1 \mathrm{H}, \mathrm{Ar}-4^{\prime}-\mathrm{OH}\right), 9.62$ (brs, $\left.1 \mathrm{H}, \mathrm{Ar}-5^{\prime}-\mathrm{OH}\right) ;{ }^{13} \mathrm{C}-\mathrm{NMR}$ $\left(150 \mathrm{MHz}\right.$, DMSO-d $\left.d_{6}\right) 21.4,42.9 \times 2,52.0 \times 2,56.9,110.8,119.7,120.9,123.3,129.0,129.3,133.9,135.5$, 135.7, 141.4, 145.3, 151.0, 169.1, 194.9; ESI-MS $m / z$ (\%) 510.72, 512.69, $514.70\left([\mathrm{M}+\mathrm{H}]^{+}, 48,100,52\right)$; HR-MS (ESI) calcd for $\mathrm{C}_{20} \mathrm{H}_{20} \mathrm{Br}_{2} \mathrm{~N}_{2} \mathrm{O}_{4}[\mathrm{M}-\mathrm{H}]^{-}: 510.969$, found: 510.9676 .

Compound 23b: Yellow solid, final yield 8.3\%, m.p. $64.5-66.3^{\circ} \mathrm{C} ;{ }^{1} \mathrm{H}-\mathrm{NMR}\left(600 \mathrm{MHz}\right.$, DMSO- $\left.d_{6}\right) \delta$ : 3.35-3.88 (m, 8H, piperazine-2", 3", 5", 6"--H), 4.49 (s, 2H, Ar-2- $\left.\mathrm{CH}_{2}-\right), 6.96$ (s, 1H, Ar-3'-H), 7.07-8.20 (m, 8H, piperazine- $\left.\mathrm{C}_{6} \mathrm{H}_{4^{-}}, \mathrm{Ar}-6^{\prime}, 3,4,6-\mathrm{H}\right), 9.75$ (brs, $\left.1 \mathrm{H}, \mathrm{Ar}-4^{\prime}-\mathrm{OH}\right), 10.43$ (brs, $\left.1 \mathrm{H}, \mathrm{Ar}-5^{\prime}-\mathrm{OH}\right) ;{ }^{13} \mathrm{C}-\mathrm{NMR}$ $\left(150 \mathrm{MHz}, \mathrm{DMSO}-d_{6}\right) 19.0 \times 2,51.5 \times 2,56.5,110.8 \times 2,112.9 \times 2,113.9,119.8,120.9,123.4,126.2$, 129.0, 129.4, 132.2, 133.9, 135.6, 135.7, 141.5, 145.2, 150.9, 195.0; ESI-MS $m / z$ (\%) 590.19, 591.91, 593.79 $\left([\mathrm{M}+\mathrm{H}]^{+}, 70,100,50\right)$.

Compound 24b: Yellow solid, final yield 16.1\%, m.p. 217.0-218.5 ${ }^{\circ} \mathrm{C}$; FT-IR (ATR) $v\left(\mathrm{~cm}^{-1}\right)$ : 3363, 3010, 2699, 1633, 1585, 1500, 1411, 1365, 1298, 1119, 1031, 798, 639; ${ }^{1} \mathrm{H}-\mathrm{NMR}\left(600 \mathrm{MHz}, \mathrm{DMSO}-d_{6}\right) \delta$ : $2.86\left(\mathrm{~s}, 3 \mathrm{H}\right.$, piperazine-4"- $\left.\mathrm{CH}_{3}\right), 3.64-3.77(\mathrm{~m}, 8 \mathrm{H}$, piperazine-2", 3" , 5", 6"- $\mathrm{H}), 4.60\left(\mathrm{~s}, 2 \mathrm{H}, \mathrm{Ar}-2-\mathrm{CH}_{2}-\right)$, 6.97 (s, 1H, Ar-3'-H), 7.10 (s, 1H, Ar-6'-H), 7.55 (s, 1H, Ar-6-H), 7.91 (d, J = 9.0 Hz,1H, Ar-3-H), 7.98 (d, $J=10.2 \mathrm{~Hz}, 1 \mathrm{H}, \mathrm{Ar}-4-\mathrm{H}), 10.06$ (brs, $\left.2 \mathrm{H}, \mathrm{Ar}-4^{\prime}-\mathrm{OH}, \mathrm{Ar}-5^{\prime}-\mathrm{OH}\right) ;{ }^{13} \mathrm{C}-\mathrm{NMR}$ (150 MHz, DMSO- $d_{6}$ ) 19.0, 42.5, $49.1 \times 2,56.5 \times 2,110.6,119.8,121.1,122.3,128.5,132.5,132.8,134.5,141.7,145.2,150.8$, 158.3, 194.4; ESI-MS $m / z(\%) 482.75,484.62,486.57\left([\mathrm{M}+\mathrm{H}]^{+}, 50,100,40\right)$; HR-MS (ESI) calcd for $\mathrm{C}_{19} \mathrm{H}_{20} \mathrm{Br}_{2} \mathrm{~N}_{2} \mathrm{O}_{3}[\mathrm{M}+\mathrm{H}]^{+}:$484.9894, found: 484.9927 .

Compound 25b: Yellow solid, fianl yield 14.4\%, m.p. 208.0-210.0 ${ }^{\circ}$ C; FT-IR (ATR) $v\left(\mathrm{~cm}^{-1}\right)$ : 3479, 3194, 3006, 2622, 2519, 2260, 1657, 1604, 1406, 1284, 1190, 1013, 798, 639; ${ }^{1} \mathrm{H}-\mathrm{NMR}\left(600 \mathrm{MHz}\right.$, DMSO-d $\left.{ }_{6}\right) \delta: 1.27$ $\left(\mathrm{d}, J=9.6 \mathrm{~Hz}, 6 \mathrm{H}\right.$, piperazine-4"- $\left.\mathrm{CH}_{3}\right), 3.18-3.58\left(\mathrm{~m}, 9 \mathrm{H}\right.$, piperazine- $2^{\prime \prime}, 3^{\prime \prime}, 5^{\prime \prime}, 6^{\prime \prime}-\mathrm{H}$, piperazine-CHMe ${ }_{2}$, 4.17 (s, 2H, Ar-2-CH $\left.2_{2}\right), 6.97$ (s, 1H, Ar-3'-H), 7.10 (s, 1H, Ar-6'-H), 7.56 (s, 1H, Ar-6-H), 7.75 (d, $J=12.0 \mathrm{~Hz}, 1 \mathrm{H}, \mathrm{Ar}-3-\mathrm{H}), 7.91(\mathrm{~d}, J=10.2 \mathrm{~Hz}, 1 \mathrm{H}, \mathrm{Ar}-4-\mathrm{H}), 10.00$ (brs, 2H, Ar-4'-OH, Ar-5'-OH); ${ }^{13} \mathrm{C}-\mathrm{NMR}\left(150 \mathrm{MHz}\right.$, DMSO- $\left.d_{6}\right) 16.7 \times 2,45.9,49.2 \times 2,56.7,57.8 \times 2,110.7,120.0,121.2,122.7,126.0$, 128.4, 130.7, 132.9, 134.7, 141.6, 145.1, 150.9, 194.5; ESI-MS $m / z$ (\%) 510.70, 512.77, $514.75\left([\mathrm{M}+\mathrm{H}]^{+}, 55\right.$, 100, 57); HR-MS (ESI) calcd for $\mathrm{C}_{21} \mathrm{H}_{24} \mathrm{Br}_{2} \mathrm{~N}_{2} \mathrm{O}_{3}[\mathrm{M}+\mathrm{H}]^{+}:$513.0210, found: 513.0218.

Compound 26b: White solid, final yield 13.9\%, m.p. 160.0-162.0 ${ }^{\circ} \mathrm{C}$; FT-IR (ATR) $v\left(\mathrm{~cm}^{-1}\right)$ : 3194, 2798, 2524, 2361, 1652, 1588, 1412, 1292, 1192, 1015, 883, 639; ${ }_{1} \mathrm{H}-\mathrm{NMR}\left(600 \mathrm{MHz}\right.$, DMSO- $\left.d_{6}\right) \delta:$ 3.12-3.44 (m, 9H, piperazine-2", 3", 5", 6"- $\left.-\mathrm{H}, \mathrm{Ph}_{2} \mathrm{CH}-\right), 4.39$ (s, 2H, Ar-2- $\left.\mathrm{CH}_{2}-\right), 6.95$ (s, 1H, Ar-3'-H), 7.09 (s, 1H, Ar-6'-H), 7.33-7.74 (m, 12H, Ar-H, Ar-4"'--H), 7.92 (d, J = 10.2 Hz, 1H, Ar-4-H), 9.00 (brs, 2H, Ar-4'-OH, Ar-5'-OH); ${ }^{13}$ C-NMR (150 MHz, DMSO- $\left.d_{6}\right) 40.5 \times 2,48.9 \times 2,56.5,73.6,110.6,112.8,119.6,120.9 \times 2$, $126.7,127.2,128.5 \times 4,128.9,129.6 \times 4,130.0,133.2,133.7,135.2 \times 2,141.3,145.2,150.8,194.8$; ESI-MS $m / z(\%) 634.80,636.74,638.50\left([\mathrm{M}+\mathrm{H}]^{+}, 55,100,45\right)$; HR-MS (ESI) calcd for $\mathrm{C}_{31} \mathrm{H}_{28} \mathrm{Br}_{2} \mathrm{~N}_{2} \mathrm{O}_{3}[\mathrm{M}-\mathrm{H}]^{-}$: 635.0370, found: 635.0389 .

Compound 27b: Yellow solid, final yield 15.1\%, m.p. 56.0-58.0 ${ }^{\circ} \mathrm{C} ;{ }^{1} \mathrm{H}-\mathrm{NMR}\left(600 \mathrm{MHz}, \mathrm{DMSO}-d_{6}\right) \delta$ : 2.22-2.31 (m, 10H, piperazine-2", $\left.3^{\prime \prime}, 5^{\prime \prime}, 6^{\prime \prime}-\mathrm{H}, \mathrm{Ar}-2-\mathrm{CH}_{2}-\right), 3.31\left(\mathrm{t}, J=10.8 \mathrm{~Hz}, 2 \mathrm{H}\right.$, piperazine-4" $\left.-\mathrm{CH}_{2}-\right)$, $3.45\left(\mathrm{t}, J=10.2 \mathrm{~Hz}, 2 \mathrm{H}, \mathrm{HO}-\mathrm{CH}_{2}-\right), 6.92\left(\mathrm{~s}, 1 \mathrm{H}, \mathrm{Ar}-3^{\prime}-\mathrm{H}\right), 7.04\left(\mathrm{~s}, 1 \mathrm{H}, \mathrm{Ar}-6^{\prime}-\mathrm{H}\right), 7.37(\mathrm{~d}, J=12.0 \mathrm{~Hz}, 1 \mathrm{H}$, Ar-3-H), 7.41 (d, $J=1.8 \mathrm{~Hz}, 1 \mathrm{H}, \mathrm{Ar}-6-\mathrm{H}), 7.66$ (d, $J=12.6 \mathrm{~Hz}, 1 \mathrm{H}, \mathrm{Ar}-4-\mathrm{H}), 9.83$ (brs, 2H, Ar-4'-OH, Ar $\left.-5^{\prime}-\mathrm{OH}\right) ;{ }^{13} \mathrm{C}-\mathrm{NMR}\left(150 \mathrm{MHz}\right.$, DMSO- $\left.d_{6}\right) 52.9 \times 2,53.2 \times 2,58.8,59.5,60.6,110.6,111.6,113.9$, $120.3,127.9,131.7,132.2,133.2,137.7,142.5,150.7,155.9,194.5$; ESI-MS $m / z(\%) 512.92,514.96,516.81$ $\left([\mathrm{M}+\mathrm{H}]^{+}, 60,100,70\right)$.

Compound 28b: Yellow solid, final yield $18.6 \%$, m.p. $114.0-115.0{ }^{\circ} \mathrm{C} ;{ }^{1} \mathrm{H}-\mathrm{NMR}\left(600 \mathrm{MHz}, \mathrm{DMSO}-d_{6}\right) \delta$ : 3.28-3.57 (m, 6H, piperazine- $\mathrm{H}), 4.49\left(\mathrm{~s}, 2 \mathrm{H}, \mathrm{Ar}-2-\mathrm{CH}_{2}-\right), 4.72(\mathrm{~d}, J=14.4 \mathrm{~Hz}, 2 \mathrm{H}$, piperazine-H), $6.80(\mathrm{t}$, $J=7.2 \mathrm{~Hz}, 1 \mathrm{H}$, pyrimidine-5''-H), $7.00\left(\mathrm{~s}, 1 \mathrm{H}, \mathrm{Ar}-3^{\prime}-\mathrm{H}\right), 7.10\left(\mathrm{~s}, 1 \mathrm{H}, \mathrm{Ar}-6^{\prime}-\mathrm{H}\right), 7.58(\mathrm{~d}, J=2.4 \mathrm{~Hz}, 1 \mathrm{H}$, Ar-6-H), $7.91(\mathrm{~d}, 1 \mathrm{H}, J=12.6 \mathrm{~Hz}, \mathrm{Ar}-3-\mathrm{H}), 8.01(\mathrm{dd}, J=12.6 \mathrm{~Hz}, 1 \mathrm{H}, \mathrm{Ar}-4-\mathrm{H}), 8.47$ (d, J = 7.2 Hz, 2H, pyrimidine-4"', 6 "''-H), 9.70 (brs, 2H, Ar-4'-OH, Ar-5'-OH); ${ }^{13}$ C-NMR (150 MHz, DMSO-d 6 ) $40.8 \times 2$, 
$51.5 \times 2,57.0,110.7,111.8,119.7,120.9,123.3,129.0,129.4,133.8,135.5,135.7,141.5,145.3,150.9,158.6$ $\times 2,160.8,194.9$; ESI-MS $m / z(\%) 546.72,548.73,550.59\left([\mathrm{M}+\mathrm{H}]^{+}, 48,100,60\right)$.

Compound 29b: White solid, final yield 21.1\%, m.p. 193.0-195.0 ${ }^{\circ} \mathrm{C} ;{ }^{1} \mathrm{H}-\mathrm{NMR}\left(600 \mathrm{MHz}, \mathrm{DMSO}-d_{6}\right)$ $\delta: 3.08-3.77\left(\mathrm{~m}, 8 \mathrm{H}\right.$, piperazine-2", 3", 5",6"-H), 4.50 (s, 2H, Ar-2- $\left.\mathrm{CH}_{2}-\right), 6.97$ (s, 1H, Ar-3'-H), 7.03 $\left(\mathrm{dd}, J=6.6,13.8 \mathrm{~Hz}, 2 \mathrm{H}\right.$, piperazine-Ar-2"', $\left.66^{\prime \prime \prime}-\mathrm{H}\right), 7.09\left(\mathrm{~s}, 1 \mathrm{H}, \mathrm{Ar}-6^{\prime}-\mathrm{H}\right), 7.12(\mathrm{~d}, J=13.2 \mathrm{~Hz}, 2 \mathrm{H}$, piperazine-Ar-3"', 5 "''-H), $7.60(\mathrm{~d}, 1 \mathrm{H}, J=2.4 \mathrm{~Hz}, \mathrm{Ar}-6-\mathrm{H}), 7.83(\mathrm{~d}, J=12.6 \mathrm{~Hz}, 1 \mathrm{H}, \mathrm{Ar}-3-\mathrm{H}), 8.01$ (dd, $J=3.0,12.6 \mathrm{~Hz}, 1 \mathrm{H}, \mathrm{Ar}-4-\mathrm{H}), 9.39$ (brs, $\left.2 \mathrm{H}, \mathrm{Ar}-4^{\prime}-\mathrm{OH}, \mathrm{Ar}-5^{\prime}-\mathrm{OH}\right) ;{ }^{13} \mathrm{C}-\mathrm{NMR}$ (150 MHz, DMSO- $\left.d_{6}\right) 46.5$ $\times 2,51.7 \times 2,56.7,110.7,116.1 \times 2,118.4,119.7,120.9,123.3,129.0,129.4,133.9,135.5 \times 2,141.5,145.3$, 146.7, 151.0, 156.3, 157.9, 194.9; ESI-MS $m / z$ (\%) 562.96, 564.95, $566.77\left([\mathrm{M}+\mathrm{H}]^{+}, 48,100,60\right)$.

Compound 30b: Yellow solid, final yield 19.4\%, m.p. $190.0-191.5{ }^{\circ} \mathrm{C} ;{ }^{1} \mathrm{H}-\mathrm{NMR}\left(600 \mathrm{MHz}, \mathrm{DMSO}-d_{6}\right) \delta$ : 3.14-3.57 (m, 8H, piperazine-2",3", 5" 6",-H), 4.52 (s, 2H, Ar-2- $\left.\mathrm{CH}_{2}-\right), 6.97$ (s, 1H, Ar-3'-H), 7.05-7.22 (m, 5H, Ar-6'-H, piperazine-H), $7.60(\mathrm{~s}, 1 \mathrm{H}, \mathrm{Ar}-6-\mathrm{H}), 7.80(\mathrm{dd}, J=6.6,12.6 \mathrm{~Hz}, 1 \mathrm{H}, \mathrm{Ar}-3-\mathrm{H}), 8.01$ (d, $J=12.6 \mathrm{~Hz}, 1 \mathrm{H}, \mathrm{Ar}-4-\mathrm{H}), 9.35$ (brs, $\left.2 \mathrm{H}, \mathrm{Ar}-4{ }^{\prime}-\mathrm{OH}, \mathrm{Ar}-5^{\prime}-\mathrm{OH}\right) ;{ }^{13} \mathrm{C}-\mathrm{NMR}\left(150 \mathrm{MHz}, \mathrm{DMSO}-d_{6}\right) 47.4 \times 2$, $52.0 \times 2,57.0,110.7,116.7,119.7,120.2,120.9,123.3,124.0,125.5,129.1,129.4,134.0,135.8,138.7,141.4$, 145.3, 151.0, 154.5, 156.2, 195.0; ESI-MS $m / z$ (\%) 562.97, 564.95, $566.79\left([\mathrm{M}+\mathrm{H}]^{+}, 60,100,75\right)$.

Compound 31b: White solid, final yield 17.5\%, m.p. 185.0-186.0 ${ }^{\circ} \mathrm{C} ;{ }^{1} \mathrm{H}-\mathrm{NMR}\left(600 \mathrm{MHz}, \mathrm{DMSO}-d_{6}\right)$ $\delta: 3.04-3.56\left(\mathrm{~m}, 8 \mathrm{H}\right.$, piperazine-2", 3", 5", $\left.6^{\prime \prime}-\mathrm{H}\right), 4.49\left(\mathrm{~s}, 2 \mathrm{H}, \mathrm{Ar}-2-\mathrm{CH}_{2}-\right), 6.72(\mathrm{~d}, 2 \mathrm{H}, J=12.0 \mathrm{~Hz}, 2 \mathrm{H}$, piperazine-Ar-2"', 6"'-H), $6.88(\mathrm{~d}, J=12.0 \mathrm{~Hz}, 2 \mathrm{H}$, piperazine-Ar-3"',5"'-H), $6.97(\mathrm{~s}, 1 \mathrm{H}, \mathrm{Ar}-3$ '-H), 7.09 (s, 1H, Ar-6'-H), 7.59 (s, 1H, Ar-6-H), 7.80 (s, J = 12.0 Hz, 1H, Ar-3-H), 7.99 (d, J = 12.0 Hz, 1H, Ar-4-H), 9.32 (brs, 3H, Ar-4'-OH, Ar-5'-OH, Ar-4"'-OH); ${ }^{13} \mathrm{C}-\mathrm{NMR}\left(150 \mathrm{MHz}, \mathrm{DMSO}-d_{6}\right) 40.5 \times 2,48.9 \times 2,56.5$, $110.7,116.1 \times 2,119.9,120.9,124.4,125.4,126.1,136.7,137.1,138.0,141.5,145.3,150.2 \times 2,150.9,152.3$, 153.4, 184.5; ESI-MS $m / z$ (\%) 560.98, 562.97, $564.81\left([\mathrm{M}+\mathrm{H}]^{+}, 45,100,60\right)$.

Compound 32b: Yellow solid, final yield 20.5\%, m.p. 205.8-207.3 ${ }^{\circ} \mathrm{C} ;{ }^{1} \mathrm{H}-\mathrm{NMR}\left(600 \mathrm{MHz}\right.$, DMSO- $d_{6}$ ) $\delta: 5.58$ (s, 2H, Ar-2- $\left.\mathrm{CH}_{2}-\right), 6.93$ (s, 1H, Ar-3'-H), 7.06 (s, 1H, Ar-6'-H), 7.45 (d, J = 7.8 Hz, 1H, Ar-3-H), $7.52(\mathrm{~s}, 1 \mathrm{H}, \mathrm{Ar}-6-\mathrm{H}), 7.71(\mathrm{t}, J=11.4 \mathrm{~Hz}, 2 \mathrm{H}$, imidazole-4", 5"--H), $7.88(\mathrm{~d}, J=7.8 \mathrm{~Hz}, 1 \mathrm{H}, \mathrm{Ar}-4-\mathrm{H})$, $9.14\left(\mathrm{t}, J=11.4 \mathrm{~Hz}, 1 \mathrm{H}\right.$, imidazole-2"'-H), 9.70 (brs, $\left.1 \mathrm{H}, \mathrm{Ar}-4^{\prime}-\mathrm{OH}\right), 10.39$ (brs, $\left.1 \mathrm{H}, \mathrm{Ar}-5^{\prime}-\mathrm{OH}\right) ;{ }^{13} \mathrm{C}-\mathrm{NMR}$ $\left(150 \mathrm{MHz}\right.$, DMSO- $\left.d_{6}\right) 49.7,110.5,119.4,119.9,120.6,120.8,122.3,122.8,129.0,133.2,133.5,135.6,136.5$, 140.0, 145.2, 150.8, 194.7; ESI-MS $m / z(\%) 451.00,453.06,454.88\left([\mathrm{M}+\mathrm{H}]^{+}, 70,100,80\right)$.

Compound 33b: White solid, final yield 21.1\%, m.p. $217.0-218.5{ }^{\circ} \mathrm{C} ;{ }^{1} \mathrm{H}-\mathrm{NMR}\left(600 \mathrm{MHz}, \mathrm{DMSO}-d_{6}\right) \delta$ : 2.53 (s, 3H, imidazole-2"'- $\left.\mathrm{CH}_{3}\right), 5.53\left(\mathrm{~s}, 2 \mathrm{H}, \mathrm{Ar}-2-\mathrm{CH}_{2}-\right), 6.95$ (s, 1H, Ar-3'-H), 7.08 (s, 1H, Ar-6'-H), 7.19 $(\mathrm{d}, J=12.6 \mathrm{~Hz}, 1 \mathrm{H}, \mathrm{Ar}-3-\mathrm{H}), 7.50(\mathrm{~d}, J=3.0 \mathrm{~Hz}, 1 \mathrm{H}, \mathrm{Ar}-6-\mathrm{H}), 7.53(\mathrm{~d}, J=3.0 \mathrm{~Hz}, 1 \mathrm{H}$, imidazole-5"-H), $7.62(\mathrm{~d}, J=3.0 \mathrm{~Hz}, 1 \mathrm{H}$, imidazole-4"'-H), 7.85 (dd, J = 3.0, 12.6 Hz, 1H, Ar-4-H), 9.75 (brs, 1H, Ar-4'-OH), 10.39 (brs, $\left.1 \mathrm{H}, \mathrm{Ar}-5{ }^{\prime}-\mathrm{OH}\right) ;{ }^{13} \mathrm{C}-\mathrm{NMR}$ (150 MHz, DMSO-d $\left.d_{6}\right)$ 11.1, 48.4, 110.5, 118.8, 119.5, 120.9, 121.9, 123.0, 128.8, 131.9, 132.0, 133.5, 133.7, 135.5, 139.4, 145.3, 150.9, 194.6; ESI-MS $m / z$ (\%) 464.69, 466.67, $468.57\left([\mathrm{M}+\mathrm{H}]^{+}, 50,100,60\right)$.

Compound 34b: White solid, final yield 17.3\%, m.p. 170.0-172.0 ${ }^{\circ} \mathrm{C} ;{ }^{1} \mathrm{H}-\mathrm{NMR}\left(600 \mathrm{MHz}, \mathrm{DMSO}-d_{6}\right)$ $\delta: 2.20\left(\mathrm{~s}, 3 \mathrm{H}\right.$, imidazole-4" $\left.-\mathrm{CH}_{3}\right), 5.45\left(\mathrm{~s}, 2 \mathrm{H}, \mathrm{Ar}-2-\mathrm{CH}_{2}-\right), 6.90(\mathrm{~s}, 1 \mathrm{H}$, imidazole-5"-H), $7.05(\mathrm{~s}, 1 \mathrm{H}$, Ar-3'-H), $7.27\left(\mathrm{~s}, 1 \mathrm{H}, \mathrm{Ar}-6^{\prime}-\mathrm{H}\right), 7.37(\mathrm{~d}, J=12.0 \mathrm{~Hz}, 1 \mathrm{H}, \mathrm{Ar}-3-\mathrm{H}), 7.50(\mathrm{~d}, J=3.0 \mathrm{~Hz}, 1 \mathrm{H}, \mathrm{Ar}-6-\mathrm{H}), 7.87$ $(\mathrm{dd}, J=3.0,12.0 \mathrm{~Hz}, 1 \mathrm{H}, \mathrm{Ar}-4-\mathrm{H}), 8.76$ (s, 1H, imidazole-2"'-H), 9.72 (brs, $\left.1 \mathrm{H}, \mathrm{Ar}-4^{\prime}-\mathrm{OH}\right), 10.42 \mathrm{br}(\mathrm{s}, 1 \mathrm{H}$, Ar-5'-OH); ${ }^{13}$ C-NMR (150 MHz, DMSO- $\left.d_{6}\right)$ 10.6, 49.3, 110.5, 118.9, 119.5, 120.9, 122.1, 128.9, 131.3, 133.0, 133.2, 134.2, 135.4, 135.9, 140.0, 145.2, 150.9, 194.7; ESI-MS $m / z$ (\%) 464.86, 466.88, $498.75\left([\mathrm{M}+\mathrm{H}]^{+}, 54\right.$, $100,65)$.

Compound 35b: White solid, final yield 20.5\%, m.p. 235.2-236.9 ${ }^{\circ} \mathrm{C}$; FT-IR (ATR) $v\left(\mathrm{~cm}^{-1}\right.$ ): 3184, $3159,2789,2673,2260,1667,1598,1500,1383,1194,1012,882,801,640 ;{ }^{1}$ H-NMR (600 MHz, DMSO- $d_{6}$ ) $\delta: 1.20\left(\mathrm{t}, J=11.4 \mathrm{~Hz}, 3 \mathrm{H}\right.$, imidazole-2"- $\left.\mathrm{CH}_{3}\right), 2.90\left(\mathrm{q}, J=11.4 \mathrm{~Hz}, 2 \mathrm{H}\right.$, imidazole-2" $\left.-\mathrm{CH}_{2}-\right), 5.56(\mathrm{~s}$, $\left.2 \mathrm{H}, \mathrm{Ar}-2-\mathrm{CH}_{2}-\right), 6.94\left(\mathrm{~s}, 1 \mathrm{H}, \mathrm{Ar}-3^{\prime}-\mathrm{H}\right), 7.07$ (s, 1H, Ar-6'-H), $7.16(\mathrm{~d}, J=6.0 \mathrm{~Hz}, 1 \mathrm{H}, \mathrm{Ar}-6-\mathrm{H}), 7.52$ $(\mathrm{d}, J=3.0 \mathrm{~Hz}, 1 \mathrm{H}$, imidazole-5"- $\mathrm{H}), 7.54\left(\mathrm{~d}, J=3.6 \mathrm{~Hz}, 1 \mathrm{H}\right.$, imidazole-4" $\left.{ }^{\prime \prime}-\mathrm{H}\right), 7.66(\mathrm{~d}, J=3.0 \mathrm{~Hz}, 1 \mathrm{H}$, 
Ar-3-H), 7.84 (dd, J = 3.0, $12.6 \mathrm{~Hz}, 1 \mathrm{H}, \mathrm{Ar}-4-\mathrm{H}), 9.72$ (brs, 1H, Ar-4'-OH), 10.35 (brs, 1H, Ar-5'-OH); ${ }^{13} \mathrm{C}-\mathrm{NMR}\left(150 \mathrm{MHz}, \mathrm{DMSO}-d_{6}\right) 11.2,18.5,48.4,110.5,119.0,119.5,120.9,121.9,123.1,128.8,131.7,133.6$, 133.9, 135.5, 139.3, 145.3, 149.2, 150.9, 194.5; ESI-MS $m / z$ (\%) 478.78, 480.63, $482.73\left([\mathrm{M}+\mathrm{H}]^{+}, 48,100\right.$, 45); HR-MS (ESI) calcd for $\mathrm{C}_{19} \mathrm{H}_{16} \mathrm{Br}_{2} \mathrm{~N}_{2} \mathrm{O}_{3}[\mathrm{M}-\mathrm{H}]^{-}$: 478.9420, found: 478.9469 .

Compound 36b: Yellow solid, final yield 17.8\%, m.p. 140.0-141.5 ${ }^{\circ} \mathrm{C}$; FT-IR (ATR) $v\left(\mathrm{~cm}^{-1}\right)$ : 3327, 3149, $3115,3028,2975,1673,1590,1415,1283,1201,1008,786,635 ;{ }^{1} \mathrm{H}-\mathrm{NMR}(600 \mathrm{MHz}$, DMSO-d 6 ) $\delta: 1.24$ (d, $J=10.2 \mathrm{~Hz}, 6 \mathrm{H}$, imidazole-2"- $\left.\mathrm{CH}_{3}\right), 3.36(\mathrm{~m}, 1 \mathrm{H}$, imidazole-2"-CHMe 2$), 5.61\left(\mathrm{~s}, 2 \mathrm{H}, \mathrm{Ar}-2-\mathrm{CH}_{2}-\right), 6.94(\mathrm{~s}$, $\left.1 \mathrm{H}, \mathrm{Ar}-3^{\prime}-\mathrm{H}\right), 7.07$ (d, J = 12.6 Hz, 1H, Ar-3-H), 7.10 (s, 1H, Ar-6'-H), 7.53 (s, 1H, imidazole-5"'-H), 7.55 (s, 1H, imidazole-4"-H), 7.72 (s, 1H, Ar-6-H), 7.85 (d, J = 12.6 Hz, 1H, Ar-4-H), 9.75 (brs, 1H, Ar-4'-OH), 10.42 (brs, $\left.1 \mathrm{H}, \mathrm{Ar}-5^{\prime}-\mathrm{OH}\right) ;{ }^{13} \mathrm{C}-\mathrm{NMR}\left(150 \mathrm{MHz}\right.$, DMSO- $\left.d_{6}\right) 20.8 \times 2,25.2,48.5,110.5,119.3,119.5,120.9$, 121.9, 122.9, 128.8, 131.5, 133.6, 134.1, 135.6, 139.2, 145.3, 150.9, 152.3, 194.5; ESI-MS $m / z(\%)$ 492.72, 494.71, $496.60\left([\mathrm{M}+\mathrm{H}]^{+}, 48,100,58\right)$; HR-MS (ESI) calcd for $\mathrm{C}_{20} \mathrm{H}_{18} \mathrm{Br}_{2} \mathrm{~N}_{2} \mathrm{O}_{3}[\mathrm{M}-\mathrm{H}]^{-}: 492.9580$, found: 492.9537.

Compound 37b: White solid, final yield 18.3\%, m.p. 283.0-285.0 ${ }^{\circ}$ C; FT-IR (ATR) $v\left(\mathrm{~cm}^{-1}\right)$ : 3074, 2985, $2887,2780,1664,1586,1504,1408,1279,1229,1151,1013,813,623 ;{ }^{1} \mathrm{H}-\mathrm{NMR}\left(600 \mathrm{MHz}\right.$, DMSO- $\left.d_{6}\right) \delta$ : $1.19\left(\mathrm{t}, J=11.4 \mathrm{~Hz}, 3 \mathrm{H}\right.$, imidazole-2"'- $\left.\mathrm{CH}_{3}\right), 2.20\left(\mathrm{~s}, 3 \mathrm{H}\right.$, imidazole-4"'- $\left.\mathrm{CH}_{3}\right), 2.86(\mathrm{q}, J=1.4 \mathrm{~Hz}, 2 \mathrm{H}$, imidazole-2"- $\mathrm{CH}_{2}-$ ), 5.46 (s, 2H, Ar-2- $\left.\mathrm{CH}_{2}-\right), 6.90$ (s, 1H, Ar-3'-H), 7.06 (s, 1H, Ar-6'-H), 7.16 (s, 1H, imidazole-5"-H), $7.20(\mathrm{~d}, J=12.6 \mathrm{~Hz}, 1 \mathrm{H}, \mathrm{Ar}-3-\mathrm{H}), 7.54(\mathrm{~d}, J=3.0 \mathrm{~Hz}, 1 \mathrm{H}, \mathrm{Ar}-6-\mathrm{H}), 7.84(\mathrm{dd}, J=3.0,12.6$ $\mathrm{Hz}, 1 \mathrm{H}, \mathrm{Ar}-4-\mathrm{H}), 9.73$ (brs, 1H, Ar-4'-OH), 10.43 (brs, 1H, Ar-5'-OH); ${ }^{13} \mathrm{C}-\mathrm{NMR}$ (150 MHz, DMSO- $d_{6}$ ) 10.0, 11.2, 18.4, 48.1, 110.6, 119.3, 119.7, 121.0, 122.0, 128.5, 128.6, 132.0, 133.3, 133.9, 135.4, 139.6, 145.2, 148.2, 150.9, 194.4; ESI-MS $m / z$ (\%) 491.13, 493.12, 495.14 ([M - H] $\left.{ }^{-}, 48,100,45\right)$; HR-MS (ESI) calcd for $\mathrm{C}_{20} \mathrm{H}_{18} \mathrm{Br}_{2} \mathrm{~N}_{2} \mathrm{O}_{3}[\mathrm{M}-\mathrm{H}]^{-}$: 492.9580, found: 492.9518 .

Compound 38b: White solid, final yield 15.7\%, m.p. 210.3-212.0 ${ }^{\circ} \mathrm{C}$; FT-IR (ATR) $v\left(\mathrm{~cm}^{-1}\right)$ : 3415, 3336, 3144, 2927, 2791, 2681, 1654, 1587, 1496, 1416, 1284, 1153, 1012, 700, 635; ${ }^{1} \mathrm{H}-\mathrm{NMR}(600 \mathrm{MHz}$, DMSO- $\left.d_{6}\right) \delta: 5.57\left(\mathrm{~s}, 2 \mathrm{H}, \mathrm{Ar}-2-\mathrm{CH}_{2}-\right), 6.83\left(\mathrm{~s}, 1 \mathrm{H}, \mathrm{Ar}-3^{\prime}-\mathrm{H}\right), 7.01\left(\mathrm{~s}, 1 \mathrm{H}, \mathrm{Ar}-6^{\prime}-\mathrm{H}\right), 7.10(\mathrm{~d}, J=12.6 \mathrm{~Hz}$, $1 \mathrm{H}, \mathrm{Ar}-3-\mathrm{H}), 7.49(\mathrm{~d}, J=3.0 \mathrm{~Hz}, 1 \mathrm{H}, \mathrm{Ar}-6-\mathrm{H}), 7.59-7.65(\mathrm{~m}, 5 \mathrm{H}$, imidazole-Ar-H), $7.76(\mathrm{~d}, J=3.0 \mathrm{~Hz}$, $1 \mathrm{H}$, imidazole-5"-H), $7.79(\mathrm{dd}, J=3.0,12.6 \mathrm{~Hz}, 1 \mathrm{H}, \mathrm{Ar}-4-\mathrm{H}), 7.89(\mathrm{~d}, J=3.0 \mathrm{~Hz}, 1 \mathrm{H}$, imidazole-4"-H), 9.70 (brs, $\left.1 \mathrm{H}, \mathrm{Ar}-4^{\prime}-\mathrm{OH}\right), 10.39$ (brs, $\left.1 \mathrm{H}, \mathrm{Ar}-5^{\prime}-\mathrm{OH}\right) ;{ }^{13} \mathrm{C}-\mathrm{NMR}\left(150 \mathrm{MHz}, \mathrm{DMSO}-d_{6}\right)$ 49.5, 110.4, 119.3, 120.6, 120.8, 121.9, 123.1, 124.3, 128.8, $129.8 \times 2,130.0 \times 2,131.4,132.6,133.6,134.1,135.5,139.0,145.2$, 145.3, 150.8, 194.4; ESI-MS $m / z$ (\%) 525.13, 527.13, $529.13\left(\left[\mathrm{M}-\mathrm{H}^{-}{ }^{-}, 50,100,48\right)\right.$; HR-MS (ESI) calcd for $\mathrm{C}_{23} \mathrm{H}_{16} \mathrm{Br}_{2} \mathrm{~N}_{2} \mathrm{O}_{3}[\mathrm{M}-\mathrm{H}]^{-}$: 526.9403, found: 526.9444 .

Compound 39b: Yellow solid, final yield 19.1\%, m.p. 190.0-192.0 ${ }^{\circ} \mathrm{C} ;{ }^{1} \mathrm{H}-\mathrm{NMR}\left(600 \mathrm{MHz}, \mathrm{DMSO}-d_{6}\right)$ $\delta: 2.18\left(\mathrm{~s}, 3 \mathrm{H}\right.$, imidazole-4" $\left.-\mathrm{CH}_{3}\right), 2.49\left(\mathrm{~s}, 3 \mathrm{H}\right.$, imidazole-2" $\left.-\mathrm{CH}_{3}\right), 5.43\left(\mathrm{~s}, 2 \mathrm{H}, \mathrm{Ar}-2-\mathrm{CH}_{2}-\right), 6.90(\mathrm{~s}, 1 \mathrm{H}$, imidazole-5"'-H), 7.06 (s, 1H, Ar-3'-H), 7.14 (d, J = $13.2 \mathrm{~Hz}, 1 \mathrm{H}, \mathrm{Ar}-3-\mathrm{H}), 7.22\left(\mathrm{~s}, 1 \mathrm{H}, \mathrm{Ar}-6^{\prime}-\mathrm{H}\right), 7.54$ (d, $J=3.0 \mathrm{~Hz}, 1 \mathrm{H}, \mathrm{Ar}-6-\mathrm{H}), 7.85$ (dd, $J=3.0,12.6 \mathrm{~Hz}, 1 \mathrm{H}, \mathrm{Ar}-4-\mathrm{H}), 9.72$ (brs, $\left.1 \mathrm{H}, \mathrm{Ar}-4^{\prime}-\mathrm{OH}\right), 10.41$ (brs, $\left.1 \mathrm{H}, \mathrm{Ar}-5^{\prime}-\mathrm{OH}\right) ;{ }^{13} \mathrm{C}-\mathrm{NMR}\left(150 \mathrm{MHz}, \mathrm{DMSO}-d_{6}\right) 9.9,11.0,48.2,110.6,119.3,119.7,121.0,122.0,128.2$, 128.5, 132.2, 133.3, 133.7, 135.3, 139.7, 144.1, 145.2, 150.9, 194.5; ESI-MS $m / z$ (\%) 478.92, 480.90, 482.75 $\left([\mathrm{M}+\mathrm{H}]^{+}, 50,100,60\right)$.

Compound 40b: White solid, final yield $23 \%$, m.p. $162.0-163.0{ }^{\circ} \mathrm{C} ;{ }^{1} \mathrm{H}-\mathrm{NMR}\left(600 \mathrm{MHz}, \mathrm{DMSO}-d_{6}\right) \delta$ : $5.88\left(\mathrm{~s}, 2 \mathrm{H}, \mathrm{Ar}-2-\mathrm{CH}_{2}-\right), 6.93\left(\mathrm{~s}, 1 \mathrm{H}, \mathrm{Ar}-3^{\prime}-\mathrm{H}\right), 7.03\left(\mathrm{~s}, 1 \mathrm{H}, \mathrm{Ar}-6^{\prime}-\mathrm{H}\right), 7.32(\mathrm{~d}, J=12.6 \mathrm{~Hz}, 1 \mathrm{H}, \mathrm{Ar}-3-\mathrm{H}), 7.55$ (s, 1H, Ar-6-H), 7.59 (t, $J=10.8 \mathrm{~Hz}, 2 \mathrm{H}$, imidazole-Ar-H), $7.72(\mathrm{~d}, J=10.8 \mathrm{~Hz}, 1 \mathrm{H}$, imidazole-Ar-H), 7.81 (dd, $J=3.0,12.6 \mathrm{~Hz}, 1 \mathrm{H}$, Ar-4-H), $7.87(\mathrm{~d}, J=10.8 \mathrm{~Hz}, 1 \mathrm{H}$, imidazole-Ar-H), 9.47 (s, 1H, imidazole-2'-H), 9.72 (brs, $\left.1 \mathrm{H}, \mathrm{Ar}-4^{\prime}-\mathrm{OH}\right), 10.38$ (s, $\left.1 \mathrm{H}, \mathrm{Ar}-5^{\prime}-\mathrm{OH}\right) ;{ }^{13} \mathrm{C}-\mathrm{NMR}$ (150 MHz, DMSO-d $\left.d_{6}\right) 48.1,110.4,113.8$, $115.8,119.5,120.8,122.1,126.5,126.8,128.8,131.6,132.3,132.4,133.4,133.6,135.5,139.6,143.2,145.3$, 150.9, 194.7; ESI-MS $m / z(\%)$ 500.88, 502.89, $504.73\left([\mathrm{M}+\mathrm{H}]^{+}, 50,100,60\right)$. 


\subsection{Biological Assay}

EA.hy926 cells were purchased from the Cell Bank of the Chinese Academy of Sciences (Shanghai, China) and maintained in high-glucose DMEM supplemented with 10\% fetal bovineserum (FBS; Hyclone, Beijing, China), L-glutamine ( $2 \mathrm{mM}), 100$ units $/ \mathrm{mL}$ of penicillin, and $100 \mu \mathrm{g} / \mathrm{mL}$ streptomycin. Cells were incubated in a humidified incubator aerated with $5 \% \mathrm{CO}_{2}$ at $37^{\circ} \mathrm{C}$. For all experiments, EA. hy926 cells were cultured in a 96-well plate at a density of $1 \times 10^{4} / \mathrm{mL}$, grown to $70-80 \%$ confluence, pretreated with designated concentrations $0.3125,0.625,1.25,2.5,5$ and $10 \mu \mathrm{M}$ of compounds for $4 \mathrm{~h}$, and then exposed to $200 \mu \mathrm{M} \mathrm{H}_{2} \mathrm{O}_{2}$ (BHKT Clinical Reagent, Beijing, China) for another $6 \mathrm{~h}$ in fresh medium. $\mathrm{No}_{2} \mathrm{O}_{2}$-treated cells were used as controls and were incubated under the same conditions. Cell viability was determined by mitochondrial function using MTT (Sigma Aldrich, St. Louis, MO, USA) testing. The absorbance was detected at $490 \mathrm{~nm}[11,28]$.

\subsection{Molecular Docking}

Docking technology is applied to the drug discovery process for predicting the binding mode of a known active ligand. The three-dimensional structures of the compounds were drawn and all molecular modeling calculations were performed in Sybyl 2.0 software (Tripos Associates, St. Louis, MO, USA). All molecule charges were calculated by the Gasteiger-Huckel method. The energy minimization and conformational search were performed using the Tripos force field by Powell method. The X-ray crystal structure of Keap1 protein with ligand IQK701 (PDB code: 4iqk) was retrieved from the RCSB Protein Data Bank [29]. The protein was prepared for docking simulation by extracting original ligand IQK701, deleting all water molecules, adding hydrogen atoms, selecting minimized biopolymer hydrogens, minimizing sidechains, minimizing biopolymer hydrogens without C-Alpha in the Stage Minimization module, and assigning AMBER charge and AMBER7 FF99 force field. Surflex docking module was used. A small molecule ligand was docked in the active site of the binding pocket.

\section{Conclusions}

In summary, a series of novel bromophenols with nitrogen-containing heterocycles piperidine, piperazine, and imidazole were prepared and evaluated for their cytoprotective activity against $\mathrm{H}_{2} \mathrm{O}_{2}$ induced injury in EA.hy926 cells. Most compounds showed moderate-to-potent activity with $\mathrm{EC}_{50}$ values in the range of 0.9-7.4 $\mu \mathrm{M}$. Moreover, the target compound $\mathbf{2 2} \mathbf{b}$, a piperazine bromophenol, may be the most promising pharmacological candidate for further cardiovascular drug development owing to its strong cytoprotective ability. Combining with our former studies, the targeting Keap1-Nrf2 protein-protein interaction may be an emerging strategy for this series of halophenols to selectively and effectively activate Nrf2 triggering downstream protective genes that defend against injury.

Acknowledgments: This work was financially supported by the State "863" Projects of China (No. 2013AA092903), the National Natural Science Foundation of China (No. 81473100), National Science and Technology Major Project of China (No. 2017ZX09101003-001-017), Key Research and Development Plan (key project) of Shanxi Province (No. 201703D111033), the Fund for Shanxi Key Subjects Construction, Shanxi Coal Base Key Research Projects (No. MJH2014-14), the Natural Science Foundation of Shanxi Province (No. 2013011060-2), Shanxi Medical University Doctor Startup Fund (No. B03201213), the Program for the Top and Key Science and Technology Innovation Teams of Shanxi Province, the Program for the Top Young and Middle-aged Innovative Talents of Higher Learning Institutions of Shanxi Province.

Author Contributions: Qing Shan Li and Xiu E. Feng conceived and designed the experiments. Xiu E. Feng wrote the manuscript. Shu Rong Ban helped guide the experiment. Qin Jin Wang and Jie Gao performed the experiments. All authors reviewed and approved the final manuscript.

Conflicts of Interest: The authors declare that they have no competing interest. 


\section{References}

1. Feng, X.E.; Liang, T.G.; Gao, J.; Kong, D.P.; Ge, R.; Li, Q.S. Heme oxygenase-1, a key enzyme for the cytoprotective actions of halophenols by upregulating Nrf2 expression via activating Erk1/2 and PI3K/Akt in EA.hy926 cells. Oxid. Med. Cell. Longev. 2017, 2017, 7028478. [CrossRef] [PubMed]

2. Katsui, N.; Suzuki, Y.; Kitamura, S.; Irie, T. 5,6-Dibromoprotocatechualdehyde and 2,3-dibromo4,5-dihydroxybenzyl methyl ether: New dibromophenols from rhodomela larix. Tetrahedron 1967, 23, 1185-1188. [CrossRef]

3. Li, K.; Li, X.M.; Ji, N.Y.; Wang, B.G. Natural bromophenols from the marine red alga Polysiphonia urceolata (Rhodomelaceae): Structural elucidation and DPPH radical-scavenging activity. Bioorg. Med. Chem. 2007, 15, 6627-6631. [CrossRef] [PubMed]

4. Wiemer, D.F.; Idler, D.D.; Fenical, W. Vidalols A and B, new anti-inflammatory bromophenols from the Caribbean marine red alga Vidalia obtusaloba. Cell. Mol. Life Sci. 1991, 47, 851-853. [CrossRef]

5. Xu, X.L.; Song, F.H.; Wang, S.J.; Li, S.; Xiao, F.; Zhao, J.L.; Yango, Y.C.; Shang, S.Q.; Yang, L.; Shi, J.G. Dibenzyl bromophenols with diverse dimerization patterns from the brown alga Leathesia nana. J. Nat. Prod. 2004, 67, 1661-1666. [CrossRef] [PubMed]

6. Oh, K.B.; Lee, J.H.; Lee, J.W.; Yoon, K.M.; Chung, S.C.; Jeon, H.B.; Shin, J.; Lee, H.S. Synthesis and antimicrobial activities of halogenated bis(hydroxyphenyl)methanes. Bioorg. Med. Chem. Lett. 2009, 19, 945-948. [CrossRef] [PubMed]

7. Shi, D.Y.; Li, X.H.; Li, J.; Guo, S.J.; Su, H.; Fan, X. Antithrombotic effects of bromophenol, an alga-derived thrombin inhibitor. Chin. J. Oceanol. Limnol. 2010, 28, 96-98. [CrossRef]

8. Wang, W.; Okada, Y.; Shi, H.B.; Wang, Y.Q.; Okuyama, T. Structures and aldose reductase inhibitory effects of bromophenols from the red alga Symphyocladia latiuscula. J. Nat. Prod. 2005, 68, 620-622. [CrossRef] [PubMed]

9. Kurata, K.; Taniguchii, K.; Takashima, K.; Hayashi, I.; Suzuki, M. Feeding-deterrent bromophenols from Odonthalia corymbifera. Phytochemistry 1997, 45, 485-487. [CrossRef]

10. Shi, D.Y.; Li, J.; Guo, S.J.; Su, H.; Fan, X. The antitumor effect of bromophenol derivatives in vitro and Leathesia nana extract in vivo. Chin. J. Oceanol. Limnol. 2009, 27, 277-282. [CrossRef]

11. Zhao, W.Y.; Feng, X.E.; Ban, S.R.; Lin, W.H.; Li, Q.S. Synthesis and biological activity of halophenols as potent antioxidant and cytoprotective agents. Bioorg. Med. Chem. Lett. 2010, 20, 4132-4134. [CrossRef] [PubMed]

12. Lesiak, H.T.; Nowakowski, D.C.J. Applying of 1,1,1-trichloro-2,2-bis(4-methoxyphenyl)ethane for the synthesis of diphenols. J. Prakt. Chem. 1981, 323, 684-690. [CrossRef]

13. Zheng, F.L.; Ban, S.R.; Feng, X.E.; Zhao, C.X.; Lin, W.H.; Li, Q.S. Synthesis and in vitro protein tyrosine kinase inhibitory activity of furan-2-yl(phenyl)methanone derivatives. Molecules 2011, 16, 4897-4911. [CrossRef] [PubMed]

14. Li, J.G.; Feng, X.E.; Ge, R.; Li, J.K.; Li, Q.S. Protective Effect of 2,4',5'-Trihydroxyl-5,2'-dibromo diphenylmethanone, a New Halophenol, against Hydrogen Peroxide-Induced EA.hy926 Cells Injury. Molecules 2015, 20, 14254-14264. [CrossRef] [PubMed]

15. Paloque, L.; Hemmert, C.; Valentin, A.; Gomitzka, H. Synthesis, characterization, and antileishmanial activities of gold(I) complexes involving quinoline functionalized N-heterocyclic carbenes. Eur. J. Med. Chem. 2015, 94, 22-29. [CrossRef] [PubMed]

16. Zhang, Y.K.; Zhong, H.Y.; Wang, T.T.; Geng, D.P.; Zhang, M.F.; Li, K. Synthesis of novel 2,5-dihydrofuran derivatives and evaluation of their anticancer bioactivity. Eur. J. Med. Chem. 2012, 48, 69-80. [CrossRef] [PubMed]

17. Goicoechea, C.; Sanchez, E.; Cano, C.; Jagerovic, N.; Martin, M.I. Analgesic activity and pharmacological characterization of $\mathrm{N}$-[1-phenylpyrazol-3-yl]- $N$-[1-(2-phenethyl)-4-piperidyl] propenamide, a new opioid agonist acting peripherally. Eur. J. Pharmacol. 2008, 595, 22-29. [CrossRef] [PubMed]

18. Manjunatha, U.H.; Boshoff, H.; Dowd, C.S.; Zhang, L.; Albert, T.J.; Norton, J.E.; Daniels, L.; Dick, T.; Pang, S.S.; Barry, C.E. Identification of a nitroimidazo-oxazine-specific protein involved in PA-824 resistance in Mycobacterium tuberculosis. Proc. Natl. Acad. Sci. USA 2006, 103, 431-436. [CrossRef] [PubMed]

19. Matsumoto, M.; Hashizume, H.; Tomishige, T.; Kawasaki, M.; Tsubouchi, H.; Sasaki, H.; Shimokawa, Y.; Komatsu, M. OPC-67683, a nitro-dihydro-imidazooxazole derivative with promising action against tuberculosis in vitro and in mice. PLoS Med. 2006, 3, e466. [CrossRef] [PubMed] 
20. Kimura, M.; Masuda, T.; Yamada, K.; Kawakatsu, N.; Kubota, N.; Mitani, M.; Kishii, K.; Inazu, M.; Kiuchi, Y.; Oguchi, K.; et al. Antioxidative activities of novel diphenylalkyl piperazine derivatives with high affinities for the dopamine transporter. Bioorg. Med. Chem. Lett. 2004, 14, 4287-4290. [CrossRef] [PubMed]

21. Shapiro, L.A.; Offord, S.J.; Ordway, G.A. The effect of chronic treatment with a novel aryl-piperazine antipsychotic on monoamine receptors in rat brain. Brain Res. 1995, 677, 250-256. [CrossRef]

22. Yang, C.H.; Xu, G.Y.; Li, J.; Wu, X.H.; Liu, B.; Yan, X.M.; Wang, M.W.; Xie, Y.Y. Benzothiophenes containing a piperazine side chain as selective ligands for the estrogen receptor $\alpha$ and their bioactivities in vivo. Bioorg. Med. Chem. Lett. 2005, 15, 1505-1507. [CrossRef] [PubMed]

23. Jiang, Z.Y.; Lu, M.C.; You, Q.D. Discovery and development of kelch-like ECH-associated protein 1. nuclear factor erythroid 2-related factor 2 (KEAP1:NRF2) protein-protein interaction inhibitors: Achievements, challenges, and future directions. J. Med. Chem. 2016, 59, 10837-10858. [CrossRef] [PubMed]

24. Podgorsek, A.; Stavber, S.; Zupan, M.; Iskra, J. Visible light induced 'on water' benzylic bromination with N-bromosuccinimide. Tetrahedron Lett. 2006, 47, 1097-1099. [CrossRef]

25. Öztaşkın, N.; Çetinkaya, Y.; Taslimi, P.; Göksu, S.; Gülçin, İ. Antioxidant and acetylcholinesterase inhibition properties of novel bromophenol derivatives. Bioorg. Chem. 2015, 60, 49-57. [CrossRef] [PubMed]

26. Jain, A.D.; Potteti, H.; Richardson, B.G.; Kingsley, L.; Luciano, J.P.; Ryuzoji, A.F.; Ryuzoji, A.F.; Moore, T.W. Probing the structural requirements of non-electrophilic naphthalene-based Nrf2 activators. Eur. J. Med. Chem. 2015, 103, 252-268. [CrossRef] [PubMed]

27. Hu, L.; Magesh, S.; Chen, L.; Wang, L.; Lewis, T.A.; Chen, Y.; Shen, J. Discovery of a small-molecule inhibitor and cellular probe of Keap1-Nrf2 protein-protein interaction. Bioorg. Med. Chem. Lett. 2013, 23, 3039-3043. [CrossRef] [PubMed]

28. Bunnak, J.; Takigami, M.; Ito, H.; Shinozawa, T. Gamma Irradiation Effects on Cultured Cells: Investigated by the MTT Method. J. Radiat. Res. 1994, 35, 205-212. [CrossRef] [PubMed]

29. Marcotte, D.; Zeng, W.K.; Hus, J.C.; Mckenzie, A.; Hession, C.; Jin, P.; Bergeron, C.; Lugovskoy, A.; Enyedy, I.; Cuervo, H.; et al. Small molecules inhibit the interaction of Nrf2 and the Keap1 Kelch domain through a non-covalent mechanism. Bioorg. Med. Chem. 2013, 21, 4011-4019. [CrossRef] [PubMed]

Sample Availability: Samples of the compounds are available from authors.

(c) 2017 by the authors. Licensee MDPI, Basel, Switzerland. This article is an open access article distributed under the terms and conditions of the Creative Commons Attribution (CC BY) license (http://creativecommons.org/licenses/by/4.0/). 